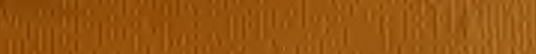
i l|

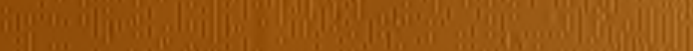
if 9 ,

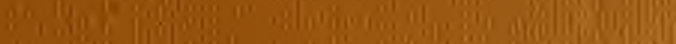
y

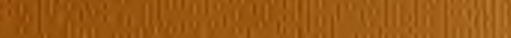

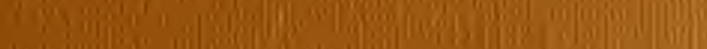

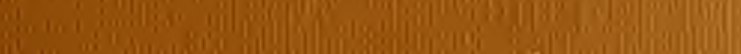

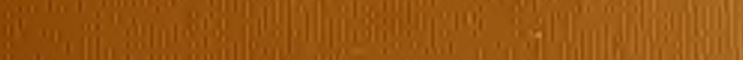

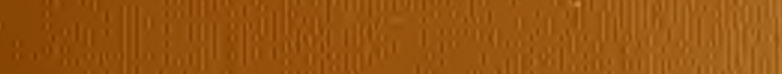
I I

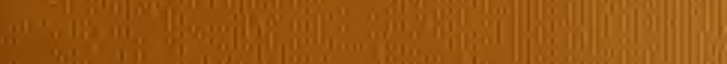

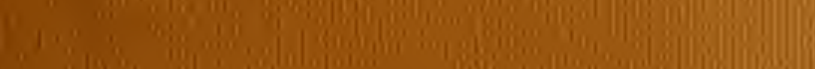
|m! !

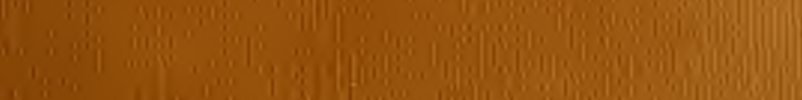

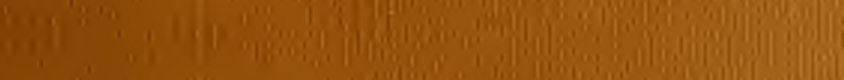

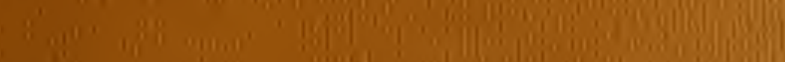

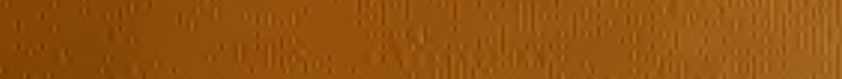
I.

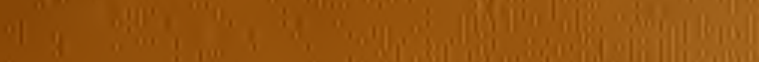
PI:

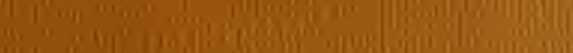

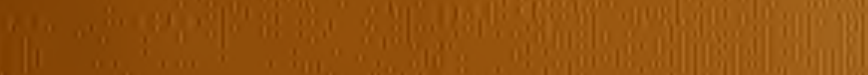

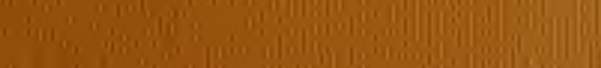
s.m. n $3=5$.

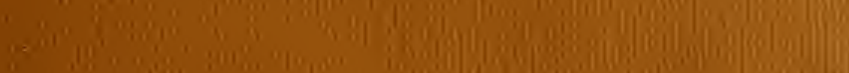

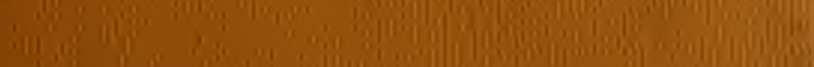

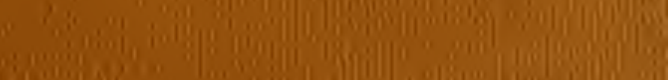

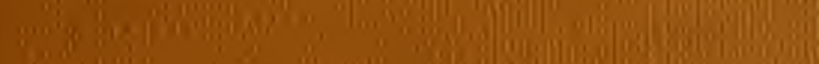
${ }_{1}^{6}$

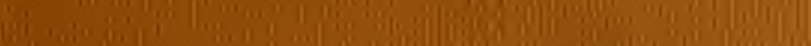

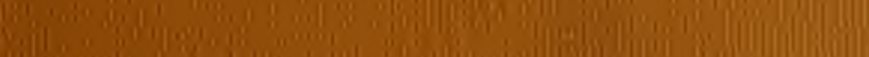
IIX),

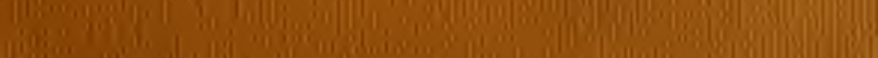




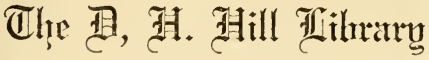

Dinth Cintina State College SB60
N5 


\section{SB601}

\section{1}

NE

63811

This BOOK may be kept out TWO IVEEKS ONLY, and is subject to a fine of FIVE CENTS i day thereafter. It is due on the day indicated below:

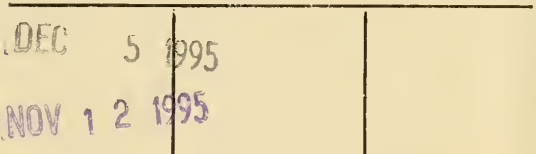





\section{LES MALADIES PARASITAIRES DES PLANTES}



11. NiCOLLE et J. MAGROL

(DE L'JNSTITUT PASTEUR)

\title{
LES MALADIES
}

\section{PARASITAIRES}

\section{DES PLANTES}

(INFESTATION-INFECTION)

MASSON ET GIR EDITEURS

\author{
LIBRAIRES DE L'ACADÉMIE DE MÉDECINE
} I2O, BOULEVARD SAINT-GERMAIN, PARIS 
$=\overline{T o u s ~ d r o i t s ~ d e ~ T r a d u c t i o n ~}=$ de Reproduction et d'Adaptation $=$ réservés pour tous pays. $=$ 


\section{LES MALADIES PARASITAIRES}

\section{DES PLANTES}

\section{AVANT-PROPOS}

Le médecin qui a approfondi l'étude des maladies parasitaires (largo sensu) de l'homme - surtout s'il connait l'essentiel des affections animales de même naturc - ne peut échapper au besoin d'acquérir une série de vues d'ensemble. Qu'y a-t-il au fond de tous ces symptòmes et de toutes ces lésions; à quoi se réduit l'action de cette infinité de parasites et la réaction des organismes envahis; quel sens exact ont les expressions : virulence, immunité et tant d'autres, que l'on emploie avec une incroyable facilité? Comment répondre et ne généraliser ni trop ni trop peu? En interrogeant toutes les "pièces du procès "; en considérant non seulement la patholugie des animaux supérieurs, mais encore celle des animaux inférieurs et surtout celle des plantes. On peut le dire sans exagération : pas de Médecine générale, si l'on ignore ce qui se passe dans le monde végétal. In sycmble 
alors, qu'un "bon " livre de phytopathologie résoudra facilement la question. Or, un tel livre n'existe pas; nous entendons par là un ouvrage, bref et assez complet cependant, conçu avec liesprit propremenl médical (qu'on ne voie pas là une critique, aussi malveillante que peu déguisée, des publications actuelles sur les affections des plantes; rien de plus éloigné de notre pensée). Le livre désiré faisant défaut, il a fallu l'écrire. Nous espérons avoir ainsi satisfait, en même temps que la nôtre, la curiosité de beaucoup de savants : médecins et vétérinaires, dont nous parlons la langue; biologues, de diverses "directions ", qu’intéresse ce qu'on eût appelé jadis, si heureusement, l" " histoire naturelle " des parasites; phytopathologues, enfin, auxquels, en échange des documents précieux qu'ils nous ont fournis, nous proposons un plan que nous croyons nouveau et des vues personnelles qui ne sauraient les laisser indifférents.

D'ailleurs, l'expérience est déjà faite; plusieurs de nos amis, médecins ou "naturalistes ", qui ont pris connaissance du manuscrit, en affirment l'intérêt; MM. les Professeur's Marchal, Molliard et Foëx, de leur côté, après lecture, nous ont manifesté leur approbation et donné d'utiles avis, dont nous sommes heureux de les remercier.

Voici maintenant, les principes suivis dans la composition de notre ouvrage. Rassembler le plus grand nombre possible de matériaux. Après examen critique, rejeler tous les documents incom- 
plets ou suspects. Parmi les données utilisables, faire une seconde élimination, afin d'éviter un encombrement stérile et ne retenir que les maladies, soit très importantes, soit très instructives (nous serons donc volontairement incomplets). Classer les affections des plantes, suivant la nature des parasites qui les engendrent; puis, dans chaque groupe ainsi établi, répartir les diverses maladies en s'inspirant de l'observation clinique. Donner alors une interprétation claire et raisonnable du mécanisme de chaque affection, de chaque groupe, de la totalité des maladies végétales. - Nous avons été excessivement brefs sur les caractères des parasites (et de leurs hòtes), écrivant un livre de pathologie, non un traité d'histoire naturelle. Ajoutons encore que notre ouvrage concerne les maladies " spontanées "; parmi les maladies " expérimentales ", seront seules envisagées celles qui reproduisent fidèlement les premières ou en éclaircissent le mécanisme.

Quelques définitions indispensables et nous entrerons, comme l'on dit, in medias res.

Certains êtres vivants se nourrissent exclusivement de substances inorganiques, telle la majorité des plantes et diverses bactéries; on les appelle souvent autonomes.

D'autres, les saprophages, utilisent, pour leurs besoins, la matière qui a vécu.

Les derniers, auxquels convient le nom de biontophag'es (employé par quelques auteurs), s'alimen- 
tent aux dépens d'organismes étrangers. Le mode de vie correspondant est dénommé prédatisme ou parasitisme, suivant, aime-t-on à répéter, que l'agresseur " dévore ou exploite l'être auquel il s'en prend ": formule commode, mais un peu imagée et très insuffisante. On ajoute, habituellement, qu'il existe tous les intermédiaires entre le " prédatisme " et le "parasitisme ", ce qui diminue la valeur de la distinction.

Les parasites se relient, cela va sans dire, aux prédateur's par leur action spoliatrice; action parfois encore purement mécanique, mais d'ordinaire bien plus complexe. Ils s'en différencient profondément par toute une série d'effets, liés à des secrétions spécifiques : ernpoisonnement local ou général, irritation de nature variée, digestion des éléments cellulaires ambiants.

On doit donc nommer maladie parasitaire, l'ensemble des altérations anatomiques et fonctionnelles qu'engendre un parasite chez un être vivant.

Encore quelques remarques. On se sert généralement du mot infestation en matière de "gros" parasites et du mot infection en matière de parasites " microscopiques ", pour désigner l'état de l'organisme envahi. Nous respectons cet usage, mais il semble que le terme infection conviendrait très bien pour tous les cas. - Nous sommes contraints d'employer couramment des expressions telles que : moyens d'attaque, moyens de résistance, faute de pouvoir les remplacer par des 
termes tels que : mode d'action, mode de réaction, plus scientifiques mais infiniment trop généraux. Il faut, avant tout, être compris. - Pour ce qui concerne les caractères généraux des enzymes (ou diastases) et des toxines, dont on parle à chaque instant dans cet ouvrage, nous renvoyons au livre de l'un de nous, "Antigènes et Anticorps ", 1920.

Nous tenons à remercier ici notre éditeur, M. Masson, de la confiance qu'il nous a témoignée, en acceptant un ouvrage quelque peu inattendu el en le présentant avec son soin habituel. Après mûre réflexion, il a paru, à M. Masson et à nous, indispensable de sacrifier les figures (que nous possédons toutes), afin de rendre le livre plus abordable, surtout au monde des étudiants. Du reste, les descriptions nécessaires se trouvent dans le texte et ceux qui ont lu ce texte n'ont pas été arrêtés par le manque d' "illustration ".

M. NICOLLE J. MAGROU 
I

MALADIES DES PLANTES

DUES AUX ANIMAUX 

Les végétaux ne sont altaqués que par des métazoaires, sauf l'unique exception suivante.

Un flagellé, le Leptomonas Davidi (Lafont), habite le latex de diverses euphorbes, en des points variés de la zone tropicale; on le rencontre également en Portugal. Le parasite peut atteindre toutes les parties des plantes sensibles, mais il offre une tendance particulière à se limiter. Son pouvoir pathogène semble réel, quoique variable. La maladie naturelle parait transmise par les hémiptères; la maladie expérimentale peut-être reproduite par eux (Bouet et Roubaud) ou par inoculation directe de suc infecté (Noc et Stévenel) - Laveran et Franchini ont apporté de récentes contributions à la flagellose des euphorbes; nous ne pouvons malheureusement insister davantage sur le sujet.

Nous ne dirons que quelques mots des altérations que délerminent les mélazoaires chez les végétaux inférieurs.

Chez les algues (surtout marines), des nématodes, des rotifères et même des copépodes peuvent déterminer des excroissances; on a vu parfois la moule commune en produire (fucus). Les polypores offrent éventuellement des nodosités dues aux nématodes ou aux diptères. Les acariens infestent, dans certains cas, les lichens. Les bryophyles sont assez souvent attaqués par 
les nématodes (galles en artichaut); les ptéridophytes, par les acariens, les hyménoptères et, plus fréquemment, les diptères, qui les détruisent ou y provoquent la formation de cécidies.

Il ne sera question, maintenant, que des maladies des phanérogames.

Eliminant les prédateurs sans intérêt, tels que les escargots et limaces, nous devrions examiner, en allant des êtres les plus évolués aux êtres les moins évolués (comme nous avons cru devoir le faire, systématiquement, dans cet ouvrage) : les acariens, les insectes et les nématodes. La nécessité d'éviter des redites nous oblige à faire précéder l'étude des acariens de celle des insectes. 


\section{MALADIES DUES AUX INSECTES}

\section{INSECTES PARASITES \\ EN GÉNÉRAL}

Nombre d'insectes se nourrissent de tissus végétaux; d'une manière générale, ce sont de simples prédaleurs et il semble que nous pourrions les éliminer de notre travail. Deux raisons nous conduisent à les y maintenir : d'abord, certains d'entre eux passent toute leur vie sur la plante attaquée, ce qui leur donne vraiment figure de parasites; en second lieu, les destructions, opérées par les prédateurs, constituent de véritables expériences, qui nous montrent comment les végétaux souffrent quand tel organe se trouve, totalement ou partiellement, brutalement ou lentement supprimé. Les notions, ainsi acquises, offrent le plus grand intérêt.

Beaucoup d'autres insectes suçent le contenu cellulaire; ils demeurent sur les plantes durant toute leur existence. Ces spoliateurs, dont l'action est du reste plus complexe qu'on ne le croit communément, représentent de vrais parasites : nulle contestation là-dessus. 
En face des phytophages (prédateurs et spoliateurs), se groupe la masse des insectes qui produisent des galles (ou cécidies) : insectes cécidogènes, caractérisés par la réaction qu'ils déterminent et utilisent. Notons, sans tarder, que, dans un même genre, on rencontre, communément, des espèces phytophages et des espèces cécidogènes.

Les insectes sont parasiles à l'état adulte et surtout à l'état de larve. Certains n'attaquent qu'une seule espèce de plantes; d'autres, des espèces diverses, parfois même excessivement variées. L'existence de deux hôtes successifs peut représenter la condition sine qua non de l'évolution complète des parasites.

Ceux-ci offrent souvent des particularités intéressantes, quant à leur forme et à leur reproduction. De telles particularités ne sont pas spéciales au parasitisme, mais elles s'y rencontrent avec une fréquence indéniable. Nous les rappellerons brièvement.

FORME

Les adultes présentent, dans certains cas, le phénomène du dimorphisme sexuel, qui atteint son maximum chez les coccides, où la femelle se transforme en un corps globuleux sans caractères, véritable sac à œufs. On sait que les coccides demeurent immobiles pendant la majeure partie 
de leur vie, fixés aux parties dont ils sucent les liquides.

Les larves des hémiptères ne diffèrent guère des adultes que par l'absence d'ailes. Pour les autres familles, elles offrent des aspects fort variables, en relation avec leur mode d'existence. Chez celles qui évoluent librement sur les parties aériennes, c'est le type classique de la chenille. Chez celles qui mènent une vie libre dans te sol, à l'abri de la lumière, les pattes sont courtes et les mouvements lents : on connait "le ver blanc ", lourd, mou et gras. Chez celles qui habitent les tissus végétaux, le caractère vermiforme s'accuse de plus en plus : les pattes s'effacent, les yeux s'atrophient puis disparaissent, la tête devient indistincte. Les larves des muscidés, plongées dans la pulpe des fruits, constituent le type le plus dégradé de la série.

REPRODUCTION

Les insectes parasites jouissent souvent d'une incroyable fécondité. La parthénogénèse, très répandue, favorise cette multiplication et la viviparité, assez commune chez certains groupes, en accélère encore la vitesse. 


\section{PARTHÉNOGÉNÉSE}

Elle se caractérise par le développement de l'ovule non fécondé et assure une prolifération intense, dans les conditions favorables de température et de nutrition. Le plus souvent, elle fait place à la gamogénèse, dans les circonstances inverses, mais on la voit parfois persister indéfiniment.

La parthénogénèse, accidentelle chez plusieurs espèces, représente un phénomène normal chez beaucoup d'autres Nous en citerons quelques exemples, regrettant notre brièveté sur ce sujet intéressant, mais étranger au plan de nos études actuelles.

\section{Crnipides cécidogènes.}

Chez les Rhodites, la reproduction sexuée demeure exceptionnelle et semble même manquer pour certaines espèces. La raison en est bien simple : rareté ou absence des individus mâles. Chez d'autres cynipides, on observe le curieux phénomène de la parthénogénèse cyclique régulière (Adler) : la forme agame éclot de l'automne au printemps, la forme sexuée au printemps ou en été. Ces deux formes, tellement dissemblables qu'on les avait jadis classées dans des genres séparés (nouveau type de dimorphisme), déterminent, sur le même hôte, des galles dissemblables comme aspect et souvest comme situation. 


\section{Voici 3 exemples classiques.}

La Biorrhiza aptera, forme agame, sort, soit à la fin de l'automne, soit au début de l'hiver, de cécidies ligneuses, ovales ou rondes, développées sur les racines des chènes. Elle pique les bourgeons, engendrant ainsi des galles sphériques pluriloculaires, d'où sortent, soit à la fin du printemps, soit au début de l'été, les sexués de la Biorrhiza pallida. La femelle fécondée dépose ses œufs dans les racines; les cécidies ligneuses se développent et le cycle recommence.

En automne et en hiver, les individus agames de la Dryophanta folii sortent de galles arrondies, uniloculaires et d'un jaune verdâtre plus ou moins teinté de rouge, situées à la face inférieure des feuilles des chênes. Ces individus déposent leurs œufs dans les bourgeons, engendrant ainsi des cécidies en artichaut, uniloculaires, veloutées et d'un violet foncé, d'où sortent au printemps suivant les sexués de la Dryophanta Taschenbergi. La femelle fécondée dépose ses œufs à la face inférieure des feuilles; les galles en cerise se développent et le cycle recommence.

Les cécidies du Neuroterus lenticularis sont circulaires, très légèrement coniques, d'un jaune blanchâtre ou rougeâtre et ornées de poils roux, disposés en étoiles. Elles siègent à la face inférieure des feuilles des chênes. Au printemps, sortent des individus agames, qui vont pondre sur le pédoncule des chatons mâles, engendrant ainsi des cécidies sphériques, uniloculaires, qui ressemblent à des grains de raisin. Au printemps, sortent les sexués du Neuroterus baccarum. La femelle dépose ses œufs sur la face inférieure des feuilles; les galles circulaires, ornées de poils, se développent et le cycle recommence.

\section{Pucerons cécidlogènes.}

Dans les conditions favorables, la parthénogénèse paraîl indéfinie; Slingerland a pu obtenir 
ainsi plus de 90 générations agames. La reproduction agame peut se doubler de viviparité, mais tel n'est pas le cas pour les exemples que nous allons rapporter.

Phylloxera des vignes américaines. - Au printemps, on voit sortir de l'œeut d'hiver, caché dans l'écorce des ceps, une femelle parthénogénétique aptère, la fondatrice. Celle-ci gagne les feuilles, y devient gallicole et donne naissance à 6-7 générations également agames, aptères et gallicoles. A la fin de la belle saison, les gallicoles de la dernière génération descendent vers les racines et deviennent des radicicoles. Leurs générations, toujours aptères et agames, se succèdent sur les racines, déterminant les nodosités caractéristiques.

En août et septembre, certains radicicoles se transforment en femelles ailées qui pondent, sur les parties aériennes, les œufs d'où provienment les sexués. La femelle fécondée dépose un sęul œuf (œuf d'hiver) dans l'écorce et le cycle recommence. Les ailées peuvent disperser au loin la maladie.

Evolution sur les vignes européennes. - Il résụlte des recherches des auteurs italiens (Grassi et ses élèves) que, sur les vignes européennes, le cycle évolutif se trouve le plus souvent amputé de loute sa partie épigée : ailés, sexués et gallicoles des feuilles sont supprimés. L'œuf d'hiver n'est que très rarement pondu. Les générations gallicoles sont exceptionnelles ou abortives. La reproduction parthénogénétique indéfinie radicicole constitue la règle.

Nous avons dit que la présence de deux hôtes était parfois indispensable pour le développement complet des insectes parasiles. Citons quelques exemples classiques, dans lesquels le cycle, tantôt 
complet, tantôt incomplet, coïncide avec la parthénogénèse.

\section{Cycle du Cynips Calicis.}

(Cycle régulier).

En avril, la femelle agame pond sur les bourgeons mâles du Quercus cerris, engendrant de petites galles coniques (formées aux dépens d'une moitié d'anthère), qui sont mûres en mai. Il sort alors des sexués (Andricus cerris), jadis classés dans un autre genre. Les femelles fécondées pondent entre le gland et la cupule des jeunes fruits du Quercus pedunculata, engendrant des cécidies tronc-coniques, ligneuses, à 5-8 carènes, dont la chambre larvaire est précédée d'une antichambre ouverte, cécidies qui se détachent au printemps suivant (quelquefois au printemps de la troisième année seulement). Il en sort des femelles agames. Elles pondent sur les chatons mâles du Quercus cerris et le cycle recommence.

\section{Cycle des Chermes (Adelges).}

(Cycle, complet ou non, avec parthénogénèse - Blochman, Dreyfus, Chlodkowski, Marchal. Nous renvoyons aux intéressants travaux de ce dernier, pour les nombreux détails qu'il nous faut omettre ici).

Chermes pini. - La race indigène se reproduit indéfiniment, par voie agame, sur le pin. La race orientale offre une évolution complète, dont voici le résumé.

Sur le Picea orientalis, nait la fondatrice, venue d'un œuf fécondé; elle engendre des femelles parthénogénétiques, aptères comme elle, qui produisent des galles en ananas. Il en sort des émigrantes ailées, allant sur le pin et donnant naissance aux exilées (aptères), lesquelles hivernent et engendrent, lors du printemps, les sexupares. Celles.ci retournent sur le Picea et donnent naissance aux sexués. Les femelles fécondées pondent 
des œufs, d'où sortiront les fondatrices et le cycle recommence.

La race indigène dérive certainement de la race orientale; en l'absence de l'hôte, Picea orientalis, elle a perdu le mode de reproduction sexué.

Chermes strobi. - La race indigène se multiplie indéfiniment par voie agame sur le Pinus strobus. La race américaine donne vraisemblablement des sexués sur le Picea nigra .

Chermes Nüsslini. - Parthénogénèse sur Abies; sexués sur Picea orientalis. (Le Chermes picex, à reproduction indéfinie sur Abies, dérive sans doute du Ghermes Nüsslini).

\section{INSECTES PHYTOPHAGES}

ENUMÉRATION (PRINCIPAUX TYPES)

\section{Diptères.}

(Tipulides el cécidomyies).

Ils ne sont dangereux qu'à l'état larvaire.

Les femelles pondent: dans le sol; sur les feuilles, tiges, bourgeons, fleur's, fruits (quelquefois, dans la peau d'un fruit - mouche des oranges).

Les larves rongent: les feuilles, racines, tiges herbacées, bulbes. Elles peuvent pénétrer dans les fruits mûrs (mouches des cerises et des olives) et se nourrir de leur pulpe.

\section{Hémiplères (homoptères).}

Les phylophtires (poux des plantes), à l'étal larvaire et adulte, absorbent les sucs des feuilles, tiges, racines, bourgeons, fruits. Ils comprennent surtout les aphides 
(pucerons) et les coccides. Les pucerons causent d'énormes dégâts chez les plantes les plus variées. Les cochenilles ne sont pas moins redoutables. Citons, parmi elles, les Aspidiolis de diver's arbres fruitiers, la Diaspis pentagona du mûrier, la cochenille blanche de la vigne, le Lecanium de l'olivier (le "miélat " de ces deux derniers constitue un excellent milieu de culture pour la fumagine), l'Icerya purchasi, couvrant divers arbres de taches neigeuses et détruit par le Novius cardinalis (originaire, comme lui, de l'Australie et importé pour en avoir raison).

\section{Lépidoptères.}

Ils ne sont dangereux qu'à l'état larvaire.

Les femelles pondent sur les diverses parties des plantes.

Les larves rongent : les tiges herbacées, feuilles, fleurs, bourgeons, jeunes pousses, racines (ver gris). Elles peuvent pénétrer dans les graines (alucite), feuilles (teigne du poireau), fruits (pyrales, Cochylis, Eudemis), tubercules (teigne de la pomme de terre), tiges herbacées (pyrale du maïs), bois (cossus ronge-bois, zeuzère du marronnier, sésie apiforme) - et détruisent peu à peu ces diverses parties. Les chenilles demeurent souvent $2-3$ ans dans le bois.

\section{Hyménoplères.}

(Tenthrédinides et urocérides.)

Les femelles pondent : sur les feuilles et les écorces; dans les feuilles (lophyres), les tiges herbacées (cèphe des chaumes), les bourgeons (cèphe commun).

Les larves, nées à la surface des plantes, rongent les feuilles et les pousses ou pénètrent dans le bois et le minent (Sirex). - Les larves, nées dans les feuilles, les tiges, les bourgeons, les détruisent peu à peu. 


\section{Coléoptères.}

Ils sont dangereux à l'état adulte et surtout à l'état de larve.

Les adultes rongent les feuilles, bourgeons, fleurs, grains, jeunes pousses, tiges herbacées. Certains creusent des galeries entre le bois et l'écorce et même en plein bois.

Les femelles pondent : dans le sol (hanneton); dans les tiges herbacées (saperde grêle), les bourgeons (anthonomes), les fruits (charançon des noisettes); entre le bois et l'écorce ou dans le bois (scolytides) - ou : sur les feuilles, bourgeons, fruits, écorces.

Les larves, nées dans le sol ou à la surface des plantes, rongent les feuilles, bourgeons, fleurs, racines (ver blanc) ou pénètrent dans les feuilles (orchestes), graines (bruches), racines (charançon de la carotte), écorces (buprestes), bois (cérambycides). - Les larves, nées dans les fruits, graines, écorces, bois, les détruisent peu à peu. Elles peuvent demeurer dans le bois plusieurs années (2-5 ans, selon les espèces).

Certains groupes de coléoptères, habituellement saprophages, deviennent parfois phytophages (silphides). Certains autres, parasites des arbres récemment abattus ou affaiblis, s'attaquent ensuite aux arbres vigoureux (scolytides).

\section{Orthoptères.}

Les acridiens, jeunes et adultes, dévorent tout ce qu'ils rencontrent; chacun connaît leurs méfaits.

EFFETS

Nous distinguerons, à cet égard, les prédateurs et les spoliateurs. Ces derniers sont surtout repré- 
sentés par les hémiptères; les premiers, par la majorité des autres insectes.

\section{PRÉDATEURS}

Les lésions produites, peu intéressantes en ellesmêmes, retentissent sur le dévelopnement et la reproduction des végétaux attaqués; elles amènent souvent aussi la mort des plantes ou organes jeunes. Affaire de siège, d'étendue et de rapidité. La marche des accidents se compte, suivant les cas, par jours, par semaines, par mois, par années.

\section{Lésions des feuilles.}

D'autant plus graves qu'elles surviennent plus près du début de la végétation.

Chez les espèces herbacées, la dénudation totale entraine souvent la mort : l'individu atteint se dessèche bientôt. La dénudation accentuée engendre un état chétif de la plante, avec diminution de la quantité des fruils, qui n'arrivent pas d'ordinaire à maturité; avec atrophie des racines et tubercules, qui demeurent pauvres en amidon et en sucre.

Chez les végétaux ligneu.x jeunes, la dénudation totale ou très marquée peut amener une dessiccation rapide des pousses, suivie de la mort de celles-ci. Chez les arbres adultes, les rameaux ne périssent point; ils se couvrent de nouvelles 
feuilles, soit pendant l'èté, soit l'année suivante, selon que la perte a eu lieu tôt ou tard et, aussi, selon l'espèce affectée. Mais les fruits manquent ou avortent, les nouvelles feuilles restent clairsemées, les pousses ultérieures débiles et peu abondantes, le bois mince. - La dénudation renouvelée peut tuer la plante.

Mécanisme. - La perte des feuilles supprime l'élaboration de la sève et, partant, la formation des réserves. On comprend donc qu'elle soit très grave au printemps et relativement peu en été. En été, la formation de l'anneau ligneux a pris fin, les bourgeons de l'an suivant sont constitués, les réserves emmagasinées.

Lésions des fleurs, fruits, graines.

Sans retentissement général.

Fleurs. - Selon les cas, destruction ou arrêt de développement.

Fruits. - De même. Parfois, la croissance continue un certain temps (éventuellement accentuée au début), mais la chute précoce demeure inévitable. Les graines avortent.

Graines. - Selon les cas, elles ne germent pas ou donnent des plantes naines, qui meurent vite.

Lésions des rameaux.

(Végétaux ligneuxi). - Les jeunes sujets peuvent succomber aux lésions étendues des rameaux, 
parfois même en peu de temps. Les adultes résistent. Si, chez eux, la lésion est grave, on voit, audessus d'elle, les feuilles tomber, le plus souvent après avoir jauni (ou rougi, quand il s'agit de résineux); la branche se dessèche ensuite et, après sa mort, un bourgeon adventice fournit le rameau de remplacement. Lorsque de nombreuses branches ont péri et que la régénération s'opère normalement, l'arbre prend des aspects imprévus et souvent décrits. Si la lésion reste moins sévère, les rameaux ne meurent pas, mais souffrent; leur souffrance se traduit par un arrêt de développement plus ou moins accentué, la diminution des feuilles et des fruits, souvent par l'avortement de ces derniers.

Mécanisme. - Dans les parties situées au-dessus de la lésion, l'ascension de la sève brute se trouve soit arrêtée soit gênée, ce qui provoque une inanition totale ou partielle : mort ou état de souffrance. Dans les parties situées au-dessous, la descente de la sève élaborée se trouve, soit arrêtée, soit gênée; le pronostic quoad vitam est lié, pour le cas d'arrêt, à l'étendue des lésions et à la quantité des réserves disponibles.

Lésions des tiges herbacées et troncs ligneux.

Tiges herbacées. - Chez les plantes annuelles, la mort survient le plus souvent; ailleurs, les pieds restent chétifs el stériles. Chez les plantes vivaces, 
l'organisme résiste, le rhizome formera une nouvelle tige.

Troncs ligneux. - Les lésions étendues sont souvent fatales chez les résineux : le sujet atteint dépérit peu à peu, perd ses aiguilles et succombe dans l'année. Les feuillus résistent mieux, mais montrent des signes non équivoques de maladie : bourgeons moins abondants, feuillage peu fourni, fruits plus rares. Cette déchéance progressive ne conduit que lentement à la mort.

Même mécanisme que précédemment.

Lésions des racines.

Chez les espèces herbacées, la destruction totale amène un flétrissement plus ou moins rapide, suivant la richesse en eau; la mort, fatale, peut survenir dans l'espace de quelques jours. La destruction partielle permet quelquefois la survie.

Chez les régétaux ligneux jeunes, la destruction totale demeure très grave, la destruction partielle amène un état chétif des pousses, avec développement médiocre des feuilles et des fleurs. Chez les végétaux ligneux âgés, les lésions étendues des racines ne sont guère le fait des insectes.

Même mécanisme que plus haut.

Lorsque les lésions ne provoquent point une mort rapide, des régénérations sont possibles, comme nous l'avons vu. L'étude des divers modes de 
cicatrisation des blessures (formation d'assises subéreuses, de cals ou de bourrelets) sort de notre étude. Par contre, nous devons rappeler que tout traumatisme ouvre la porte aux parasites les plus divers.

\section{SPOLIATEURS}

('e qui caractérise surtout leur action, c'est la fréquence d'anomalies de développement, dans lesquelles nous refusons de voir des cécidies (galles organoïdes de Küster). De quoi s’agit-il réellement? Il s'agit d'un processus atrophique et d'une déchéance fonctionnelle, bien que l'on puisse noter, éventuellement, la multiplication de certaines parties et l'apparition de bourgeons adventices - mais jamais la naissance de tissus nouveaux. Ce qui domine, c'est le " phénomène-tassement ", donnant le faux aspect d'hypertrophie, alors qu'il traduit simplement le "phénomène-réduction ". Les plantes atteintes languissent plus ou moins et demeurent souvent stériles. Examinons, avec quelques détails. Les entre-nœuds, arrêtés dans leur croissance, se ramassent sur une faible longueur et les parasites se trouvent ainsi abrités par la multitude des feuilles atrophiées et tassées, dontl'agglomération revêt des aspects très variés. Semblable " foisonnement " n'est pas rare non plus au niveau des sommités florales. Dans les deux cas, les feuilles ou les enveloppes des fleurs peuvent, tantôt s'affronter, tantôt se souder. Lorsqu'il s'y joint une 
néoformation véritable - et seulement alors - on peut parler de galle. Les cécidies coexistent volontiers avec les anomalies dont nous venons de parler, mais une identilé de cause ne doit jamais se confondre avec une identité de nature - moins que jamais quand il s'agit de processus diamétralement opposés (atrophie - néoformation).

Nous pensons que la spoliation se double souvent d'un empoisonnement général, dù aux sécrétions toxiques des parasites. Notre manière de voir s'appuie sur deux ordres de preuves. D'abord, l'absence fréquente de proportionnalité entre la gravité des accidents et les pertes subies. Ensuite, l'existence assez commune de lésions maculeuses au niveau des parasites, lésions manifestement nécrotiques, que l'action d'un poison peut seul expliquer.

Les spoliateurs, comme les prédateurs, peuvent amener la mort des plantes, dans un temps fort différent selon les cas.

MÉCANISME DE L'INFESTATION

\section{ÉLECTIVITÉ LES PARASITES}

Essentiellement variable. Certains détruisent des plantes très diverses, d'autres un nombre modéré de genres, voire d'espèces. Deux cécidomyies, absolument identiques sous tous les rapports, 
attaquent: l'une le blé seul (mouche de Hesse), la seconde l'avoine seule (cécidomyie de l'avoine); c'est là leur unique caractère distinctif (Marchal). L'instinct (sur lequel nous n'avons pas à nous expliquer ici, mais que nous admettons comme fait) guide les insectes et les larves libres; pour les larves qui naissent au sein des tissus et y demeurent jusqu'à leur transformation, l'instinct de la mère joue un rôle décisif, lors de la ponte. L'électivité reflète la nature des besoins alimentaires, la voracité en mesure l'étendue.

\section{SENSIBILITÉ DES PLANTES}

Très variable également. Elle se relie aux questions d'espèce, d'individu, d'âge, de fonctionnement (normal ou non). Elle diffère d'un organe à un autre, comme on le sait.

\section{MOYENS D'ATTAQUE DES PARASITES}

Prédateurs. - ('e qui domine, c'est, avant tout, la puissance de l'armature buccale. Mais d'autres agents peuvent se joindre à ce facteur mécanique ou même le remplacer. Ainsi, le cossus ronge-bois secrète une bave susceptible de ramollir les tissus ligneux; ainsi, les larves vermiformes de muscides, vivant dans les fruits, doivent produire des enzymes qui solubilisent le contenu et les parois cellulaires. 
Spoliateurs. - L'importance de la succion ne fait pas le moindre doute : le Dactylopius vitis saigne littéralement la vigne. L'importance de l'intoxication nous semble aussi peu niable. Nous en avons dit les raisons; ajoutons que, dans bien des cas, l'épuisement seul demeure incapable d'expliquer la gravité des accidents, comme le remarquent, brièvement mais nettement, certains auteurs. Il convient donc d'admettre que les deux causes s'associent diversement selon les circonstances.

\section{MOYENS DE RÉSistance DES PLANTES}

L'immunité naturelle des végétaux, mal connue en sa nature, apparaît comme liée, isolément ou conjointement: à la résistance matérielle des tissus, à l'absence de composés nutritifs appropriés, à la présence de corps nuisibles (produits de désassimilation, notamment, s'accumulant, on le sait, dans la périphérie, donc aux portes d'entrée). Mais il n'existe pas de résistance absolue, car certains parasites peuvent, soit forcer les obstacles mécaniques, soil se contenter d'aliments qui paraissent médiocres, soit encore rester indifférents devant les substances habituellement toxiques (ou les neutraliser).

Une fois attaquée, la plante ne saurait se défendre contre les prédateurs; on conçoit qu'elle résiste aux effets des spoliateurs si elle compense 
ses pertes et si elle demeure insensible à l'action des poisons émis (ou les neutralise).

\section{INSECTES CÉCIDOGE்NES}

ENUMÉRATION (PRINCIPAUX TYPES)

Les chiffres que nous allons citer, pour fixer les idées, ont été établis par Houard (Zoocécidies de l'Europe et du bassin de la Méditerranée) et se rapportent aux galles vraies et aux " galles organö̈des". Ils sont donc inexacts, si l'on admet notre point de vue.

Les diptères fournissent (actuellement) 486 espèces gallicoles, les hyménoplères 290 , les hémiptères 2:33, les coléoptères 113, les lépidoptères 59.

\section{Diptères.}

On rencontre près de 500 espèces chez les cécydomyides (genres : Cecidomyia, Contarinia, Dasyneura, Mayetiola, Oligotrophus, Perrisia, Rhabdophaga, Rhopalomyia, notamment) et près de 70 chez les muscides (genres Tephritis et Trypeta, surtout).

\section{Hémiptères (homoptères).}

Les coccides, qui donnent rarement des cécidies chez nous, en déterminent beaucoup et de très compliquées, chez les plantes d'Australie. Les aphides fournissent près de 200 espèces (genres : Adelges, Aphis, Myzoxylus, Pemphigus, Tetraneura, avant tout). Les

Nicolte el Magrov. - M. P. des plantes. 
psyllides sont représentés par plus de 40 espèces (genres Psylla et Trioza, principalement).

\section{Lépidoptères.}

On y rencontre une cinquantaine d'espèces gallicoles, principalement chez les torlricides (genre Cochylis, notamment).

\section{Hyménopières.}

Les cynipides fournissent environ 250 espèces (genres: Andricus, Aulax, Biorrhiza, Cynips, Dryophanta, Neurolerus, Rhodiles, notamment); les chalcidides, une vingtaine (genres Isostoma et Blastophaga, surtout); les tenthrédinides, un peu plus (genre Pontania, entre autres).

\section{Coléoptères.}

On trouve peu d'espèces cécidogènes chez les buprestides, scolylides, cérambycides, chrysomélides; on en rencontre une centaine chez les curculionides (genres: Apion, Mecinus, Ceutorrhynchus, principalement).

La femelle pond ses œufs sur les organes des végétaux ou dans leur intérieur. Celles des larves qui naissent extérieurement gagnent ou non les tissus profonds. Sur et dans les galles, les larves évoluent tantôt jusqu'à la nymphose (quand celleci dọit avoir lieu), lantôt jusqu'à l'état parfait. 
EFFETS

\section{ÉTUDE DES GALLES}

Elle date de Malpighi. L'illustre savant en a décrit plus de 60 espèces; il a indiqué clairement le mécanisme de leur formation, ainsi que les rapports du parasite el des tissus développés sous son influence. - Contentonsnous de citer encore Réaumur et, parmi les contemporains : Schlechtendal, Hartig, Nalepa, Rübsaamen, Lacaze-Duthiers, Beyerinck, Thomas (créateur du mol cécidie), Küster, Kieffer, Houard et Molliard.

\section{(A) Siège.}

Les galles occupent surtout les organes aériens, mais ne sont pas exceptionnelles sur les racines (agents : les ceutorrhynques chez les crucifères, les biorrhizes sur les chênes, le phylloxera sur la vigne). Les racines aériennes des Cattleya peuvent être atteintes par une cécidomyie, les rhizomes des chrysanthèmes par une rhopalomyie.

Les cécidies des feuilles et des bourgeons abondent; nous en avons cité et nous en citerons encore des exemples.

Les galles des tiges et des rameaux (bien étudiées dans la thèse de Houard), offrent une extrème fréquence et traduisent l'attaque d'insectes très variés.

Les galles des fleurs sont relativement peu communes, celles des fruits charnus exceptionnelles, celles des fruits secs moins rares. 


\section{(B) Forme.}

La plus simple est représentée par les erineums, que nous étudierons avec les acariens. Puis viennent: les galles développées en surface et les galles développées en profondeur. Cette division, due à Küster, bien qu'arbitraire, offre l'avantage d'ètre simple et claire.

\section{GALLES DÉVELOPPÉES EN SURFACE}

Enroulements el plissements. (Des enveloppes florales et surtoul des fenilles).

Grande variété de forme et d'étendue; transition nette ou insensible avec les parties saines; couleurs diverses (normale, vert clair, jaune, rouge); bords soudés ou simplement accolés; épaississement habituel des parties atteintes.

Les parasites siègent à la surface du limbe, dans la concavité de la volute, souvent tapissée de poils. D'ordinaire, la feuille est enroulée de bas en haut. Parfois, on la voit totalement repliée et la soudure de ses bords lui donne l'aspect d'une gousse, aspect particulièrement curieux chez les légumineuses, où il est dù aux Perrisia. [Les Perrisia et les Pemphigus sont peut-être les deux genres qui déterminent le plus souvent l'enroulement des limbes]. 
Les cécidies dont nous venons de parler meurent, soit avec la feuille elle-même, soit auparavant.

Galles en bourse.

(A peu près spéciales aux feuilles).

Le limbe, hypertrophié, se déprime en doigt de gant; la face supérieurc bombe, affectant des aspects fort variés (sphérique, claviforme... éventuellement articulé ou rameux) et offrant volontiers des colorations anormales. La cavité de la poche ainsi produite regarde donc vers le bas; l'orifice d'entrée, étroit, est épaissi et fréquemment villeux. Des poils se rencontrent souvent aussi à l'intérieur, éventuellement garni de saillies. Nombre d'insectes engendrent des galles en bourse; celle du Pemphigus cornicularius peut acquérir 20 centimètres de long; nous retrouverons bientôt celles des Tetraneura (aunes).

Les cécidies dont nous parlons sèchent ou noircissent, avant ou après la mort des feuilles.

GALLES DÉVELOPPÉES EN PROFONDEUR

\section{Tumeurs.}

Elles siègent sur les racines, tiges, rameaux, pétioles et affectent, suivant les cas, l'apparence globuleuse, fusiforme, mamelonnée... Elles répondent à des néoformations, tantôt superficielles, 
tantôt profondes; chez les premières, le parasite demeure extérieur et fait ainsi le diagnostic.

Les tumeurs, dues aux parasites superficiels, évoluent d'une façon différente suivant que l'altaque est circonscrite et temporaire ou étendue et répétée. Dans le premier cas, le nodule s'efface après le départ de l'insecte et il ne reste aucune trace apparente de la maladie. Dans le second cas, les lésions s'accroissent et se compliquent. Ainsi dégénèrent les racines de la vigne, infestée par le phylloxera et les rameaux du pommier, infestés par le puceron lanigère. Les tumeurs se fissurent; sur le bord des fissures, apparaissent des nouvelles nodosités, qui se trouvent dénudées à leur tour et ainsi de suite, pendant des années. On sait que l'infection secondaire par la Nectria ditissima multiplie fréquemment les dégâts du puceron lanigère.

Les tumeurs, dues aux parasites profonds, évoluent très simplement. L'insecte sorti, la perte de substance se trouve limitée par une couche de liège et l'état normal se rétablit progressivement.

\section{Productions plus différenciées.}

Ce sont les galles au sens vulgaire du mot; le prototype est fourni par la "noix de galle», due au Cynips tinctoria. Leur nombre et leurs variétés défient toute description d'ensemble. Aussi nous bornerons-nous à rappeler quelques types classiques. 
Cécidies des fenilles. - Excessivement fréquentes sur les chênes : sphériques, ovoïdes, lenticulaires, réniformes, cylindriques, fusiformes...; de couleur et de consistance très diverses; dues, le plus souvent, aux cynipides. - Communes sur beaucoup d'autres plantes; citons : la galle sphérique de la Pontania salicis du saule et la galle de l'Oligotrophus reaumurianus du tilleul. Cette dernière se compose d'une production interne ovoïde, contenue dans une cupule (comme un œuf dans son coquetier) et l'abandonnant pour tomber sur le sol.

Cécidies des bourgeons. - Excessivement fréquentes, aussi, sur les chènes : en artichaut, en citron, en corne, sphériques, ovoïdes...; de couleur et consistance très variéees; dues encore, le plus souvent, aux cynipides. - Communes chez bien d'autres végétaux; rappelons les galles en ananas, que les Adelg'es déterminent sur les Piceas.

Cécidies des fruits. - Chènes : galle de l'amande et de la cupule (cynipides). Figuier sauvage : galles arrondies et brillantes de la Blastophaga psenes. Pavols : galles de l'Aulav: papaveris (fruit gonflé et déformé).

La Blastophaga psenes, qui infeste le fruit du figuier sauvage (caprifiguier), paraît indispensable pour la fécondation du figuier cultivé et, surtout, pour l'obtention de figues savoureuses. Le procédé de la " caprification ", connu de toute antiquilé dans la zone méditerranéenne, a été importè avec succès en Californie 
Le Rhodites rosæ produit, sur les diverses parties du rosier, les cécidies chevelues que tout le monde connaît (bedeguars). - Mentionnons simplement les galles des fleurs et rappelons la ressemblance, notée depuis longtemps, entre les cécidies et les fruits. Cette ressemblance est particulièrement étrange quand elle simule le fruit de l'arbre attaqué (galles des Adelges et cônes femelles des Picéas - galles de l'Andricus glandulce et glands).

A l'iniérieur, les cécidies bien différenciées montrent plusieurs loges, habitées par les larves. Ces loges occupent le centre du tissu néoformé, dont la consistance varie avec la nature et l'âge de la galle.

La durée des cécidies oscille dans d'énormes limites (quelques semaines, de nombreux mois). Elles tombent, d'ordinaire, le moment venu. Elles s'ouvrent quelquefois d'elles-mêmes, suivant des modes fort divers; habituellement, c'est le parasite qui en perfore les parois pour sortir.

Le plus souvent, la galle meurt quand l'évolution in vivo de la larve a atteint le degré voulu, mais on peut voir cellc-ci demeurer longtemps dans la cécidie morte ou, inversement, la cécidie survivre longtemps au départ de son producteur (artificiellement cultivées, les galles de la Pontania du saule restent fraîches et vertes pendant des mois!. 


\section{(C) Structure.}

Enroulemements et plissements. - La lésion consiste dans une hypertrophie du mésophylle et surtout du parenchyme lacuneux. Les méats intercellulaires de ce dernier disparaissent ou s'atténuent, l'assise en palissade perd son aspect normal et se trouve remplacée par un tissu compact, formé d'éléments irréguliers. Au niveau de la cécidie, les faisceaux vasculaires croissent anormalement et leur partie libérienne assure une nutrition plus intense des tissus néoformés (Houard). L'enroulement est dù, dans la règle, à l'épaississement du parenchyme lacuneux, qui entraine l'incurvation des parties sus-jacentes.

Galles en bourse. - Mèmes caractères généraux.

Tumeurs superficielles. - Lors d'attaque circonscrite et temporaire, les tissus situés sous le parasite s'hypertrophient, formant un parenchyme dont les cellules, volumineuses, conservent des parois minces pendant la vie active de la larve (qui se nourrit à leurs dépens). Les faisceaux vasculaires augmentent d'épaisseur, pour les raisons indiquées. Finalement, lorsque le parasite est parti, les éléments anatomiques, dans la région correspondante, épaississent leurs membranes et diminuent de volume (Houard). - Lor's d'attaque étendue et répétée, les lésions deviennent d'autant plus confuses que l'infection s'y joint volontiers. 
Tumeur's profondes et galles bien différenciées. - Leur structure, parfois fort complexe, peut être cependant schématisée sans difficulté, grâce aux travaux de Houard et de Molliard.

Pendant la vie active du parasite, la chambre larvaire plonge dans un parenchyme néoformé, qui se différencie bientôt autour d'elle. Les assises voisines de la larve constituent le tissu nourricier : cellules au protoplasma dense et granuleux, riches en réserves albuminoïdes, grasses et amylacées (notons, toutefois, que l'amidon diminue à mesure qu'on s'approche du parasite).

Le tissu nourricier se trouve séparé du parenchyme indifférent par un anneau de sclérenchyme, d'ailleurs fort perméable alors.

La partie libérienne des faisceaux vasculaires voisins assure la nutrition du tissu alimentaire. Lorsque le parasite siège un peu loin de ces faisceaux, on voit s'en détacher de minces conduils d'irrigation néoformés, qui vont s'insérer sur l'anneau du sclérenchyme (Houard). Ajoutons que le système vasculaire, d'où émanent ces canaux, se trouve toujours fortement dissocié (multiplication des éléments parenchymateux qui entourent fibres et vaisseaux).

La croissance de la galle suit, pari passu, celle de l'insecte.

Au momenl de la mélamorphose (tolale ou non), le développement s'arrête; les cellules de l'anneau scléreux épaississent de plus en plus leurs parois, 
dont les ponctualions permettent cependant les échanges liquides et gazeux strictement indispensables à la vie des parasites; le tissu nourricier dégénère, ses éléments se flétrissent et sèchent.

Qu'arrive-t-il finalement? Chez les végétaux herbacés, les galles meurent un peu après la plante qui les porie. Chez les végétaux ligneux, tantôt la cécidie tombe, tantôt elle reste en place. Dans le premier cas, son élimination est due à la formation d'une couche subéreuse; les structures normales des parties atteintes se rétablissent ensuite, mais le microscope décèle toujours des traces de la lésion passée. Dans le second cas, après le départ du parasite, la galle se trouve isoléc des tissus sains par le même processus (formation de liège) et le développement de ceuxci continue.

\section{AUTRES EFFETS DES INSECTES CÉCIDOGÈNES}

Les insectes cécidogènes ne sont guère dangereux que lorsqu'ils agissent en spoliateurs (phylloxera, puceron lanigère). On retrouve d'ailleurs fréquemment, associécs aux galles, les anomalies que provoquent volontiers ces spoliateurs et sur la nature desquelles nous nous sommes expliqués plus haut.

Mais la formation des cécidies, par elle-même, comporte de réels inconvénients. La nutrition des parties sus-jacentes se trouve diminuée ou abolie 
pour deux raisons, tantôt isolées, tantôt réunies : gêne mécanique apportée à la circulation des sucs nourriciers et déviation de ces sucs, au profit des tissus néoformés. Les parties en question deviennent chétives, se déforment parfois et meurent assez souvent.

MÉCANISME DE LA CÉCIDOGÉNÉSE

\section{ÉLECTIVITÉ DES PARASITES}

Variable, comme pour les phytophages. Bornonsnous à rappeler iciles races des chermes (Marchal). Mentionnons également un fait très intéressant. Les cuf's de certains Rhodites, qui n'attaquent jamais les rosiers, déterminent la formation de galles, quand on les dépose sur ces végétaux (Beyerinck).

\section{SENSIBILITÉ DES PLANTES}

Citons quelques chiffres, fournis par Houard et indiquant les familles les plus fréquemment atteintes (ces chiffres, qui englobent les cécidies " organoïdes", ne sont point exacts d'après notre point de vue).

Monocolylédones. - 173 espèces se montrent sensibles; les graminées occupent le premier rang, parmi les familles infestées.

Dicotylédones. - 2. 053 espèces; familles principale- 
ment attaquées: fagacées (901 espèces), composées (664), salicacées.(573), rosacées (500), légumineuses (481), crucifères (359), labiées (217), ombellifères (181), rubiacée (162), scrophulariées (139).

\section{MOYENS D'ATTAQUe DES PARASITES}

Pour Malpighi, la galle traduit la réaction de l'organisme vis-à-vis d'un venin, que la femelle insère en déposant ses œufs. Mais il ajoute que la larve peut produire éventuellement une substance de nature semblable lors de sa croissance et irriter ainsi les tissus qui l'environnent.

Lacaze-Duthiers, Darwin, Kiieffer... ont adopté soit la première, soit la seconde de ces conceptions. Beyerinck a prouvé que, selon les circonstances, le liquide toxique émis durant la ponte, l'œuf ou la larve devaient être incriminés.

Dans le cas de la Pontania, la cécidie débute rapidement, même si l'ouf avorte; dans le cas de la Biorrhiza, le liquide demeure inactif et l'œuf seul intervient; pour la plupart des cynipides, la larve constitue l'agent cécidogène.

Il semble que, le plus souvent, ce soient les sécrétions larvaires qui agissent. L'évolution des galles suit d'ordinaire, avec régularité, celle des parasites, s'arrêtant prématurément quand ceux-ci meurent d'une mánière inopinée, " normalement ", quand ils ont terminé leur évolution in sivo.

La belle expérience qui suit, due à Molliard, confirme cette idée. 
La femelle de l'Aulax papaveris dépose scs cufs sur les lamelles placentaires des pavols. Ces lamelles s'hypertrophient, se soudent et forment une masse compacte, creusée de logettes (galle typique). Le liquide, obtenu en faisant macérer dans l'eau les larves qui habitent les logeltes, engendre la tuméfaction des placentas, quand on l'injecte suivant l'axe du pistil (Papaver rhoeas).

Les galles sont donc déterminées par des venins, c'est-à-dire des toxines. La diversité des cécidies, sićgeant sur un même organe de la même plante, réflète la diversité des poisons qui les ont engendrées.

\section{MOYENS DE RÉSISTANCE DES PLANTES}

Mêmes réflexions générales que pour les phytophages. L'exemple le mieux connu d'immunité est celui des vignes américaines, qui résistent (d'une façon d'ailleurs fort variable, selon les races) aux attaques du phylloxera. Il s'agit d'un caractère propre des racines, transmissible par les graines. Les greffons européens, entés sur des souches américaines, bénéficient de cette immunité, mais ne l'acquièrent jamais personnellement, même après des années.

\section{CÉCIDOGENÈSE}

La femelle, avons-nous dit, dépose ses œufs à la surface ou à l'intérieur des végétaux. Lors d'éclosion extérieure, la larve peut continuer son déve- 
loppement in situ ou pénétrer au sein des tissus. La pénétration s'effectue tantôt passivement, tantôt activement. Dans le premier cas (le plus habituel), les tissus irrités se soulèvent, englobent le parasite, puis se réunissent, formant une chambre close. Dans le second cas (divers cynipides), la larve se creuse une cavité, par nécrose et dissolution des éléments anatomiques voisins; cette cavité se ferme, le moment venu et l'irritation, persistante, cesse désormais d'être accompagnée de la fonte des tissus (Weidel, Magnus).

Superficielle ou interstitielle, la larve entretient, durant sa vie active, la réaction dont elle bénéficie, réaction cellulaire et vasculaire. Grâce à cette dernière, la sève élaborée afflue abondamment par les conduits libériens.

Les auteurs ne donnent guère de précisions sur la manière dont le parasite s'alimente. Il semble que, le plus souvent, il suce le contenu des éléments nourriciers. En tout cas, on ne saurait douter que la larve secrète des enzymes, qui solubilisent les réserves de la couche alimentaire. On le voit pour l'amidon; l'étude chimique des cécidies le dèmontre, pour les autres substances nutritives.

Les recherches de plusieurs savants et notamment celles de Molliard (cécidies de la Tetraneura ulmi), ont établi nombre de faits intéressants, au sujet de la chimie des galles. Voici les principaux.

Augmentation de la teneur en eau, des sucres réduc- 
teurs, des tannins, des acides libres, de l'azote nitrique et ammoniacal, de l'asparagine. Disparition du saccharose; diminution des polysaccharides et de l'azote protéinique. Le parasite consomme donc avidement les réserves de l'hỏte, en même temps qu'il gêne leur élaboration (locale; surtout quand il siège dans les feuilles). L'analogie est réelle et pas seulement apparente avec les fruits; l'insecte joue, dans la galle, le rôle que l'embryon joue dans ceux-ci (Molliard).

A un moment donné, le parasite ne secrète plus rien et va, désormais, mener une vie latente, jusqu'au jour de sa sortie. L irritation formative cesse; la galle tombe ou non. Elle meurt quand ses réserves sont épuisées, époque fort variable. Avant de mourir, elle utilise une partie des aliments accumulés pour épaissir l'anneau de sclérenchyme; la couche nourricière dégénère.

Houard a étudié, microscopiquement, l'action cécidogène qui détermine l'hyperplasie caractéristique des tissus et montré qu'elle décroit en s'éloignanl du parasite. Il existe, conséquemment, un rayon d'activité; sa longueur dépend de la taille des larves et de leur nombre, de l'âge et de la slructure des organes attaqués (certainement, aussi, de la * force " du poison émis par les larves).

Les parasites secrètent donc: des toxines, qui irritent et des enzymes, qui solubilisent; double type de sécrétions que nous relrouverons dans toute la série des agents pathogènes, animaux, végétaux et bactériens.

Comment agissent les poisons cécidogènes? 
Plusieurs auteurs ont comparé les néoformations parasitaires des végétaux avec celles que produisent les solutions hypertoniques. Nous admettons parfaitement que des changements osmotiques interviennent. Le mécanisme doit donc être le suivant : suractivité fonctionnelle, amenant l'augmentation des déchets et, partant, une concentration plus grande du suc cellulaire - doù : afflux de sève et transformation de l'excitation désassimilatrice en excitation formative (désassimilation surcompensée).

Encore un mot, pour terminer. Les rapports entre la larve et les tissus nouveaux ont été mis en parallèle, avons-nous dit, avec ceux qui unissent l'embryon et le fruit. Une comparaison plus éloignée, mais toujours de même ordre, se trouve chez Malpighi. Pour lui, la larve, dans la galle, rappelle à bien des points de vue, le fotus dans la matrice. Le grand anatomiste inaugurail, par celte vue suggestive, l'histoire du " parasitisme embryonnaire ", aux modalités variées, au mécanisme fondamental univoque.

PROPHYLAXIE ET TRAITEMENT

Il n'est pas sans intérêt d'en rappeler les lignes essentielles.

On interdira l'entrée et la circulation des végétaux étrangers, susceptibles d'héberger les parasites (nous 
devons le phylloxera et le puceron lanigère à l'Amérique, l'Eudemis à l'Italie, l'Icerya purchasi à l'Australie). On ne sèmera que des graines intactes.

On collectera les insectes dangereux, par divers moyens; on les détruira par écrasement, flambage, submersion. On les arrêtera éventuellement dans leur marche (barrages, fossés).

On en débarrassera les plantes : par le pétrole, les huiles lourdes, le phénol, le jus de tabac, les sels de cuivre, le sulfure de carbone, l'anhydride sulfureux, l'acide cyanhydrique, les arsenicaux - en ayant soin de ne pas intoxiquer les végétaux infestés.

On les " déviera ", à l'aide de plantes-pièges.

On leur opposera des insectes entomophages, des champignons el bactéries pathogènes.

On pratiquera l'alternance des cultures, les labours profonds en fin de saison; on sèmera et récoltera à des époques choisies.

Des moyens analogues seront employés dans la lutte contre les acariens et les nématodes.

Inutile de faire observer que le traitement demeure externe et rien de plus. 


\section{MALADIES DUES AUX ACARIENS}

Nous ne parlerons ici que des ériophyides, dont plus de 250 espèces attaquent les phanérogames. Ces acariens se comportent, en gros, comme les hémiptères. Ils sont donc, avant tout, spoliateurs, mais souvent aussi cécidogènes.

\section{ACTION SPOLIATRICE}

(Sourent doublée, selon nous, d'une action toxique). Elle se traduil par l'épuisement, d'intensité fort variable, auquel s'ajoutent fréquemment les anomalies de croissance, que nous avons déjà étudiées avec détails. Anomalies tantôt localisées, tantôt généralisées. Voici un exemple typique de ces dernières (Molliard).

L'extrémité des bourgeons de la menthe poivrée, où siège l'Eriophyes menthce, rappelle, dans son aspect, les sommités défleuries du basilic (menthe poivrée basin liquée). Les tiges, qui portent ces masses foliacées terminales, se ramifienl considérablement et deviennent presque circulaires. Les grandes feuilles de la base des rameaux apparaissent serrées, larges, sans dents, nervatipalmées (nanisme des cellules du mésophylle, développement réduit du parenchyme en palissade). L'es- 
sence est plus abondante que normalement, mais contient moins de menthone.

Chez la menthe poivrée, comme chez beaucoup d'autres plantes hébergeant des ériophyides, la stérilité résulte de l'infestation.

\section{ACTION CÉCIDOGÉNE}

Les parasiles peuvent délerminer des erineums (caractéristiques des acariens), des enroulements et plissements des feuilles (n'offrant rien de spécial), des galles en bourse (identiques aux types déjà cilés), des galles profondes (rares).

\section{Erineums.}

Fossetles siégeant à la face inférieure des feuilles, avec boursouflures correspondantes à la face supérieure. Dans les fossettes, feutrage argenté ou rose pâle, logeant les parasites. Au microscope : poils de forme extrêmement variée, que sucent les acariens et qui meurent, soit avant, soit après la fin de l'évolution de ceux-ci.

\section{Galles profondes.}

Les parasites habitent tantôt le tissu cortical, tantôt la moelle des tiges ou des rameaux; ils sont entourés de parenchyme néoformé (Eriophyies pini, Eriophyies obiones - Molliard). On peut aussi les rencontrer dans le mésophylle hypertrophié (variole des pomacées). 


\section{MALADIES DUES AUX NÉMATODES}

Il s'agit toujours d'anguillulides. Certains de ces némathelminthes, les dorylaimes, sont exclusivement prédateurs; ils mènent une vie libre et perforent les radicelles de la betterave. Les autres, seuls intéressants pour nous, libres au début du stade larvaire, puis parasites, se montrent soit spoliateurs, soit destrucleurs, soit cécidogènes.

\section{SPOLIATEURS}

Nous prendrons pour type l'Heterodera Schachtii, qui attaque les racines de nombreux végétaux, notamment de la betlerave.

Peu après la levée des plants, les feuilles deviennent jaunes et se flétrissent; parfois même la betterave noircit et meurt. Lorsqu'elle résiste, de nouvelles feuilles apparaissent, petites et vert sombre. L'état général demeure médiocre. Les racines, atrophiées et pauvres en sucre, offrent un chevelu très développé; à leur surface, se voient des semis de points blancs (femelles remplies d'œufs).

Les larves, d'abord libres dans le sol, pénètrent sous l'écorce des racines, puis deviennent adultes et sexuées. Les femelles font hernie extérieurement, comme on vient de le noter, transformées en masses globuleuses (sacs à œufs) et souvent vivipares. Les mâles, aux 
métamorphoses plus complexes, sortent de la racine, fécondent les femelles et meurent.

Il s'agit donc de phénomènes d'épuisement, doublés sans doute de phénomènes d’intoxication.

\section{DESTRUCTEURS}

Nous citerons comme exemple le Ty-lenchus devastator, qui infeste des végétaux fort variés, notamment les graminées et les planles à oignons.

Graminées. - Les tiges deviennent bulbeuses à leur base, ce qui tient au " tassement "que provoquent les entrenœuds raccourcis. Pour le même molif, les plantes se montrent courtes et trapues. Les premières feuilles jaunissent, les suivantes apparaissent atrophiées, élargies de la base, souvent épaissies et crispées. Les épis avortent ou demeurent rudimentaires.

Les larves, plus résistantes à la dessiccation que celles de l'Heterodera Schachtii, pénètrent dans les entrenœuds des jeunes tiges, s'y développent, détruisent les tissus, deviennent sexuées et engendrent de nouvelles larves qui arrivent au sol, le moment venu.

Plantes à bulbes. - Tiges trapues et contournées. Feuilles pâles, tachetées de jaune, épaissies çà et là, gaufrées. Inflorescences incomplètes ou avortées. Entrenœuds raccourcis, avec renflements noueux. Tuniques des bulbes tuméfiées, gommeuses, foncées (souvent par anneaux concentriques). Infections consécutives fréquentes.

Parasites dans la tige et le bulbe, au sein de cavités. Tissus plus ou moins hypertrophiés, puis fonte muqueuse des cellules.

Fèves. - Taches vertes et, successivement: rouges, brunes, noires - sur les tiges, feuilles el gousses.

OEillets. - Entrenœuds raccourcis, extrémité des 
pousses renflées; élargissement des feuilles et parfois des enveloppes florales.

[Nota. - Contrairement aux Helerodera, les Tylenchus n'offrent pas de dimorphisme sexuel.]

Par conséquent : anomalies de développemenl, désintégration des tissus (éventuellement associée à leur hypertrophie) et, dans certains cas, taches nécroliques - donc : troubles de nutrition, empoisonnement local et général, digestion des éléments cellulaires.

\section{CÉCIDOGÈNES}

Parasites des fenilles.

Divers Tylenchus déterminent, chez l'Achillea millefolium, l'Artemisia vulgaris, l'A gropyrum repens.., des tuméfactions du limbe plus ou moins accentuées. Le parenchyme lacuneux, épaissi, offre des cavités remplies de parasites. Au voisinage de ceux-ci, les cellules sont totalement dégénérées (Molliard). Semblables lésions se voient aussi sur la tige, les pétioles, les enveloppes florales.

\section{Parasites des fruits.}

Tylenchus phalaridis, Tylenchus agrostidlis. - Ovaires énormes, en bouteille, brun pourpre, contenant des némalodes. Glumelles épaissies, étamines avortées. Tylenchus dipsaci. - Dans la tête et les ovaires du chardon, parasites nombreux. Les tissus atteints se 
tuméfient, puis brunissent et sèchent. Nématodes très résistants à la dessiccation.

Tylenchus tritici (Needham, 1743). - Plantes plus courtes et jaunissant prématurément; aspect chétif; feuilles plissées, épis irréguliers et avortés. Grains noirs, arrondis, atrophiés; enveloppe épaisse et ligneuse ; contenu blanc, farineux (milliers de larves, en état de vie latente).

Les grains de "blé niellé » pourrissent dans le sol, les parasites libérés "ressuscitent " sous l'influence de l'humidité et gagnent les jeunes plantes. Montant entre les gaînes, ils arrivent aux fleurs, y pénètrent, déterminent les galles caractéristiques des ovaires et deviennent sexués. La femelle dépose ses cufs dans la cécidie, puis elle meurt, ainsi que le mâle. Les larves éclosent et se trourent bientol en état de vie latente, par suite de la dessiccation des tissus. Elles peuvent " renaitre " après plus de 20 ans, dit-on, si on les humecte (nous les avons vues revivre au bout de 14 ans).

La cécidie du blé se compose d'un tissu homogène que le parasite consomme et d'une enveloppe scléreuse, qui s'épaissit progressivement.

\section{Parasites des racines.}

On doit citer, avant tout, l'Heterodera radicicola, qui atteint de nombreuses plantes. Celles-ci périssent, après avoir présenté, sur leurs racines, des renflements hébergeant les parasites.

Suivant Molliard, le nématode, situé dans le parenchyme cortical hypertrophié, se trouve entouré de cellules géantes multinucléées ( 200 noyaux et plus), qui lui servent d'aliment et dont il ne reste aucune trace quand sa taille est devenue définitive. Ces cellules proviennent de la transformation d'éléments vasculaires (phénomène déjà vu par Vuillemin et Legrain). La transformation commence au niveau de la tête du parasile. Finalement, un manteau scléreux isole ce dernier. 
Tandis que le Tylenchus devastator se montre surtout destructeur, les nématodes dont nous venons de parler se montrent surtout cécidogènes. Ils n'en occasionnent pas moins de graves altérations locales et, surlout, des troubles généraux fort marqués.

Les maladies, déterminées par les nématodes, sont d'ordinaire subaiguës. Leur mécanisme se résume dans les procès déjà mentionnés : spoliation, intoxication, destruction et, Irès fréquemment, néoformation. 

II

MALADIES DES PLANTES

DUES AUX PHANÉROGAMES 

Un millier de dicotylédones, dont environ 500 loranthacées, peuvent vivre aux dépens de nombreux phanérogames.

Certaines de ces plantes parasites continuent à produire de la chlorophylle et à former des feuilles; d'autres, dépourvues de pigment, remplacent leur feuillage par des écailles ou peuvent même offrir un système végétatif étonnamment réduit. Parmi les premières, nous citerons : diverses rhinantées (rhinantes et mélampyres, parasites des graminées - pédiculaires et euphraises, parasites des plantes des prairies); diverses santalacées; le g'ui (loranthacée); la cassythe (lauracée). Parmi les secondes, mentionnons : les orobanches (parasites des légumineuses, du trèfle notammenl); les cuscutes (convolvulacées); les cytinacées.

Les phanérogames parasites offrent, dans la règle, une réduction marquée de leur appareil reproducteur (des organes femelles, principalement) et un état peu différencié des cmbryons. Pareilles modifications peuvent du reste exister 
chez les végétaux saprophytes et même autonomes.

L'infestation s'opère par les fruits ou les graines. Ces dernières sont excessivement nombreuses et conservent fort longtemps le pouvoir de germer. Fruits et graines doivent surtout leur dissémination au vent et aux oiseaux.

DESCRIPTION SOMMAIRE DES PARASITES ET DE LEURS EFFETS

PARASITES DES RAMIFICATIONS PRINCIPALES

Gui.

Voici comment évolue cette planle singulière. Le fruit, collé en hiver sur l'arbre, germe au printemps; la tigelle perce l'écorce des jeunes rameaux et forme une plaque adhésive, d'où naît un suçoir. $\mathrm{Au}$ printemps de la troisième année seulement, apparaissent les deux premières feuilles; pendant la quatrième annéc, un rameau nait à l'aisselle de chaque feuille et se termine par deux feuilles nouvelles. Et ainsi de suite. Parallèlement, le suçoir se ramifie entre le bois et l'écorce, formant des veines verdatres, d'où émanent des suçoirs secondaires. Tous ces suçoirs résorbent les tissus de l'hôte sur leur passage; leurs vaisseaux s'anastomosent avec les siens.

Le gui peut se développer sur beaucoup d'arbres, mais il est souvent difficile d'infester une 
espèce sensible, en s'adressant à du gui développé sur une autre espèce, également sensible. Il existe donc des races, plus ou moins étroitement spécialisées dans leur aptitude parasitaire. Le gui du tilleul constitue la moins différenciée, car on "l'inocule " aisément à des arbres très divers.

Il faut observer, également, que l'affinité du gui pour une espèce végétale donnée varie selon l'habitat de celle-ci, c'est-à-dire la nature du sol et les autres conditions de vie qui régissent sa composition intime.

On connaît les inconvénients du parasite pour son hôte, dont les branches atteintes produisent peu de fruits et se couvrent de bois mort. Ces branches offrent souvent des intumescences nodulaires ou fusiformes.

\section{PARASITES DES TIGES}

\section{Cuscutes.}

Aussi connues que le gui et infiniment plus redoutables pour les dégàts qu'elles occasionnent (notamment dans les champs de luzerne et de trèfle). Elles ont été étudiées surtout par Mirande, dont nous suivrons le travail, aujourd'hui classique.

La graine germe au printemps dans le sol et produit une plantule filiforme, douée de mouvements de nutation irréguliers. Si cette plantule nc 
rencontre pas un hôte approprié, elle meurt en quelques jours, car ses racines rudimentaires sont incapables de la nourrir. Au cas contraire, elle croìt, s'élève en s'enroulant autour de la tige parasitée et offre des mouvements de nutation réguliers dans un sens constant. Elle se fixe par des suçoirs; la racine dégénère et la plante s'isole ainsi de la terre.

Le développement, souvent très rapide, produit ce lacis inextricable des tiges grêles, rouges ou jaunes, que chacun se rappellera immédiatement. A mesure que le parasite lianoïde s'élève, les parties inférieures dépérissent et meurent peu à peu, alors même que l'hôte n'offre encore aucun signe d'épuisement. Il est aisé d'obtenir l'infestation des plantes sensibles, en plaçant sur elles un brin de cuscute; la croissance progresse très vite.

Les suçoirs cheminent dans les tissus de l'hôte, s'attaquant d'abord au contenu des cellules, puis à leurs parois. De la surface des suçoirs émanent des filaments (cellules absorbantes), tandis que de leur axe partent des vaisseaux qui s'anastomosent avec ceux de la plante nourricière. Les suçoirs laissent diffuser des enzymes, qui solubilisent les réserves de la zone voisine de l'hôte; ils résorbent ensuite ces produits, rendus mobilisables, tandis que leurs vaisseaux puisent, par continuité avec ceux de l'hôte, les sels dissous venus du sol.

On répète que les phanérogames parasites se nourrissent directement de la sève élaborée qu'ils 
prélèvent; rien de plus inexact : ils modifient le contenu cellulaire de l'hôte, afin de pouvoir l'absorber, puis édifient leurs tissus et constituent leurs réserves aux dépens de ces matériaux, en les transformant selon leur manière propre. Seul, peut-ètre, le glucose " passe droit ", de la plante nourricière au parasite; ni les alcaloïdes, ni les glucosides ne traversent les suçoirs.

La cuscute emmagasine de l'arnidon. Sa croissance correspond à la solubilisation de celui-ci. Il se reforme ensuite dans les parties supérieures de la tige, quand elles sont fixées. Avant la floraison, la réserve d'amidon est énorme; elle disparait en entier, au cours du développement des organes reproducteurs.

Chez la cuscute, les écailles remplacent les feuilles. La chlorophylle, toujours insuffisante pour jouer un rôle utile, se montre d'autant plus abondante que l'hôte souffre davantage; le pigment, jaune ou rouge, évolue d'une façon opposée.

Le parasite dont nous parlons épuise les plantes herbacées; il peut faire périr les rameaux jeunes des arbustes, mais reste inoffensif pour les arbres véritables. L'hôte réagit par des hypertrophies légères, localisées au niveau de la pénétration des suçoirs.

[La cassythe se comporte en gros comme les cuscutes. Cependant les jeunes plantes forment parfois des racines normales, qui leur permettent de mener temporairement une vie indépendante].

Nicolle et Magrou, - M. P. des plantes. 


\section{PARASITES DES RACINES}

\section{Rhinanthées.}

Elles revêtent l'aspect de végétaux aulonomes, bien que leur's racines soient fixées sur celles d'autres espèces. Cette fixation s'opère au moyen de suçoirs, dont les vaisseaux s'anastomosent avec ceux de l'hòte. Malgré le caractère apparemment accessoire de ce parasitisme, les rhinanthées ne sauraient atteindre leur complet développement, ni donner des fleurs, sans le secours des plantes nourricières (auxquelles elles sont peu nuisibles d'ordinaire).

[Pour certaines santalacées, la vie parasitaire demeure facultative].

\section{Urobanches.}

On en connait les tiges squameuses et les fleurs sessiles. La graine ne germe qu'au contact d'une racine appropriée. L'embryon émet un suçoir, qui pénètre dans cette racine el assure la croissance ultérieure du parasite. Celui-ci développe alors des racines propres, pouvant pénétrer à leur tour dans celles de l'hôte et engendrer, l'an suivant, des hampes florifères. Les vaisseaux des suçoirs communiquent librement avec ceux de la plante nourricière.

Les orobanches épuisent les végétaux herbacés. 


\section{Cytinacées.}

Ces parasites, cachés dans les tissus de l'hỏte, sont atrophiés au plus haut point. Les fleurs paraissent seules extérieurement, après avoir crevé l'écorce; fleurs parfois énormes (un mètre de diamètre) chez les Rafflesia, parasites des Cissus (lianes de l'Insulinde). L'appareil végétatif des Rafflesia se réduit à quelques filaments " mycéliens "; celui du Crtinus hypocystis (parasite des cistes) forme une sorte de thalle, situé entre le bois et le cambium et composé de cellules indifférenciées. - Lors de la floraison des parasites, des bourgeons se constituent sous l'écorce el déchirent celle-ci pour s'épanouir librement.

Les maladies, dues aux phanérogames parasites, se montrent, suivant les cas, aiguës ou lentes. Les plantes herbacées, attaquées par la cuscute ou par les orobanches, deviennent chétives, jaunissent et n'arrivent pas à maturité; les jeunes sujets succombent rapidement. Les vignes, infestées par la cuscute, prennent un aspect languissant, les sarments s'arrêtent dans leur développement, les fruits " grillent » au soleil; si la maladie récidive plusieurs années de suite, les souches se rabougrissent. Les rhinanthées et le gui sont bien moins dangereux. 
MÉCANISME DE L'INFESTATION

\section{ÉLECTIVITÉ DES PARASITES}

Notons d'abord que certains d'entre eux peuvent mener, éventuellement, une vie libre (Santalum album). Les autres ont toujours besoin d'envahir les végétaux étrangers, pour assurer leur croissance ou, tout au moins, leur reproduction. Cnmme on l'a vu, les rhinanthées sont reliées par leurs racines aux racines de la plante nourricière, les cuscutes par leurs tiges à la tige de celle-ci; les orobanches s'implantent dans les racines de l'hôte, le gui dans ses rameaux; les cytinacées constituent de véritables endoparasites. Le gui présente des races, plus ou moins spécialisées. Les cuscutes et orobanches, suivant l'espèce à laquelle elles appartiennent, se montrent capables d'infester un nombre fort variable de végétaux.

\section{SENSIBILITÉ DES PLANTES}

Elle dépend, avant tout, de l'espèce et des conditions d'existence. Nous venons de rappeler qu'elle diffère selon les organes, d'où la localisation caractéristique de chaque agent d'infestation. D'ordinaire, les tissus jeunes sont seuls atteints; mais le parasite, une fois installé, peut croître pendant longtemps avec eux (gui). 
Pierce a montré que la cuscute s'enroule purement et simplement autour d'un bloc de moelle de sureau, tandis qu'elle ébauche des suçoirs, dès que le bloc est imprégné de l'extrait de plantes sensibles.

\section{MOYENS D'ATTAQUE DES PARASITES}

Les parasites pénètrent toujours de la même façon, développant des suçoirs qui digèrent les tissus sur leur passage. La curieuse expérience suivante (Molliard) imite bien le phénomène.

On introduit, dans l'axe hypocotylé d'un haricot, une graine de cresson alénois en germination. La racine principale de la plantule pousse, forme de vrais suçoirs et dissout les parenchymes de l'hôte.

Grâce aux enzymes qu'ils secrètent, les parasites s'approprient d'abord le contenu des cellules et, le moment venu, dissolvent complètement le reste. Ce sont donc des spoliateurs "perfectionnés " et des " destructeurs méthodiques". Secrètent-ils aussi des poisons "toxiques " (si l'on peut dire) et des poisons " irritants" (au sens de Malpighi)? Le dépérissement, parfois très rapide, des hôtes, plaide pour l'existence des premiers, les hypertrophies locales pour celle des seconds.

Nous avons parlé, tout à l'heure, de spoliation perfectionnée, s'exerçant par le jeu des enzymes; une autre spoliation, bien plus simple et portant 
seulement sur la sève brute, s'exerce en même temps par les anastomoses vasculaires qui unissent l'hòte et le parasite.

Cette union rend compte du fait original que rapportent Viala et Boyer. La cuscute de la vigne, croissant avec brutalité, isole quelquefois du reste de l'hôte des graines, fragments de grappe, feuilles, ramuscules, qui lui restent attachés. Ces parties demeurent vivantes, les raisins se développent et mûrissent, grâce au pont vasculaire représenté par la cuscute.

MOYens DE RÉsistance des PLANTES

Suivant l'espèce du végétal, naturellement ou artificiellement infesté, la croissance des parasites sera nulle, précaire, florissante. On peut entretenir la cuscute en vie, pendant au moins 4 ans, sur des plantes sensibles; l'inoculation échoue ou ne donne que des développements chétifs, quand on choisit des plantes résistantes. Comment concevoir cette résistance? Elle tient évidemment, soit a l'absence de matières nutritives convenables, soit à la présence de substances hostiles. Parni ces dernières, on incrimine souvent les glucosides et les alcaloïdes qui, d'après Mirande, entraveraient la croissance des suçoirs en neutralisant les enzymes qu'ils laissent diffuser. Dans les rares cas où la cuscute progresse au milieu de tissus gorgés d'alcaloïdes, on trouve les suçoirs remplis de gouttes huileuses; pour Mirande, les acides gras, 
issus de ces gouttes, vont insolubiliser les poisons voisins.

La prophylaxie (cuscute, orobanches) consiste à ne semer que des graines, pures de tout mélange avec celles des parasites. Une fois les champs infestés, on commencera par arracher les pieds malades et les brûler; si l'envahissement continue, il faudra retourner la terre et souvent pratiquer des assolements.

Le traitement (gui) se résume daus la section des rameaux atteints; quand le parasite occupe les grosses branches, on l'enlève avant sa fructification.

Les agents d'infestation, que nous venons de passer en revue, possèdent tous les stigmates des parasites. D'autre part, leur taille permet de les étudier avec une parfaite exactitude. Aussi représenteroni-ils à nos yeux comme le " grossissement naturel » des parasites plus petits et nous fourniront-ils, sur le mode d'action de ces derniers, des éclaircissements précieux et de bon aloi.

L'histoire des phanérogames parasites offre de frappantes analogies avec celles de la greffe et du "parasitisme embryonnaire " végétal.

L'expérience séculaire prouve que, dans le premier cas, les deux individus associés conservent leurs caractères propres et les travaux récents n'ont jamais permis de saisir le passage de substances chimiques définies de l'un à l'autre. Il se produit donc, au niveau du bourrelet, la même chose qu'au niveau du raccord entre le parasite et son hôte. Tel un parasitè, le greffon ne peut vivre 
que sur certains sujets et il s'y développe d'autant mieux que ceux-ci lui conviennent davantage.

Strictement parlant, l'embryon représente toujours, lui aussi, un parasite; mais, quelquefois, la plantule n'abandonne la plante-mère qu'après avoir alteint une taille assez grande (genres Rhizophora et Avicennia): on a pu alors, sans abus de langage, prononcer le mot de viviparité. 


\section{III}

\section{MALADIES DES PLANTES DUES AUX THALLOPHYTES}



Nous ne dirons qu'un mot sur les maladies des végétaux, délerminées par les algues.

Diverses algues infectent d'autres algues (surtout marines), produisant en général des hypertrophies cellulaires ou des ramifications anormales. On a cité des excroissances, chez les lichens et les hépatiques, dues à des cyanophycées. Enfin, l'Anaboena cycadearum (cyanophycée également) détermine des déformalions des racines chez diverses cycadées (nodules, affectant volontiers l'aspect coralloide).

Pareillement, nous serons bref, quant aux altéralions que produisent les champignons chez les végétaux inférieurs.

Des champignons des genres Olpidium, Synchitrium et Pythium (oonycètes) peuvent se développer sur diverses algues ou à leur intérieur; dans le premier cas, ils épuisent le contenu des cellules; dans le second, ils désintègrent les éléments anatomiques ou en déterminent l'hypertrophie. Des représentants du genre Hypomyces (ascomycètes) peuvent occasionuer des maladies chez les champignons supérieurs, notamment la " môle ", caraclérisée par des déformations variées, de profondes altérations et une tendance marquée à la pourriture. Des champignons du genre Prthium amè 
nent, par épuisement, la mort de certaines équisétacées et filicinées. Enfin, des exoascées (ascomycètes) peuvent engendrer de véritables galles chez les fougères.

Il ne sera question, maintenant, que des maladies cryptogamiques des phanérogames. 


\section{PRINGIPAUX CHAMPIGNONS PATHOGENES}

ÉNUMÉRATION

Nous rappellerons, en quelques mots, les caractères des différents groupes de champignons, mentionnant, à propos de chaque groupe, ceux de ces représentants dont nous aurons à parler ici, ainsi que le nom des maladies qu'ils déterminent.

\section{BASIDIOMYCÉTES}

Thalle à membrane cellulosique, formé de filaments cloisonnés (mycélium).

Spores naissant sur des basides.

Le mycélium peut former des cordons et des sclérotes.

Les basides représentent des cellules à deux noyaux. Ceux-ci se fusionnent (caryogamie), se divisent (en 4 le plus souvent), gagnent la surface, s'entourent de protoplasma et s'isolent par une sorte de bourgeonnement. Ainsi naissent les basiodiospores, qui, en germant, redonnent un nouveau mycélium.

Chez les ustilaginées et les urédinées, la baside résulte de la transformation d'une probaside (appelée téleutospore, chez les urédinées). Chez les urédinées, il peut exister, en dehors des téleutospores, des urédospores, des œcidiospores et des œcidiolispores, ces dernières semblant incapables de germer. 
Voici l'énumération des hasidiomycètes dont il sera question plus loin.

Hétérobasidiées (baside généralement cloisonnée).

Ustilagrnées. - Champignons divers produisant le charbon des céréales; Ustilago violacea (charbon des caryophyllées).

Tilletiées. - Tilletia tritici (carie du blé).

Urédrnées. - Puccinia graminis (rouille linéaire des céréales, rouille de l'épine-vinette). Uromyces pisi (rouille des légumineuses et de l'Euphorbia cyparissias), Melampsora pinitorqua (rouille du peuplier et rouille courbeuse du pin sylvestre), Melampsorella caryophyllacearum (rouille des caryophyllées, chaudrons et balais de sorcière du sapin pectiné).

\section{Homobasidiées (baside unicellulaire).}

Polyporées. - Nombreux polypores, déterminaut la pourriture du bois des tiges el des rameaux (parfois des racines).

Agaricinées. - Armillaria mellea (pourridié de divers arbres).

\section{ASCOMYCÈTES}

Thalle à membrane cellulosique, formé de filaments. cloisonnés (mycélium).

Spores naissant dans des asques, entourées ou non d'un périthèce. 
Le mycélium peut former des cordons et des sclécotes.

Les asques ont pour origine une cellule à deux noyaux, qui se fusionnent (caryogamie). Cette cellule, née de l'ascogone, s'allonge ensuite en massue et, dans son intérieur, naissent les ascospores (8, le plus souvent). Celles-ci, lors de leur germination, redonnent un nouveau mycélium. Le périthèce manque chez les gymno. ascées et les exoascées.

Conidies. On peut observer des appareils conidiens, d'ailleurs très variés. Les pycnides ne sont que des conceplacles conidiens.

OEufs. Certains ascomycètes produisent des œufs, tantôt par isogamie, tantôt et le plus souvent par hétérogamie (plus ou moins marquée; chez les laboulbéniacées, on distingue neltement l'oosphère et l'anthérozoïde). En germant, l'œuf produit un embryon filamenteux (ascogone).

Chez les ascomycètes qui ne forment pas d'œufs, il peut y avoir un oogone, véritable ascogone parthénogénétique, mais le plus souvent l'ascogone se développe sur un rameau mycélien non différencié (apogamie).

Voici l'énumération des ascomycètes dont il sera question plus loin.

Exonscées. - Exoascus deformans (cloque du pêcher), Exoascus pruni (pochettes du prunier), Evoascus cerasi (balais de sorcière du cerisier).

Discomrcètes. - Dasyscypha Willkommii (chancre du mélèze), Sclerotinia fuckeliana (pourriture grise de la vigne), Sclerotinia libertiana (nécrose progressive de diverses plantes), Sclerotinia trifoliorum (nécrose progressive de diverses légumineuses), Sclerotinia bulborum (nécrose progressive de diverses plantes à oignons). 


\section{Pyrénomycètes. - Diverses Rosellinia (pourri-} dié d'arbres variés), Guignardia Bidwellii (black rot de la vigne), Sphoerella tabifica (pourriture du cœur de la betterave), Nectria ditissima (chancre des arbres fruitiers), Fusarium vasinfectum (flétrissure du melon d'eau, du cowpea et du cotonnier).

Périsporiacées. - Diverses érysiphées (blancs des céréales), Uncinula necator (blanc de la vigne), champignons, encore mal connus, des fumagines.

\section{OOMYCÈTES}

Thalle à membrane cellulosique, formé de filaments non cloisonnés (mycélium).

Sporanges, naissant à l'extrémité de filaments mycéliens; il en sort des spores, qui, germant, redonnent un nouveau mycélium.

Formes levure, chez certaines mucorinées immergées.

Conidies $=$ spores exogènes, formées à l'extrémité de filaments mycéliens. Chez les péronosporées, elles donnent des sporanges, d'où sortent des spores, qui se transforment en zoospores.

OEufs. Dans certaines espèces, dus à la fusion de deux gamètes, naissant à l'extrémité de deux filaments mycéliens. L'œuf produit une sorte d'embryon, le zygote, qui engendre un tube germinatif, d'où résulteront, suivant les cas, soit un sporange, soit un mycélium. Les gamètes peuvent être semblables (isogamie) : mucorinées - ou dissemblables (hétérogamie): saprolégniées, entomophthorées, peronosporées. Dans le second cas, on distingue aisément l'oogone et l'anthéridie. Les mucorinées pathogènes ne donnent jamais d'œuf en culture, chaque thalle étant unisexué. 
Nous n'étudierons que les oomycètes suivants, appartenant aux péronosporées : Phytophthora infestans (mildiou de la pomme de terre), Plasmopara viticola (mildiou de la vigne), Peronospora Schachtii (mildiou de la betterave), Albugo candida (rouille blanche des crucifères), Albugo tragopogonis (rouille blanche des composées).

\section{MYXOMYCÈTES}

Thalle nu et mobile (plasmode). - Les plasmodes représentent des plaques de protoplasme, semées de nombreux noyaux et se déplaçant au moyen de pseudopodes. Ils forment des sporanges, d'où sortent des spores, qui se transforment en zoospores, lesquelles se transforment à leur tour en myxamibes. Celles-ci se multiplient, puis engendrent les plasmodes par leur fusion. Amibes et plasmodes peuvent s'enkyster, lors de conditions défavorables.

Nous n'étudierons que le Plasmodiophora brassicce (déterminant la hernie du chou).

Un dernier groupe de champignons est constitué par les fungi imperfecti. Nous ne ferons ici aucune allusion aux maladies qu'ils déterminent chez les plantes.

Les spores d'un grand nombre de champignons tombent sur le sol. Elles peuvent y demeurer long- 
temps vivantes (œufs des oomycèles, téleutospores des urédinées, spores des ustilaginées) et germent d'ordinaire à un moment donné. Quand il s'agit de parasites facultatifs, le développement continue, gràce aux débris organiques présents et rien n'empêche l'espèce de se perpétuer ainsi. Quand il s'agit de parasites stricls, le mycélium, né de la spore, périt en l'absence d'un hôte approprié ou reste filamenteux, donnant éventuellement des conidies, mais jamais des fructifications complexes.

Chez les champignons qui déterminent des maladies chroniques, le mycélium hiverne dans les rameaux, le tronc, les racines, pour reprendre son activité le printemps venu et s'étendre plus ou moins loin.

Beaucoup d'urédinées infectent successivement deux hòtes, parcourant de la sorte un cycle discontinu. Chez d'autres, le cycle se réalise sur la même plante. Chez d'autres enfin, l'évolution demeure très simple. Le tableau suivant, emprunté à Schröter, fixera les idées.

I. - OEcidiolispores, cecidiospores, urédospores, el téleutospores :

Sur le même hôte.

A uteuformes.

Sur deux hôtes différents. . . . Hétéreuformes.

II. - OEcidiolispores, œcidiospores et téleutospores . . * . . • .

III. - OEcidiolispores, urédospores, et téleutospores.........

IV. - Urédospores ct téleutospores. . . .

V. - OEcidiolispores et téleutospores (ou téleutospores seules).

Formes opsis.

Brachyformes. Hémiformes. Microformes. 
Il existe des urédinées qui, bien que ne possédant pas les 4 types de spores, sont cependant hétéroïques : les gymnosporangiums (acidiolispores, œcidiospores et téleutospores), le Puccinastrum Gueppertianum (œcidiospores et léleutospores).

Peu de champignons, strictement parasites, ont été cultivés sur les milieux artificiels, lesquels conviennent fort bien aux parasites facultatifs.

Plantes malades. En été, les spores (conidies, urédospores, œcidiospores), disséminées par le vent, vont infecter les végétaux sensibles, situés au voisinage. Les organes ou plantes atteints contaminent le sol, les fumiers, les eaux. Les graines, racines, bulbes, tubercules, constituent des facteurs de transmission redoutables.

Le rôle des oiseaux, insectes (y compris leurs larves) et mollusques terrestres, comme agents de diffusion, n'est pas niable dans bien des cas.

Enfin, les lésions dues à d'autres parasites ouvrent souvent la porte aux champignons pathogènes. 


\section{PRINGIPALES AFFEGTIONS CRYPTOGAMIQUES}

Les maladies cryptogamiques des plantes, connues de tout temps, n'ont été éludiées que depuis une époque relativement récente. Parmi les savants du xvin ${ }^{e}$ siècle, il faut citer : Tillet, Duhamel du Monceau et Tessier. Parmi ceux du xix ${ }^{\ominus}$ : Mathieu de Dombasle, Bénédict Prévost, les Tulasne, Duchartre, Planchon, Millardel, Prillieux, Berckeley, Hartig, Brefeld, Zopf, Sorauer, Franck, von Tubeuf, de Bary, Woronine.

Nous décrirons sommairement diverses affections, choisies entre les plus importantes, en $y$ joignant quelques maladies sans grand intérêt pratique, mais très instructives au point de vue général.

MALADIES AIGLES ET SUBAIGUES

MALADIES LOCALES

AFFECTIONS DES PARTIES AÉRIENNES

\section{Fumagines.}

Certains ascomycètes déterminent, sur les feuilles et les jeunes rameaux de l'olivier, de l'oranger, du saule... 
lapparition de dépôts noirs, épais, pulvérulents, laineux ou veloulés. Le mycélium ne pénètre pas dans l'épiderme (sauf chez les astérinées) et les dégâts sont dus au trouble de la fonction chlorophyllienne, occasionné par l' "écran " cryplogamique. Nous avons vu que le miélat de divers hémiptères constituait un excellent milieu de culture pour les organismes des fumagines.

\section{Blancs.}

Srmptomes. - Blanc des céréales. Les feuilles se recouvrent d'un duvet floconneux, auquel succède une poudre fine (spores); maladie en général bénigne. Blanc de la vigne. On aperçoit d'abord un revêtement gris terne, à odeur de moisi (Ö̈dium Tuckeri des anciens auteurs), puis les feuilles brunissent et sèchent (les fleurs et jeunes pistils également); les fruits durcissent et se fendent.

Mécanisme de l'infegtion. Lésions. - Blanc des céréales. Agent : Erysiphe graminis. Infection par les ascopores, puis les conidies. Elles germent à la surface des feuilles; le mycélium y forme un lacis et enfonce des suçoirs au sein des cellules épidermiques, dont la structure est moins gravement altérée que dans le cas suivant (spoliation et intoxication modérée). Périthèce et asques. Les ascopores se forment et germent au printemps suivant. - Blanc de la vigne. Agent : Uncinula necalor (origine américaine). Infection par les conidies, reproduite expérimentalement. Spoliation et inloxication marquée. Périthèces rares, mode d'hivernage du parasite inconnu.

\section{Rouilles.}

Nous prendrons comme type la rouille linéaire des céréales et la maladie de l'épine-vinette qui alterne avec elle. 
Symptomes. - Chez les céréales. En été, sur les feuilles, pustules allongées, qui se fendent et libèrent une poussière orangée. A l'arrière-saison, mêmes apparences, mais poudre noire. - Chez l'épine-vinette. $\mathrm{Au}$ printemps, sur la face supérieure des feuilles, taches rouges, arec points noirs saillants (orifice des œcidioles); puis, sur la face inférieure, taches orangées, bombées, avec de petiles pustules qui ne tardent pas à s'ouvrir (œcidiums).

Mécanisme de L'infegtion. Lésions. - Agent : Puccinia graminis. Chez les céréales. Le mycélium, né d'une acidiospore (venue de l'épine-vinette), pénètre par les slomates, se multiplie sous l'épiderme des feuilles et envoie des suçoirs dans les cellules. Après 78 jours, laches caractéristiques et urédospores, que libère la déchirure de l'épiderme et qui disséminent la maladie jusqu'en automne. A ce moment, le mycélium forme les téleutospores, d'où naîtront, l'hiver terminé, les basidiospores, susceplibles d'infecter l'épine-vinette et non les graminées. - Chez l'épine-vinette, le mycélium, issu de la basidiospore, traverse la cuticule entre deux cellules et se répand dans le mésophylle (toujour's exlérieur aux éléments anatomiques). Après 7-8 jours, les œcidioles (en cloche) naissent d'un lacis serré de filaments; ensuite, on voit apparaltie des œecidiums (en bouteille), qui ne lardent pas à déchirer l'épiderme. Le rôle des cecidiolispores demeure obscur; les œcidiospores infectent les graminées, non l'épine-vinette.

La puccinie épuise, puis nécrose les éléments superficiels des feuilles, chez les graminées. Chez l'épinevinette, il se produit d'abord une hypertrophie du mésophylle.

\section{Mildious.}

(Affections maculeuses).

Les auteurs anglo-saxons emploient le mot "mildew » dans le sens de "blanc" ?.

Syмptômus. - Mildiou de la pomme de terre. - La 
maladie éclate subitement dans les temps humides et se propage avec rapidité. Taches brunes, qui augmentent vite d'étendue; les feuilles atleintes se fanent, se crispent, prennent un aspect grillé et tombent. Autour des taches, apparait le duvet blanc caractéristique. - Mildiou de la vigne. Mêmes symptômes sur les feuilles et les fleurs; nombre de grains, mal nourris, n'arrivent pas à maturité. Les grains mûrs, infectés, offrent des macules livides, reposant sur une base indurée; le reste du fruit, altéré dans sa nutrition, se ramollit, puis sèche et tombe. Les temps humides favorisent l'extension de la maladie. - Mildiou de la betterave. Ici, les feuilles atteintes offrent un épaississement marqué. La végétation s'arrête; tantôt la plante meurt, tantôt l'affection guérit (temps sec), mais les racines demeurent petites et pauvres en sucre.

Mécanisme de l'infection. Lésions. - Mildiou de la pomme de terre. Agent: Phytophthora infestans (venu des Andes). Cultivé par Matruchot et Molliard. Les conidies germent (comme toujours) sous l'influence de l'humidité. Il en nait des zoospores, qui produisent un mycélium. Celui-ci pénètre à travers l'épiderme, circule entre les cellules sous-jacentes et envoie des suçoirs dans leur intérieur. Finalement, il les nécrose : le contenu se coagule, se contracte, brunit et devient indistinct. Les filaments du parasite émigrent des parties qu'ils ont altérées vers les régions saines, en développant des conidiophores à la limite des taches. Les conidiophores sortent par les stomates et les spores qu'ils portent disséminent la maladie. Taches et conidies se forment très vite. Le Plyytophthora infeslans ne produit pas d'œufs, semble-t-il, dans la nature, mais Clinton et Pettybridge en ont obtenu in vitro; son mode d'hivernage demeure inconuu. - Mildiou de la ligne. Agent : Plasmopara viticola (origine américaine). Mème mécanisme, mais le parasite donne des œufs (spores d'hiver) dans les feuilles mourantes. Ces œufs, libérés par la pourriture, germent au printemps et infectent les plantes; les infections suivantes sont 
dues aux conidies. Les escargots jouent un rôle important comme agents de diffusion de la maladie. Mildiou de la betterave. Agent : Peronospora Schachtii. Même mécanisme. CEufs. Tandis que le Phytophthora infestans et la Plasmopara viticola épuisent et nécrosent simplement les tissus, le Peronospora détermine auparavant lem hypertrophie.

[Les jeunes tubercules de pomme de terre peuvent être infectés par les conidies du Phytophthora, tombées sur le sol humide. On voit alors apparaître des taches, qui brunissent rapidement, sous l'influence d'une pourriture bactérienne (Matruchot et Molliard)].

Aulres affections maculeuses.

(Pourrilure grise et black rot de la vigne).

Sruptomes. - Pourriture grise. - Taches brunes, auxquelles succède l'apparition d'un duvet caractéristique. Après la mort des feuilles, sclérotes noirs, puis pézizes brunâtres. Sur les jeunes rameaux, le parasite peut atteindre les tissus profonds. Les grains jeunes sont détruits, les grains plus anciens n'offrent que des lésions superficielles, sous lesquelles la pulpe se concentre; le vin acquiert alors un goût qui rappelle celui des vins cuits el la lésion, bénigne et favorable, prend le nom de pourriture noble. - Black-rot. La maladie se développe par poussées successives, pendant les temps pluvieux et n'éclate pas brusquement, comme le blanc ou le mildiou. Elle ne frappe que les parties jeunes. Sur les feuilles, taches entourées d'une marge saillante plus foncée et se recouvrant de points noirs (fruits conidiens). Sur les jeunes rameaux, mêmes taches caractéristiques, qui se fendillent souvent. Les grains sont détruits et semés de fruits conidiens, d'où leur aspect chagriné typique.

Mécanisme de l'infection. Lésions. - Pourriture grise. Agent : Sclerotinia fuclieliana. Habituellement saprophyte, elle devient pathogène en milieu chaud et 
humide. Facile à cultiver (conidies et sclérotes, pas de pézizes). L'infection se fait par le mycélium; même mécanisme que pour les autres Sclerotinia (voir plus loin), mais, ici, la maladie demeure limitée. - Black rot. Agent : Guignardia Bidwellii (origine américaine). Cultivée par Viala et Pacottet, qui ont reproduit l'affection avee des cultures pures. Première invasion, due aux ascospores: attaques suivantes, dues aux stylospores (des pycnides). Le mycélium traverse la cutitule entre deux cellules, puis gagne les éléments sousjacents. Les taches évoluent en quelques jours; sur les feuilles, une lame de liège bride leur extension; sur les fruits, cette réaction manque et la totalité de l'organe périt. Les parasites détruisent les tissus par nécrose. Ils ont besoin d'un milieu très acide, que les cellules jeunes seules peuvent fournir. lls forment des périthèces el asques, qui hivernent.

[Une foule de Seploria et de Phyllosticla (ascomycètes) engendrent des affections maculeuses des feuilles].

\section{AFFECTIONS DES RACINES}

\section{Hernie du chou.}

Symptomes. - On voit apparattre, sur les racines, des excroissances de forme et de volume très variables. A la coupe, elles sont formées d'un tissu blanc et charnu. Elles pourrissent rapidement, surtout par les temps humides; leur teinte devient alors grisatre et leur consistance molle.

Mécanisue de L'infiction. Lésions. - Agent : Plasmodiophora brassicœ. Les spores du parasite, transformées successivement en zoospores et en myxamibes, pénètrent sous ce dernier état par les poils radicaux. Arrivées dans le parenchyme cortical, les amibes y forment des plasmodes. Les éléments anatomiques envahis angmentent de volume et se multiplient, puis 
perdent leur protoplasme et leur noyau. Le plasmode, après avoir détruit une cellule, pénètre dans la cellule voisine, perforant ses parois. Quand les aliments sont épuisés, il produit des spores. Bientôt, des bactéries, qui coexistent avec les plasmodes (ayant été introduits par les myxamibes - Pinoy), mais sont demeurées jusque là inertes, prolifèrent et amènent la pourriture des parties malades et la libération des spores. Et le cycle recommence.

Le Plasmodiophora détermine par conséquent l'hypertrophie et l'hyperplasie des cellules, dont il tue ensuite et absorbe le contenu.

MALADIES LOCALISEES

Les descriptions qui suivent montreront en quoi les maladies localisées diffèrent des maladies locales.

\section{CIIARBONS}

Charbons des céréales.

Symptomes. - Toutes les parties de la fleur sont hypertrophiées et converties en une masse blanche, à laquelle succède la poudre noire caractéristique. Chez le maïs, les altérations s'exagèrent énormément et peuvent siéger dans des points variés des parties aériennes (rarement, des racines). Il s'agit de tumeurs, souvent plus grosses que le poing, formées d'une pulpe blanchâtre veinée de noir, qui fait place à un amas de poudre olivâtre (spores), bientòt libéré par rupture des parois. On peut voir apparaitre des fleurs femelles chez les infforescences mâles, mais l'ovaire avorte toujours.

Mécanisue de l'infection. Lésions. - Agents : Ustilaginées diverses. Le mycélium infecte les végétaux au 
moment de leur germination, pénétrant par les stomates des cotylédons. Il chemine ensuite, de bas en haut, le long de la moelle, entre les cellules, sans les léser et croît parallèlement à l'hôte. Le contenu mycélien s'accumule dans les parties supérieures du parasite, qui fructifieront et abandonne les parties inférieures, dont il ne reste plus trace chez la plante adulte. L'Ustilago maydis peut attaquer directement les portions jeunes des végétaux adultes. - L'Ustilago tritici détermine une maladie bénigne des fleurs; celles-ci produisent des grains fertiles, mais infectés (on voit le parasite dans l'embryon): il en naîtra des pieds charbonneux (charbon héréditaire - Brefeld).

Le mycélium des ustilaginées, d'abord inoffensif (spoliation minime) détermine, au niveau des organes où il va fructifier, la néoformation d'un parenchyme riche en amidon, qu'il consomme entièrement. Il sera remplacé, lui-même, par ses spores colorées. Celles-ci (probasides) germent à partir de l'été ou de l'hiver, donnant des basides, d'où naissent des basiodiospores. Les basiodiospores peuvent germer, aussitôt produites et engendrer le charbon, soit naturel, soit expérimental.

\section{Charbon des caryophyllées.}

L'Ustilago violacea fructifie dans les anthères de diverses caryophyllées, dont les grains de pollen se trouvent remplacés par une poudre violette (spores). Il détermine, chez les fleurs femelles de Melandryum album et rubrum (dioïques), l'apparition d'organes mâles, aux dépens de rudiments normalement indistincts.

\section{CARIE DU BI.É}

Sympromes. - La tige des plantes malades est plus forte el d'un vert plus sombre. Après floraison, les pis- 
tils prennent une teinte foncée et les épis, droits, avec leurs glumes et leurs glumelles très écartées, offrent l'aspect ébouriffé typique. Le contenu des grains, d'abord blanchâtre, se transforme en une poudre brune, à odeur de poisson pourri.

Mécanisme de L'infection. Lésions. - Agent : Tilletia Iritici. Le mycélium pénètre au niveau de la radicule, pendant la germination du végétal; il se comporte ensuite comme celui des ustilaginées " charbonneuses » et fructifie dans les grains. Infection expérimentale facile, avec les basiodiospores que l'on fait préalablement germer. Quand on inocule trop de parasites, il s'ensuit un développement massif et la plante meurt (Kühn).

\section{ROUILLES BLANCHES}

Symptomes. - Rouille blanche des crucifères. Les feuilles sont déformées et boursouflées; les tiges d'inflorescence, hypertrophiées, s'incurvent; les enveloppes florales apparaissent épaissies et vertes; à l'extrémité des filets, volumineux, les anthères manquent ou restent vides; les ovaires, foncés et oblongs, ne renferment pas d'ovules. Sur les parties malades, pustules éburnées, qui se déchirent et libèrent une poudre blanche. - Rouille blanche des composées. Affection limitée aux feuilles.

MÉcanisme De L'infection. Lésions. - Rouille blanche des crucifères. Agent: Albugo candida. Même mécanisme que pour les charbons. Conidiospores, brisant l'épiderme et essaimant des conidies; œufs, dans les tissus malades. Ces œufs germent au printemps; le mycélium, venu des zoospores, infecte les jeunes plantes. Les végétaux adultes sont réfractaires aux conidies. - Rouille blanche des composées. Agent : Albugo tragopogonis. Peut infecter les plantes adultes. 
UALADIES GÉNÉRALES

Nous en distinguerons 3 lypes: infections massives, maladies vasculaires, nécroses progressives.

\section{INFECTIONS MASSIVES}

Chez les jeunes végétaux, peu résistants, les parasites envahissent volontiers tout l'organisme, qui périt très vite.

Nous avons déjà signalé le cas du blé, infecté expérimentalement par un excès de spores de Tilletia.

Citons encore la maladie des jeunes semis. Elle s'observe sur divers arbres forestiers, notamment en milieu humide et chaud. La tige et les colylédons noircissent, la plante meurt et les parties nécrosées se recouvrent d'un duvet blanc. Agent: Phytophthora cactorum, formant des conidies (les conidiospores sortent par les stomates ou à travers la cuticule) et des neufs (dans les tissus morts): double source d'infection. Le mycélium, issu d'une zoospore et cloisonné (fait exceptionnel chez les oomycètes), pénètre au niveau du collet, se multiplie abondamment entre les cellules, les spolie (suçoirs), puis les tue.

\section{MALADIES VASCULAIRES}

\section{Pourriture du cour de la betterave.}

Symptomes. - Les grandes feuilles s'abaissent vers la terre, jaunissent et sèchent; les pétioles offrent, à leur face supérieure, des taches blanchâtres, entourées de points bruns (périthèces). Toutes les feuilles naissantes noircissent et se dessèchent. L'apogée de la 
maladie s'observe en seplembre; un nouveau feuillage apparaît alors autour du cœur mort, mais il demeure chétif et les racines restent pelites et pauvres en sucre.

Mécanisme de L'infecrion. Lésions. - Agent : Sphœrella labifica. Le mycélium, venu des ascospores qui ont hiverné, pénètre dans le pétiole et le nécrose (tissus bruns et secs, au-dessous des taches), d'où la mort des feuilles. Puis, il suit les gros vaisseaux et arrive jusqu'au collet, d'où la mort du bourgeon terminal. La parasite fait périr les organes par oblitération vasculaire ; il semble également jouir d'un pouvoir nécrosant direct.

Flétrissement du melon d'eau, du cowpea et du colonnier.

(Bien étudié par E. Smith). Symptones. - Melon d'eau. Flétrissement subit et terminaison fatale rapide, surtout chez les jeunes plantes. Chez les plantes plus âgées, quand arrive la pluie, il peut se manifester une " résurrection transitoire ", suivie de morl définitive dès que le temps redevient sec. Sur le végétal qui a péri, apparaissent des conidies et périthèces rouges. - Cowpea. Au traver's de la tige, verte et translucide, les vaisseaux altérés se reconnaissent à leur aspect sombre. - Cotonnier. Moins sensible. Guérison possible; on voit alors de nouvelles pousses s'élever de la base de la tige et masquer celle-ci (qui a succombé).

Mécanisme de L'infection. Lésions. - Agenl : Fusarium vasinfectum. Se trouve dans le sol, que l'on peut infecter avec des cultures pures; on reproduit ainsi la maladie sans difficulté, Melon d'eau. Le mycélium, issu des ascospores qui onl hiverné, pénètre par la racine près de la base des tiges, oblitère les vaisseaux d'une façon progressive et amène le flétrissement, en arrêtant le cour's des liquides. Post mortem, il gagne les parenchymes, puis la surface où il fructifie. 
Au début du flétrissement, les vaisseaux peuvent ètre remplis jusqu'à proximité de la racine; ils offrent une coloration brune, ainsi que les éléments voisins. Quand l'envahissement vasculaire reste encore relativement limité, si on sectionne la tige au-dessus des parties malades et qu'on la plonge dans l'eau, le flétrissement disparaît. - Cowpea. Toul le système vasculaire peut être pris lors de la mort. - Cotonnier. Parasites moins nombreux, mais répartis sur une longue élendue.

NéCroses progressives (dues a des S'clerolinia)

Dans le cas de la Sclerotinia fuctieliuna, les lésions, engendrées par le mécanisme qui va être décrit, demeurent limitées, comme räous l'avons déjà dit. Il n'en est pas de mème pour les maladies suivantes.

\section{Affections dues à la S. libertiuna.}

Symptomes. - La surface des tiges, chez beaucoup de plantes cultivées (milieu chaud et humide), se recouvre d'un revêtement ouaté, puis la plante meurt.

Mécanisme de l'infection. Lésions. - Habituellement saprophyte, la Sclerotinia devient pathogène lors des conditions indiquées. Culture facile (pas de conidies, sclérotes). L'infection, naturelle ou expérimentale, se fait par le mycélium, qui pénètre jusqu’à la moelte, nécrosant les tissus devant lui. Dans la moelle el l'extrémité des tiges, après dessiccation, se forment des sclérotes qui, en présence de circonstances favorables, engendrent des pézizes. De Bary a suivi de près le mode d'action du parasite. Le mycélium, placé sur une jeune tige de fève, se fixe, par des crampons, aux cellules épidermiques et secrète un poison qui tue d'abond celles-ci, puis les éléments du parenchyme 
cortical (contraction du protoplasma et brunissement). Dans les tissus détruits, le parasite se développe et nécrose les parties plus profondes, où il se multiplie ensuite. Il s'agit donc d'un organisme qui ne peut croître que chez les lissus préalablement tués par lui ; il les attaque alors chimiquement. De Bary a montré que les substances actives, contenues dans le suc de carottes infectées, amènent d'abord la mort des cellules végétales, puis la dissolution des lamelles moyennes (expériences in vitro). La Sclerotinia produit donc une toxine nécrosante et des enzymes dissolvants.

\section{Affections dues ¿̀ la $S$. trifoliorum.}

La Sclerotinia trifoliorum tue diverses légumineuses, par le même mécanisme. Les parties vertes jaunissent puis brunissent, les feuilles se fanent et tombent, la plante meurt, couverte d'un velouté blanc. Il $s^{\prime} y$ forme ensuite des sclérotes cl des pézizes.

\section{Affections dues à la $S$. bulborum.}

Le parasite attaque divers végétaux à oignons (déterminant, entre autres, la " morve " noire des jacinthes). Peu après la floraison, les feuilles jaunissent, le bulbe brunit et la plante rneurt. On voit ensuite apparaître superficiellement sclérotes et pézizes.

Chez les Sclerolinia, les ascopores des pézizes germent au printemps et engendrent un mycélium qui, tantôt mène une vie indépendante, tantôt infecte les végétaux voisins. Répétons que la chaleur et l'humidité favorisent le passage de l'état saprophyte à l'état pathogène. 


\section{MALADIES CHRONIQUES}

Ce sont, loutes, des maladies locales, à marche plus ou moins extensive. L'affection de l'Euphorbia cyparissias, envahie par l'Uromyces pisi, peut cependant être considérée comme générale, au point de vue clinique; nous l'étudierons en terminant.

AFFECTIONS DES PARTIES AÉRIENNES

\section{NÉCROSES}

Rouille courbeuse du pin sylvestre.

Symptones. - Sur les rameanx des plantes adultes, on voit apparaître des taches jaune pâle, qui s'accompagnent d'un arrêt de développement unilatéral, occasionnant l'incurvation caractéristique. Selon la gravité de la maladie, le rameau sèche ou continue à pousser (il prend alors, en se redressant, la forme d'une s. italique). Chez les plantes de 1-2 ans, l'infection de la lige peut amener la mort ; chez les végétaux plus âgés, celle-ci ne survient que lorsque les points d'attaque sont très nombreux.

Mécanisme de L'infection. Lésions. -- Agent : Melampsora pinitorqua. Elle détermine une rouille typique sur les feuilles du peuplier, où se développent les téleutospores. Ces spores germent au printemps, engendrant le mycélium, qui pénètre le tissu cortical du pin et le détruit. Dans la concavité des rameaux malades, se forment les œcidioles et œcidiums; les œcidiospores, libérées par rupture de l'épiderme, infectent les feuilles du peuplier. 
Le mycélium hiverne chez le pin, au sein des lésions; chaque année, il se "réveille " et étend ses ravages. Le parasite, intercellulaire, envoie des suçoirs dans les éléments voisins; il peut envahir toute la profondeur du liber et les rayons médullaires. 11 spolie et nécrose.

Les pins sont indemnes à partir de 30 ans.

\section{CHA TCPES}

\section{Chancre du mélèze.}

Srmptomes. - Au printemps, sur un rameau, les aiguilles rougissent et meurent ; à la base de ce rameau, l'écorce cède et la résine coule. L'affection s'arrête pendant l'été ; les parties mortifiées s'affaissent; les tissus voisins bourgeonnent, mais ils sont détruits vers l'automne par la reprise de l'infection. Celle-ci s'aggrave chaque année el l'ulcère gagne concentriquement. Sur l'écorce morte, apparaissent des pézizes rouges.

La maladie peut durer jusqu'à 80 ans; inversement, elle peut atleindre des arbres centenaires (Hartig).

Mícanisme de l'infection. Lésions. - Agent : Dasyscypha Willkommii (parasite de blessure). Le mycélium se glisse entre les éléments de l'écorce, les tue et les envahit. 11 délruit ensuite le cambium et arrête ainsi tout développement dans le territoire nécrosé. En été, un bourrelet limite les parties mortifiées; en automne, il est lui-même mortifié par le mycélium redevenu actif. Hartig a réalisé l'infection expérimentale.

\section{Chancre des arbres fruiliers.}

Srmptomes. - Sur une branche, en un point, l'écorce se déprime, brunit el meurt. La nécrose gagne, surtout en long; il se forme des fissures concentriques profondes et l'écorce s'en va par lambeaux. La plaie ne 
présente aucune tendance à guérir. Au centre, tissus morts et desséchés; à la périphérie, bourrelets cicatriciels, successivement formés et rongés, qui montrent souvent de petits points rouge corail (périthèces et fruits conidiens). Le chancre fait facilement le tour des jeunes rameaux et amène la mort des parties situées au-dessus; au niveau des branches plus fortes, la lésion demeure limitée, mais aucun fruit ne se développe.

MéCanisme de L'infegtion. Lésions. -- Agent : Nectria ditissima (parasite de blessure). Le mycélium circule entre les cellules; il envahit ainsi l'écorce et les parties superficielles du bois (par les rayons médullaires) les tue et "s'installe n dans les éléments détruits. A la périphérie des lésions corticales, il forme des coussinets, recouverts de conidies et de périthèces, qui apparaissent bientôt au dehors. Alternatives de nécrose et de réparation, caractéristiques des chancres. Le mycélium hiverne au sein des tissus morts et redevient actif, le printemps arrivé.

\section{POURRITURES}

Pourritures du bois, duesaux gros champignons.

Les gros champignons, notamment divers polypores, mènent d'ordinaire une vie saprophytique, sur les bois abattus qu'ils détruisent; mais il n'est pas rare de les voir s'attaquer aux arbres vivants, avec une préférence incontestable pour les individus vieux ou affaiblis. Tout le monde connait leurs fructifications en " chapeaux", surtout celles de l'amadouvier.

lls rongent le trone et les branches, progressivement; un peu moins lentement, dans le cas du Polyporus hispidus, le plus dangereux, quoad vitam. Ce sont des parasites de blessure, affectant les feuillus et les résineux. 
Le mycélium gagne le bois de cœur, par les rayons médullaires. Les parties malades prennent une teinte brune, puis blanchissent (pourriture blanche), se transformant en masses légères, semblables à de la charpie et bientôt pulvérulentes. Il nait ainsi des cavités, tapissées de mycélium blanchâtre et séparées des régions saines par une ligñe brun foncé ; cavités qui augmentent de nombre et de volume, se réunissent et évident le cylindre ligneux. Le mycélium envahit ensuite l'écorce et va fructifier à la surface; les chapeaux s'accroissent chaque année. Dans certains cas, les parties malades gardent un ton vineux (pourriture rouge); parfois, les altérations débutent au niveau de l'aubier; ailleurs, le bois âgé est miné en anneaux ou en croissants... le mécanisme fondamental demeure toujours le même. Le mycélium dissout d'ordinaire les lamelles moyennes avant les parois internes des cellules, mais pas constamment. Les éléments du bois, d'abord bruns, blanchissent à mesure qu'ils sont désintégrés; concurremment; le parasite prend leur place.

\section{HYPERTROPHIES}

\section{Cloque du pécher.}

Srmptomes. - Les feuilles apparaissent bosselées, crispées, épaissies, cassantes, jaune pâle ou rosées. Elles se recouvrent, à un moment donné, de fins dépôts veloutés. L'extrémité des rameaux montre des boursouflures charnues et décolorées. Sur les fruits (quand il s'agit de brugnons), on observe des taches pâles et saillantes.

MéGanisme de l'infection. Lésions. - Agent : Exoascus deformans. Le mycélium, né d'une ascospore, pénètre dans l'écor'ce, puis dans la moelle et les rayons des jeunes rameaux. Au printemps (mais pas l'été), il gagne les feuilles, cheminant entre les cellules épidermiques et détermine l'hypertrophie du mésophylle, qui 
se transforme en parenchyme homogène et décoloré, à développement surtout superficiel (d'où le boursouflement). Le mécanisme de l'infection est le même pour l'extrémité des jeunes rameaux et les fruits : action cécidogène typique. Le parasite forme des asques, qui apparaissent après rupture de la cuticule. Il hiverne dans l'écorce.

\section{Pochettes du prunier.}

Symptomes. - Les jeunes pistils se transforment en sacs allongés et pâles, à surface inégale. Les fruits (pochettes, prunes cornichonnées), sans noyaux, deviennent absolument méconnaissables.

Mlécanisme de L'infection. Lésions. - Agent : Exoascus pruni. Le mycélium pénètre dans l'écorce, d'où il envahit les fleurs au printemps. Il se glisse entre les cellules épidermiques, produisant une déformation des parois du pistil (hyperplasie du mésocarpe, qui devient homogène), avec atrophie de l'endocarpe et des embryons. Parfois, les étamines se tuméfient. Asques sous la cuticule, visibles après déchirure de celle-ci. Le parasite hiverne dans l'écorce. Action cécidogène type, ici encore.

\section{BALAIS DE SORCIÉRE}

Balais de cerisier.

Symptomes. - Sur un ou plusieurs rameaux tuméfiés, apparaissent des touffes qui se dressent d'ordinaire verticalement (mais pendent quelquefois), plus ramifiées que les pousses normales. Les feuilles, épaisses, brillantes, plissées, tachées de rouge, se couvrent de fins dépôts veloutés et tombent de bonne heure. Pas de fleurs, comme on le voit immédiatement de loin, au printemps. Le balai meurt après quelques années. 
Mécanisme de L'infection. Lésions. - Agent : Exoascus cerasi. Le mycélium, né d'une ascospore, pénètre dans un bourgeon, circule entre les cellules et envahit la moelle, les rayons et l'écorce, dont il détermine l'hypertrophie (tissu homogène, avec vaisseaux larges, mais à parois minces). Il gagne ensuite les feuilles (asques, apparaissant sur le cuticule rompue). Il hiverne au sein des rameaux.

L'Exoascus secrète un poison, qui irrite les tissus et en détermine l'hypertrophie. Il provoque également, suivant le même nécanisme, la croissance prématurée des bourgeons dormants. Par contre, il entraîne la stérilité du balai. La mort de celui-ci tient peut-être, pro parte, à l'intoxication chronique, mais nous pensons qu'elle relève surlout d'une irrigation insuffisante, comme cela se voit dans beaucoup de néoformations pathologiques.

\section{Chaudrons el balais du sapin pectiné.}

Symptones. - Ghaudrons. On voit apparaître, sur le tronc et les rameaux, des renflements au niveau desquels l'écorce sèche et se crevasse, produisant des ulcérations qui augmentent d'étendue chaque année. - Balais. Ils coexistent souvent avec les chaudrons. Une ou plusieurs branches portent alors comme de petits arbres nains, d'aspect singulier, dont la " tige " engendre souvent des jets latéraux; d'où l'ensemble broussailleux caractéristique. Les feuilles de ces balais sont courtes, larges, épaisses, presque décolorées et distribuées sans ordre (au lieu d'être longues, étroites, minces, vertes, disposées sur deux rangs). Elles se recouvrent d'œcidioles et d'œcidiums orangés et tombent vers la fin de l'été. En hiver, les balais se recomnaissent de loin à leur aspect de petits buissons dépouillés, au milieu de branches dont la verdure persiste. Après un nombre d'années parfois long, la curieuse production se détache, laissant une vilcération persistante. 
Mécanisme de L'infection. Lésions. - Agent : Melampsorella caryophyllacearum, déterminant la rouille chez les caryophyllées. Sur les feuilles de cellesci se développent des téleutospores, origine du mycélium qui infecte le sapin. Le parasite pénètre dans l'écorce, le liber et même le bois du second hòte, circulant entre les cellules, au sein desquelles il envoie des suçoirs. Les parties atteintes s'hypertrophient, puis se nécrosent. Les balais sont dus à l'envahissement des bourgeons, comme chez le cerisier. Le mycélium hiverne dans les tissus malades.

Les chaudrons représentent des néoplasies de faible vitalité; les balais, des réactions moins étendues localement, mais compliquées du développement des bourgeons dormants. Ici encore, les balais demeurent stériles.

AFFECTIONS DES RACIVES

POURRITURES (POURRIDIÉS)

Pourridié dâ au Polyporus annosus.

Symptomes. - La maladie atteint surtout les résineux. Habituellement, évolution lente : les branches se dessèchent, les unes après les autres. Parfois, cours subaigu : mort en quelques mois. Plus rarement, marche aiguë : au moment de l'apparition des premières feuilles, les pousses se flétrissent subitement et la plante périt.

MéCanisme de L'infection. Lésions. - D'ordinaire, le parasite, vivant librement dans le sol, envahil les plaies du collet. Ailleurs, on observe la contamination d'une racine par une racine malade, voisine. Le mycélium se développe au sein du liber, puis gagne le bois, le long des rayons; il tue les éléments anatomiques, les dissout (pourriture rouge) el prend leur place. Il va ensuite fructifier extérieurement (conidies et chapeaux). 


\section{Pourridié dî̀ à l'Armillaria mellea.}

Symptomes. - La maladie atteint les feuillus et les résineux. Elle érolue comme la précédente, plus sévère dans les terrains humides que dans les terrains secs.

Mécanisme de l'infection. Lésions. - Deux modes d'envahissement, ici encore, mais les lésions demeurent limitées à l'écorce (pourriture blanche). Le mycélium forme, entre le liber et le bois, des lames blanches; phosphorescentes, d'où naissent des rhizomorphes, qui traversent l'écorce, rampent extérieurement, se répandent dans le sol et peuvent infecter les racines voisines. Des chapeaux apparaissent, en automne, au pied des souches, sur les arbres morts (rarement sur les parties mortes des arbres vivants).

\section{Pourridié dî à la Rosellinia necatrix.}

Symptomes. - La maladie atteint surtout vigne et arbres fruitiers. Mêmes formes cliniques. Noter la première année, des fruits souvent très nombreux.

Mécanisme de l'infection. Lésions. - Toujours deux modes d'envahissement. Le mycélium se ramifie entre le liber et le bois, puis envahit ce dernier et le détruit. Il produit ensuite, sous l'écorce, des sclérotes qui engendrent des conidiophores. Les racines se recouvrent alors d'un revêtement floconneux, blanc puis grisâtre, formant des cordons qui disséminent la maladie. Sur les souches mortes, pycnides et périthèces.

\section{MALADIE DE L'EUPHORBIA CYPARISSIAS, DUE A L'UROMYCES PISI}

Symptomes. - Les plantes atteintes offrent une curieuse transformation de leurs caractères habituels. La tige, droite et élancée, montre des entre-nœuds 4-6 fois plus longs que normalement; les ramifications 
manquent; les feuilles, petites, ovoïdes et épaisses, s'étendent jusqu'à la cime, porlant les acidioles et œcidiums du parasite; les fleurs font défaut. Les parties aériennes meurent après fructification de l'Uromyces. Chaque année, la maladie recommence.

Mécanisme de L'infection. Lésions. - L'Uromyces pisi détermine une rouille typique chezles légumineuses; les téleutospores formées constituent l'origine du mycélium qui envahit l'euphorbe. Ce mycélium pénètre au niveau du collet de la jeune plante, croit avec elle, en suivant surtout les faisceaux vasculaires et la moelle et sporule dans les feuilles. Il hiverne dans les rhi. zomes. Les œcidiospores infectent les légumineuses.

Il s'agit donc d'une anomalie de développement, accompagnée de stérilité et suivie de mort précoce des portions aériennes. Seul, le mésophylle présente de l'hyperplasie; la tige, étirée, conserve sa structure normale. Le mycélium, intereellulaire, n'envoie des suçoirs, au sein des éléments voisins, que lorsque ceuxci ont franchi le stade " embryonnaire » et commencent à montrer des vacuoles (époque où s'arrête la croissance de la plante). Quand les suçoirs ne sont pas encore formés, si on soumet le végétal au double effet de la chaleur et de l'humidité, il se débarrasse des parasites. Le point végétatif, ainsi guéri (par un mécanisme inconnu), produit des feuilles normales, que le mycélium du rhizome ne saurait infecter désormais. Mais dès que les vacuoles des cellules et les suçoirs de l'uromyces ont apparu, c'est-à-dire quand le développement du végétal va prendre fin, la chaleur humide ne fait plus disparaitre le parasite (Tischler).

Faut-il considérer la maladie de l'euphorbe comme locale ou comme générale? Cliniquement, il s'agit bien d'une maladie générale, puisque la plante est frappée dans toutes les parties qui émergent du sol et attaquée dans le rhizome. Au point de vue du mécanisme, on peut assimiler l'affection à une maladie chronique du rhizome, avec extension périodique chez la tige et ses dépendances. 


\section{MÉCANISME DE L'INFECTION}

PARASITES FACULTATIFS

ET PARASITES STRICTS

Les parasites facultatifs sont ceux qui, pouvant mener indéfiniment la vie saprophytique, deviennent plus ou moins souvent pathogènes. Ils eontinuent, d'ailleurs, leur vie saprophytique dans l'organisme, n'envahissant les tissus qu'après les avoir tués tout d'abord. Ils sont représentés par les agents des nécroses progressives (genre Sclerotinia) et les parasites de blessure (Dasyscypha, Nectria, polypores, armillaire, Rosellinia).

Les parasites stricts comprennent la totalité des autres champignons mentionnés précédemment. Certains se cultivent dans les milieux artificiels (plus rarement dans le sol) et méritent ainsi le nom, un peu superflu, de saprophytes facultatifs. Les parasites stricts, seuls, peuvent croître au sein des tissus vivants, dont ils n'amènent la nécrose qu'après les avoir envahis; ils abandonnent ensuile les parties mortifiées, se comportant d'une façon exactement opposée à celle des parasites facultatifs. 
Facultatifs ou stricts, les parasites ne forment leurs fructifications caractéristiques que dans les organes morts ou mourants (plus rarement, dans les milieux artificiels).

\section{VIRULENCE DES' PARASITES (STRICTS)}

C'e qui caractérise les parasites stricts, c'est donc la végélabilité in vivo, en d'autres termes la virulence. Il ne faut pas confondre le mot virulence arec le mot pouvoir pathogène, lequel signifie pouvoir de délerniner une maladie et rien de plus.

La virulence offre deux aspects : qualitatif et quantitatif.

[Nous l'avons appelé électivité, quand il s'est agi de "gros " parasites; on verra tout à l'heure pourquoi].

Tantôt un champignon n'est pathogène que pour une espèce, un genre, une famille; tantôt (et moins souvent) il attaque des plantes fort diverses. Nous savons que certains représentants des urédinées se développent alternativement sur deux espèces différentes, accomplissant ainsi le cycle que d'autres parcourent sur le même hôte.

La différenciation peut rester purement fonc- 
tionnelle (au moins en apparence), une espèce cryptogamique donnée formant des races physiologiques, exclusivement adaptées à tel ou tel végétal.

Exemples : les races de la Puccinia graminis (Eriksson). Chacune produit, sur "sa " graminée, des téleutospores qui infectent régulièrement l'épine-vinette; mais les œcidiospores, nées sur celle-ci, n'infectent que la " graminée-origine ». Marchal et Salmon ont décrit des races de l'Erysiphe graminis, Jordan des races de l'Uromyces pisi.

ASPECT QUANTITATIF

Divers échantillons d'une espèce parasitaire donnée offrent, chez le même végétal, un pouvoir envahissant variable (éventuellement nul). On mesure celui-ci par la quantité minima de germes, susceptibles de déterminer sûrement l'infection.

[Chez les gros parasites, la virulence se réduit pratiquement à son aspect qualitatif. On nous approuvera donc d'avoir préféré, dans ce cas, le terme électivité, parfaitement clair, au terme " aspect qualitatif de la virulence ", inutilement compliqué].

SENSIBILITÉ DES PLANTES

L'influence de l'espèce, de la race et même de l'indioidu est de notion courante. Celle de l'âge, 
également; certains champignons n'attaquent que les plantes en germination, d'autres infectent les végétaux ou organes en voie de croissance, d'autres enfin, les tissus adultes et même séniles.

Derrière cette étiologie abstraite, se cachent des facteurs concrets encore très mal connus. Toul ce que l'on sait actuellement peut tenir dans les lignes suivantes.

Pour que le parasite se développe, il faut évidemment que la somme des conditions favorables l'emporte sur celle des conditions hostiles. Nous parlerons plus loin des dernières; les premières ont été étudiées par Massee et Miyoshi, in vitro et in sivo. Voici le résumé de quelques expériences, figurant dans leurs travaux.

In vitro. - On incorpore à de la gélatine le suc ou la décoction de plantes, soit sensibles, soit réfractaires. On recouvre le milieu d'une lame finement perforée, sur laquelle on répand les spores du champignon que l'on veut étudier. Le plus habituellement (pas toujours), les spores ne germent et le mycélium résultant ne traverse les orifices que si le suc ou la décoction proviennent d'une espèce végétale sensible.

In vivo. - On injecte, dans les feuilles de plantes réfractaires, des substances favorables au développement d'un champignon donné, puis on répand les spores de celui-ci sur le limbe. La germination el la pénétration consécutive du mycélium s'observent fréquemment (pas toujours) et il peut même arriver qu'après plusieurs passages le champignon envahisse la feuille, même sans injection favorisante préalable.

Les recherches de Massee et de Miyoshi consti- 
tuent d'utiles indications, mais le problème reste encore bien obscur dans sa complexité.

INFLUENCE DES CONDITIONS AMBIANTES

L'humidité (de l'air et du sol) joue un rôle considérable, en favorisant la formation et la germination des spores. La chaleur n'est pas moins importante, ainsi que l'ombre excessive dans bien des cas.

On connatt l'influence de l'encombrement et celle de la nature du terrain. Les engrais azotés surabondants favorisent diverses infections, notamment le mildiou de la pomme de terre.

MOYENS D'ATTAQUE DES PARASITES

Les mêmes que chez les gros parasites; comme eux, les champignons pathogènes peuvent spolier, intoxiquer, détruire.

SPOLIATION

Par la diffusion de leurs enzymes, les parasites cryptogamiques solubilisent les matières nutritives contenues dans les cellules végétales et les 
absorbent ensuite. - Il faut bien savoir que la spoliation se complique couramment de nécrose.

Nous distinguerons : l'intoxication proprement dite, de connaissance banale et l'irritation, que l'on doit rapporter, depuis Malpighi, à des poisons doués de propriétés excitantes. S'agit-il, dans ce dernier cas, de substances spéciales ou de toxines faibles, mais opérant d'une façon continue? La question ne semble avoir fait l'objet d'aucune recherche; nous indiquerons, plus tard, les raisons qui militent en faveur de la seconde hypothèse.

\section{INTONICATION PROPREMENT DITE}

Elle se manifeste par des lésions locales et des troubles généraux.

Lésions locales. - Dégénérescences mal connues, qui aboutissent ordinairement à la nécrose : contenu cellulaire indistinct et rétracté, puis brunissement, gagnant les parois.

Tantòt la nécrose apparait d'abord (parasites facultatifs), tantôt elle résulte du développement mycélien (parasites stricts). Dans ce dernier cas, elle succède à la spoliation et, éventuellement, à l'hyperplasie. Selon la teneur en eau des tissus et de l'atmosphère, l'eschare sera sèche (cas le plus 
habituel) ou humide. La nécrose est souvent suivie de destruction, tantôt légère, tantôt d'intensité variće.

Troubles généraux. - Il faut faire intervenir, croyons-nous, le facteur empoisonnement dans l'explication des anomalies de croissance, de la stérilité, de l'affaiblissement général, dont la spoliation et les désordres mécaniques sont loin de rendre toujours un compte suffisant.

\section{IRRITATION}

Hypertrophie et surtout hyperplasie des tissus. Formation de parenchymes indifférenciés. Cellules riches en eau; offrant des membranes minces et des noyaux volumineux; contenant parfois beaucoup d'amidon, rarement beaucoup de chlorophylle (le contraire est de règle). Vaisseaux relativement peu nombreux, larges, à parois minces.

D'ordinaire, les parties néorformées sont finalement détruites par l'agent pathogène lui-même; mais, dans certains cas, la mort résulte simplement de l'insuffisance d'irrigation.

Il faut attribuer aussi à un effet excitant la croissance prématurée des bourgeons dormants (balais de sorcière) et le développement d'organes reproducteurs rudimentaires (charbons du maïs et des caryophyllées). 
Causée par les enzymes cytolytiques des parasites. Toujours précédée de nécrose, elle se manifeste au plus haut point dans les pourritures (généralement sèches).

Les destructions étendues engendrent des troubles mécaniques d'une extrème gravité - les oblitérations vasculaires pareillement, rappelons-le.

En résumé, les champignons pathogènes spolient et détruisent par leurs enz̧mes, nécrosent et irritent par leurs toxines.

\section{MOYENS DE RESISTANCE DES PLANTES}

Les causes de l'immunité naturelle demeurent obscures. On sait toutefois qu'il est possible de produire, par sélection, des races de blé réfractaires à la rouille, des races de cotonnier réfractaires à la flétrissure, des races de chou réfractaires à la " jaunisse ".

La jaunisse, maladie très grave, reconnaît pour agent le Fusarium conglutinans, qui s'éternise dans le sol. Jones ensemence, en terrain infecté, des graines d'individus exceptionnellement résistants. Parmi les plantes qui se développent, il choisit les sujets indemnes et sème encore leurs graines en terrain infecté. Et ainsi de suite. Après plusieurs années, il obtient des races héréditairement résistantes. 
Tisdale a étudié, comparativement, l'infection chez les individus sensibles et réfractaires d'une même espèce végétale.

Un Fusarium, voisin de celui de la jaunisse, se montre irrégulièrement pathogène pour le lin. Chez les sujets sensibles, il pénètre dans les vaisseaux, puis envahit toute la plante, qui succombe rapidement. Chez les sujets résistants, le développement du parasite se trouve ralenti (par quel mécanisme?) et le végétal a le temps de former une assise subéreuse, qui élimine le champignon avant qu'il ait atteint le système vasculaire.

Les croisements entre individus sensibles et individus résistants donnent des résultats variables, mais avec tendance à l'état réfractaire. (Dans le cas du blé, indemne contre la puccinie, il s'agirait au contraire, suivant Biffen, d'un caractère mendélien simple).

\section{PATHOGENIE}

INFECTIONS EXPERIMENTALES

Complétant l'étude anatomo-clinique, elles ont aidé puissamment à reconstiluer le mécanisme intime des maladies cryptogamiques.

On réalise le plus souvent l'infection avec les spores, parfois avec le mycélium - comme cela se produit d'ailleurs naturellement.

Infection avec les spores. - Il faut déposer celles-ci dans une goutle d'eau, au point choisi (spores des péronosporées et ustilaginées ; urédospores et œcidiospores 
des urédinées....). Pour les téleutospores, il est indispensable de les faire germer d'abord in vitro, afin d'obtenir les basidiospores, seules directement actives. Infection avec le mycélium. - Pour les Sclerotinia, on dépose les filaments sur des jeunes tiges. Pour les parasites de blessure, on prélève un fragment de bois infecté, on l'insère dans une entaille faite à l'arbre sain, puis on applique un bandage protecteur (afin d'éviter l’évaporation et les contaminations étrangères).

MODES DE PENETRATION DES PARASITES

Les plantes et organes jeunes sont protégés par la cuticule et quelquefois les dépôts cireux; les adultes, par le liège. La cuticule constitue une barrière très peu résistante.

Chez les érysiphées, véritables épiphytes, les suçoirs seuls pénètrent in sioo. Les Sclerotinia n'envahissent les tissus qu'après les avoir nécrosés. Les autres parasites s'introduisent, suivant les cas, par les stomates (filaments des urédospores et œcidiospores, majorité des filaments des péronosporées), la cuticule (filaments des téleutospores, majorité des filaments des ustilaginées - le mycélium du Phytophthora infestans pénètre soit par les stomates, soit par la cuticule), les blessures (parmi les parasites de blessure, les agents des pourridiés peuvent seuls attaquer éventuellement les organes intacts).

$\mathrm{Au}$ sein des tissus, les filaments, d'abord extracellulaires, envoient ou non des suçoirs dans les 
éléments anatomiques voisins. Certains mycéliums envahissent ensuite électivement les vaisseaux; d'autres, le moment venu, prennent la place des cellules qu'ils ont tuées. Le Plasmodiophora brassica représente un endophyte type.

Chez le blé, infecté par l'Ustilago tritici, le parasite pénètre dans l'embryon; la plante-fille, née d'une graine fertile mais contaminée, montre un charbon héréditaire.

EVOLUTION DES ACCIDENTS

Après le stade d'incubation, parfois fort court, la maladie se déroule, essentiellement variable suivant les cas. Elle peut être, avons-nous dit : aiguë, subaiguë, chronique - locale, localisée, générale - curable ou mortelle.

\section{AFFECTIONS AIGUES, SUBAIGUES, CHRONIQUES}

Quelles sont les causes qui régissent la durée des accidents? Les unes tiennent à la plante, les autres au parasite. Un végétal annuel ne saurait offrir d'infection chronique, cela va sans dire. Les végétaux herbacés, avec leurs tissus riches en eau et en substances nutritives dissoutes, constituent des terrains favorables aux envahissements rapides (surtout lorsque l'humidité intervient); pour des raisons opposées, l'état ligneux impose une longue 
évolution aux troubles morbides. Sur la même espèce végétale, au même âge, le cours des accidents sera évidemment lié à la virulence et à la toxicité des parasites.

AfFECTIONS LOCALES, Localisées, GÉNÉRALES

Dans les maladies locales, l'agent pathogène ne possède certainement qu'une virulence ou une toxicité modérées, mais il faut admettre aussi que la plante se défend contre lui. Comment? Quelquefois, par la formation d'assises subéreuses; ailleurs (maladies chroniques), grâce au sommeil hivernal, qui réduit considérablement l'alimentation du parasite et transforme l'affection continue en affection intermittente; dans tous les autres cas, par des réactions humorales de nature inconnue, mais qui seules peuvent expliquer la limitation des accidents.

Dans les maladies localisées, tant que le parasite ne fructifie pas encore, ses besoins et ses moyens d'attaque restent médiocres et la résistance de l'hôte n'a pas besoin d'être bien marquée. Mais, finalement, les organes d'élection, où s'achève le développement de l'agent pathogène, deviennent le siège de lésions très graves, que la plante subit passivement. Nous disons passivement, car il est impossible de considérer l'hypertrophie initiale des tissus atteints comme un acte de défense, puisqu'elle augmente en réalité le stock alimentaire du parasite. 
Dans les maladies générales, la résistance de l'économie ou celle du système électivement touché (vaisseaux) demeurent nulles, tandis que la virulence et la toxicité de l'agent causal apparaissent fort élevées.

\section{GAS CURABles, CAS MORTELS}

La guérison s'accompagne toujonrs de pertes, d'étendue variée. Elle n'est jamais suivie d'immunité. Le mécanisme, sans doute humoral dans bien des cas, nous échappe ; à cet égard, les expériences de Tischler (sur l'Euphorbia cyparissias) constituent une "amorce " intéressante.

La mort semble due, en dernier ressort, aux facteurs mécaniques : désordres considérables (infections massives, nécroses progressives), destructions du feuillage (mildiou de la belterave), oblitérations étendues (maladies des vaisseaux), altérations énormes du système conducteur de la tige ou des racines (pourritures). Il serait cependant indiqué de rechercher, dans certaines circonstances tout au moins, si l'empoisonnement général n'intervient pas.

[Réflexions identiques, pour la mort locale des parties non infectées, mais situées en dessus des lésions. Toutefois, un facteur nouveau apparait chez les balais de sorcière, qui se comportent réellement comme des phanérogames parasites : ils arrètent au passage une grande quantité de 
substances alimentaires, dont se trouvent privées les parties sus-jacentes. De mème, à un degré variable, pour bien des mycocécidies, dont le rôle spoliateur propre ne diffère point de celui que nous ont montré les zoocécidies]. 


\section{PROPHYLAXIE ET TRAITEMENT}

Nous nous contenterons de les résumer en quelques mots.

Interdire l'entrée et la circulation des végétaux étrangers, susceptibles d'être contaminés (nous devons à l'Amérique les mildious de la vigne et de la pomme de terre, le blanc de la vigne, le black rot).

Désinfecter les graines et boutures (opération délicate). Eviteı l'humidité et l'encombrement.

Braler les plantes ou organes malades, le plus tôt possible après le début des accidents.

Stériliser le sol (problème très ardu). Alterner les cultures.

Enlever largement les chancres et les polypores.

Combattre l'infection par les traitements classiques, purement externes : composés cupriques (Bénédict Prévost, Millardet), pour les charbons, les mildious, le black rot...; soufre (Duchartre), pour le blanc de la vigne. 


\section{CHAMPIGNONS SYMBIOTIQUES}

Les maladies parasitaires, suivant les circonstances, comportent un degré fort variable de gravité. II en est de très bénignes. Certains auteurs admettent mème qu'il peut y en avoir de " profitables " et les désignent sous le nom de symbioses. Ce point de vue téléologique, que nous ne saurions admettre, oppose donc maladie el symbiose, agents pathogènes et agents symbiotiques.

Pour élucider la question, interrogeons les principaux exemples, fournis par les "associations" où figurent les champignons.

\section{CHAMPIGIONS ET ORCHIDEES}

[D'après les travaux de Noël Bernard]. Les orchidées adultes montrent toujours des champignons, au sein de leurs racines. Ces champignons représentent des formes stériles de basidiomycètes inférieurs, du genre Rhizoctonia. Leur rôle est décisif pendant toute la vie du végétal, car ils 
interviennent obligatoirement dans la germination des graines, dans la production du tubercule embryonnaire et dans celle du bulbe (facteur essentiel de l'élat vivace).

GERMINATION DES GRAINES

Les orchidées sont rares, comparées à l'abondance de leurs graines; mème chez les horticulteurs, souvent pas une semence sur mille ne germe. En voici la raison. Pour que le parasite, nécessaire, amène un développement régulier, il faut que sa virulence soit optima, qualitativement et quantitativement.

Le mycélium pénètre, alors, par le pòle postérieur de l'embryon, s'installe dans les cellules de cette région, puis envahit les éléments anatomiques d'arrière en avant, respectant le point végétatif. L'immunilé de celui-ci tient à des réactions humorales, que traduit le pelotonnement des filaments parasites (comparé, par N. Bernard, au phénomène de l'agglutination).

Lorsque la virulence des rhizoctones est qualitativement nulle, aucune germination ne saurait se produire. ()uand elle est yuantilativement insuffisante, le développement commence, mais s'arrète bientôt. La croissance du mycélium reste limitée, puis ses filaments se trouvent digérés par les cellules qui leș contiennent et transformés en 
masses amorphes; la plànte, "guérie ", devient incapable de réinfection et meurt fatalement. Lorsque la virulence est quantitativement exagérée, le parasite, après avoir formé des pelotons, se multiplie sans ordre et envahit le jeune végétal, déterminant une infection massive, rapidement mortelle.

Les expériences que nous venons de résumer ont été faites en semant des graines aseptiques d'orchidées et des cultures pures de rhizoctones sur gelée nutritive.

FORMATION DU TUBERCULE EMBRYONNAIRE (PROTOCORMUS)

Quand le développement de l'orchidée peut continuer (virulence optima du parasite), on voit apparaitre un tubercule embryonnaire; puis, la tige et les radicelles se flétrissent et il ne reste que le bourgeon terminal, dont naîtront les organes de la plante adulte. Toutes les parties infectées se trouvent ainsi éliminées et le sommet végétatif, indemne, persiste seul.

La formation du protocormus, constante chez les espèces parasitées, manque chez la Bletilla hyacinthina, dont les graines peuvent germer sans le secours des rhizoclones. Il s'ensuit que ceux-ci représentent bien la cause productrice du tubercule embryonnaire. 
Le bourgeon, qui survit à l'élimination des tissus infectés, engendre le bulbe, d'où émaneront les racines et les organes aériens. Les racines ne tardent pas à être pénétrées par un nouveau mycélium, venu du sol et habituellement de même espèce que celui auquel les graines ont du leur développement. Il apparaît, ici encore, constitué de filaments pelotonnés, que limite, dans leur extension, la réaction humorale de l'hôte. Suivant N. Bernard, il faut admettre que le bulbe doit son origine aux parasites des racines : d'abord, en vertu de l'analogie avec le protocormus, puis en vertu d'autres similitudes, que nous allons bientôt rencontrer. Sauf chez la Neottia nidus-avis, le bulbe n'est jamais contaminé; cela tient à la présence de substances fungicides, sécrétées par ses éléments.

La Neottia nidus-avis demeure infectée sa vie durant; les rhizoctones occupent tous les tissus, moins le point végétatif; ils envahissent les graines, qui peuvent ainsi germer sans contamination extérieure.

MÉCANISME DE L'INFECTION

Dans le cas oì leur virulence est optima, les parasites vivent aux dépens des tissus envahis et 
s'y comportent comme des agents d'irritation. Ils provoquent ainsi la germination des graines qu'ils infectent, ni plus ni moins que l'Ustilago violacea provoque le développement des étamines dont elle atlaque les rudiments. Ils déterminent également la formation du protocormus et du bulbe, en vertu de leurs sécrétions excitantes. N. Bernard a montré que les graines aseptiques de Bletilla et de Caltleya pouvaient germer dans les milieux concentrés; d'autres auteurs ont obtenu des hypertrophies d'organes végétaux par le même mécanisme. Nous pensons avoir montré, à propos de la cécidogénèse, qu'il n'existe aucune contradiction entre l'idée de changements osmotiques et la notion de poisons irritants.

Lorsque la virulence s'exagère, c'est l'infection massive type, contre laquelle la jeune plante reste désarmée. Ailleurs, avons-nous vu, le végétal répond de la façon la plus évidente, confinant les parasites au sein des cellules et agglomérant leurs filaments. La maladie de la Neottia nidusavis, qui traduit une réaction moins énergique, est triplement intéressante par son caractère héréditaire (la rapprochant du charbon du blé, que détermine l'Ustilago tritici), sa continuité et son extension. 
N. Bernard s'est demandé si le tubercule de la pomme de terre ne devait pas, lui aussi, son origine à des parasites radicicoles. Comme ces parasites font défaut chez la plante culticée, il suppose qu'elle s'en est affranchie progressivement, grâce surtout aux conditions de culture.

De fait, chez la pomme de terre sauvage (Solanum Maglia), il existe, à l'état naturel, des champignons et des tubercules, disparaissant tous deux par la culture, sauf dans certains sols, tels que ceux qui portent des douces-amères. (La douceamère montre, constamment, des rhizomes et des parasites radicicoles).

Les recherches de Magrou confirment l'opinion de N. Bernard. L'auteur sème des graines de pomme de terre cultivée sur un terrain pauvre, au voisinage de douces-amères. Les racines sont rapidement envahies par des champignons, identiques à ceux que l'on trouve chez cette dernière; puis, suivant les cas, il se forme ou non des tubercules. L'étude histologique rend compte de ces résultats contraires.

Tout d'abord, les parasites pénètrent dans les poils absorbants et gagnent l'assise pilifère. Le mycélium se dilate en disques adhésifs, accolés aux éléments subéreux. Le centre de chaque disque émet un bourgeon 
qui perfore la paroi voisine, s'allonge, traverse la cellule et alleint le tissu cortical. Puis : ou bien l'infection continue et il se forme des tubercules ou bien elle s'arrête et il ne s'en forme point. Affaire de résistance individuelle des plantes infectées.

$1^{\text {er }}$ cas. - Pelotons mycéliens intracellulaires dans l'assise corticale moyenne. Ces pelotons engendrent des arbuscules, que les cellules digèrent. Le parasite ne continue pas moins à s'étendre, mais son envahissement demeure limité par la résistance de l'hôte; les couches corticales profondes ne sont jamais prises.

$2^{\mathrm{e}}$ cas. - Les pelotons se trouvent digérés avant la formation des arbuscules et le mycélium dégénère rapidement.

Le champignon, étudié ici, est un Mucor; quand on le met au contact de la pomme de terre, cultivée aseptiquement, il pénètre dans les radicelles.

Les tubercules semblent donc bien devoir ici leur origine aux parasites des racines. D'ailleurs, des recherches du même auteur, sur l'Orobus tuberosus et les mercuriales, viennent de mettre pareillement en évidence la relation entre la symbiose et la genèse des organes pérennants (tubercules ou rhizomes).

\section{CHAMPIGNONS DES MYCORRHIZES}

Presque toutes les plantes herbacées vivaces et les végétaux arborescents hébergent des champignons radicicoles (le plus souvent impossibles à cultiver), tandis que les plantes annuelles en sont 
indemnes. Cette association des parasites et des racines constitue les mycorrhizes (Franck, Shibata, Janse, Gallaud). Nous connaissons déjà celles des orchidées et des Solanum, les autres ont été moins complètement étudiées et ne méritent qu'une brève mention. On divise les mycorrhizes en deux groupes.

Mycorrhizes ectotrophes. - Le parasite entoure la racine d'une revêtement serré; il ne pénètre pas, s'insérant seulement entre les cellules épidermiques.

Mycorrhizes endotrophes. - Le parasite pénètre, Dans les couches superficielles, il est tantôt intra, tantôt extracellulaire; dans les régions profondes, il est toujours intracellulaire, formant des arbuscules qui sont digérés, le moment venu.

[Les champignons des mycorrhizes sont totalement inoffensifs. Pour certains auteurs, ils transmettraient à leurs hôtes les matières azotées de l'humus].

D’après N. Bernard, la répartition des mycorrhizes impose l'idée que, parmi les végétaux, tous primitivement annuels, ne sont devenus vivaces que ceux dont les racines ont été régulièrement infectées. Si l'on juge, dit-il, une telle conception trop absolue, on conviendra au moins que le parasitisme a dû représenter le facteur le plus important de cette évolution. Des recherches récentes de Magrou, sur diverses plantes annuelles (Orobus coccineus, Mercurialis annua, Solanum nigrum), montrent que ces végétaux peuvent se laisser pénétrer, comme leurs congénères vivaces, par des endophytes, mais s'en affranchissent rapide- 
ment (destruction intracellulaire). Cies faits con. firment l'idée de N. Bernard.

Chez les hépatiques, on trouve communément des champignons intracellulaires au sein du thalle; ils semblent jouer un rôle important dans la germination des spores et le développement de la plante. Chez les lycopodes et les ophioglossées, des champignons associés se rencontrent dès la germination des spores, à laquelle ils sont sans doute indispensables.

\section{CONCLUSION - CAS DE LICHENS}

Les symbioses, dues aux champignons, ne sauraient être séparées du groupe des infections cryptogamiques. Elles ne possèdent aucun caractère mystérieux et les soi-disant " avantages " que l'hôte retirerait de sa maladic, ne sont que des modifications anatomiques et fonctionnelles, relevant des mécanismes biologiques ordinaires.

On cite toujours le cas des lichens, comme type de symbiose. Ici, les deux " associés " appartiennent aux végétaux inférieurs, d'où la physionomie parliculière de l'organisme résultant.

Schwendener a démontré que tout lichen provient de la fusion intime d'un champignon (ordinairement ascomycète) et d'une algue. Les hyphes représentent le mycélium épaissi du premier, les apothécies, ses

Nícolle et Magrov, - M. P. des plantes. 
périthèces; les gonidies ne sont autres que les cellules de la seconde. Celle-ci fournirait au champignon les substances hydrocarbonées qu'elle élabore; le champignon lui transmettrait de l'eau, des matières minérales, des substances azotées.

On peut isoler facilement l'algue, moins aisément le champignon.

Bonnier a réalisé la synthèse des lichens.

M. et Mme Moreau ont établi, par des recherches précises, le caractère nettement pathologique de la symbiose lichénique (infection d'un champignon par une algue). 


\section{IV}

\section{MALADIES DES PLANTES DUES AUX BACTERIES}



Leur étude, de date relativement récente, commence avec les travaux de Burrill sur la nécrose du poirier. Elle se continue ensuite par les recherches de Prillieux, Savastano, Vuillemin, Arthur, Jones.... et surtout E. Smith. C'est à l'œuvre; désormais classique, de ce dernier que nous emprunterons la matière du chapitre qui suit, nous limitant aux maladies les mieux connues, lesquelles affectent exclusivemeni les phanérogames. 


\section{PRINGIPALES BACTÉRIES PATHOGENES}

\section{CARACTĖRES - ÉNUMÉRATION}

Celles dont il va être parlé ici constituent des bacilles ou bactériums, mobiles et sans spores, inoffensifs pour les animaux. Toutes onl été cultivées et leurs cultures pures ont permis de reproduire les maladies naturelles correspondantes. Très peu croissent à la température du corps humain. Certaines forment des colonies jaunes (Bact. hyacinthi, Bact. phaseoli, Bact. campestre, Bact. Stewarti), quelques-unes secrèient un pigment vert fluorescent (Bact. maculicolum, Bact. lachrymans).

Voici la liste des germes qui vont nous occuper.

Agents des affeclions maculeuses. - Baclerium malvacearum, bacterium sorghi, bacterium maculicolum, bacterium lachrymans, baclerium Woodsii, bacterium pruni, bacterium phaseoli, bacillus carotovorus, bacillus destructans, bacillus phytophtorus, bacillus melonis (E. Smith, Jones, Appel, Potter...).

Agents des maladies vasculaires. - Bacterium campestre (Pammel), bacillus tracheiphilus (E. Smith), bacillus hyacinthi (Heinz), bacillus Stewarti (Stewart), bacillus solanacearum (E. Smith), bacterium vascularum (Cobb). 
Agents des nécroses. - Bacillus amylovorus (Burrill), bacillus mori (Boyer et Lambert).

Agents des tumeurs. - Bacillus olece (Savastano), bacillus tumefaciens (E. Smith).

\section{HABITAT}

La majorité de ces bactéries doivent pouvoir vivre dans le sol, d'où un petit nómbre seulement ont été isolées jusqu'ici (Bac. solanacearum, Bac. phytophtorus, Bac. lumefaciens). Les agents des nécroses, par contre, semblent se conserver exclusivement dans les lésions qu'ils déterminent. Certains germes sont très sensibles à la lumière et à la dessiccation (Bac. carotovorus, Bac. tracheiphilus); d'autres demeurent vivants et virulents, pendant un an au moins, sur les graines sèches (Bact. campestre, Bac. Stewarti).

\section{AGENTS DE PROPAGATION}

Nous les mentionnerons brièvement.

Organes malades. - Graines (Bacterium campestre, Bacillus Stevarti), bulbes (Bacillus hyacinthi), greffons (Bacillus tumefaciens, Bacillus anylovorus).

Sol, eaux, fumiers. - (Bacillus phytophtorus, Bacterium campestre, Bacterium solanacearum, Bacillus tumefaciens).

Oiseaux. - (Bacillus amylorovus).

Insectes. - (Bacillus amylovorus, Bacillus tracheiphilus).

Limaçons. - (Bacterium solanacearum).

Nématodes. - (Bacterium solanacearum). 
Les affections dues aux champignons ouvrent souvent la porte aux bactéries pathogènes.

On ne saurait dire s'il faut classer parmi les bactéries l'organisme invisible qui détermine la maladie de la mosaïque (ou nielle) du tabac et que Beyerinck a dénommé contagium vivum fluidum.

Quelques mots sur celte affection. Elle atteint les feuilles, en voie de développement, des bourgeons terminaux puis latéraux. Le limbe apparait tacheté de vert pâle, avec des plages plus foncées que normalement. Les autres symptômes u'offrent rien de constant. Floraison parfaite, graines fertiles, pas d'hérédité. Le virus se trouve dans la sève et, abondamment, dans les feuilles altérées. On peut reproduire les accidents avec les sucs virulents, en piquant la tige, en contaminant le sol (si les racines offrent des plaies), en répandant les germes sur les feuilles. I a maladie naturelle est transmise par divers aphidiens.

Il s'agil donc d'une infection générale, qui ne manifeste guère ses effets quau niveau des feuilles jeunes.

Les deux maladies suivantes : enroulement des feuilles de la pomme de lerre et mosaïque du même végétal, semblent dues à des germes invisibles (Quanjer). 


\title{
PRINCIPALES AFFECTIONS BAGTÉRIENNES
}

\section{MALADIES AIGUES OU SUBAIGUES}

\author{
MALADIES LOCALES
}

AFFECTIONS MACULEUSES

Des feuilles (leaf-spots des anteurs américains).

Cotonnier. - Taches dabord humides, puis brunes et plissées, apparaissant à la face inférieure du limbe et gagnant ensuite la face supérieure. - Agent : Bacterium malvacearum.

Sorgho. - Bandes rouges ou brunâtres, qui deviennent confluentes et amènent le froncement des feuilles. - Agent : Bacterium sorghi.

Glou-fleur. - Taches brunes ou rouge sale, plus ou moins agminées; lorsqu'elles atteignent les nervures, on voit le limbe se plisser. - Agent : Bacterium maculicolum. Les inflorescences résistent à l'infection expérimentale.

Concombre. - Taches anguleuses, humides (gouttes d'exsudat bactérien), puis brunes, froncées et desquamantes; elles occupent la face supérieure des feuilles. Les pétioles et les jeunes tiges peuvent être pris; ils se dessèchent en se crevassant ou se ramollissent, suivant les cas. La récolte des fruits diminue. - Agent : Bacterium lachrymans. L'inoculation dans les fruits amène leur destruction rapide. 
OEillet. - Taches humides, puis brunes et déprimées. Elles peuvent siéger également sur les sépales et les tiges. - Agent: Bacterium Woodsii.

Les parties atteintes sont plus ou moins altérées, mais la plante résiste. On reproduit aisément les lésions caractéristiques en pulvérisant des cultures pures. Dans la maladie, naturelle ou expérimentale, l'agent pathogène pénètre par les stomates, se développe au niveau de la chambre sous-stomatique et envahit ensuite le mésophylle (incubation : 1-2 semaines). Il détermine la nécrose des tissus (habituellement sèche, parfois humide) et peut gagner ultérieurement la surface, en traversant les stomates.

Notons, une fois pour toutes, que, dans les affections bactériennes, le rôle de la spoliation demeure secondaire; aussi sera-t-il simplement sous-entendu désormais.

Des fruits (fruit-spots des auleurs américains).

Prune. - Taches d'abord humides, puis noires, qui s'étendent, s'affaissent et se déchirent. Un exsudat bactérien sort des macules encore intactes ou des fissures. Agent : Bacterium pruni. Infection par les stomates, développement dans la chambre sous-stomatique, invasion ultérieure des tissus profonds (où se forment des cavités, remplies de microbes et de débris cellulaires), issue à travers les stomates ou l'épiderme déchiré.

Haricot. - Taches vert foncé, grasses (" graisse des haricots "), entourées d'une bordure rouge diffuse. Elles demeurent sèches ou se ramollissent; elles exsudent un liquide visqueux, rempli de microbes. Les 
lésions gagnent en profondeur et les graines offrent bientôt des macules brun clair. La maladie se propage par semis de ces graines malades. - Agent : Bacterium phaseoli. Même mécanisme que dans le cas précédent.

On reproduit aisément les fruits-spots, en pulvérisant des cultures pures (incubation : 1-2 semaines); il est également lacile d’infecter les feuilles des végétaux correspondants.

Les maladies maculeuses des fruits (affections toujours locales) représentent des nécroses, volontier's humides, auxquelles succède une digestion plus ou moins marquée des tissus.

\section{POURRITURES (HUMIDES)}

Des racines, tubercules, fruils. (Soft-rots des auteurs américains).

Carolte. - Destruction rapide. - Agent : Bacillus carotovorus. On reproduit facilement la maladie par piqûre des tissus avec une aiguille infectée (culture pure); de même, chez le concombre. Les feuilles résistent à la pulvérisation des germes ou n'offrent que des lésions minimes.

Navet. - Les feuilles jaunissent et tombent; les racines brunissent et présentent un ramollissement aigu. - Agent : Bacillus destructans. On reproduit aisément la maladie par inoculation.

Pomme de terre. (Basal stem-rot et tuber rot). - . Les feuilles jaunissent et sèchent. Taches livides à la base des tiges, macules jaunes puis brunes au niveau des tubercules; finalement, fonte des tissus. - Agent : Bacillus phylophtortus. L'infection suit les vaisseaux, mais prédomine toujours dans le parenchyme. Maladie facile à reproduire par inoculation. 
Melon. - Mêmes phénomènes, même mécanisme. Agent : Bacillus melonis.

Les agents des soft-rots sont tous des parasites de blessure. Après une incubation de 1-2 jours, ils détruisent les tissus et tuent les plantes en 1-2 semaines (nécrose humide, suivie de pourriture humide).

MALADIES GÉNERALES

Il s’agit exclusivement ici de maladies vasculaires.

Nersation noire des crucifères (black rot).

Sxmptomes. - [Nous prendrons comme type la maladie du chou]. Les feuilles jaunissent, leurs nervures se dessinent en noir, les limbes sèchent et offrent l'aspect du cuir. Dans les cas sévères, on observe une chute assez rapide, précédée de flétrissement. Parfois, développement de pousses latérales. Il faut plusieur's mois pour tuer la plante ou l'altérer gravement (nanisme, asymétrie). Chez les individus atteints pendant la germination, tantôt la mort survient en quelques semaines, tantôt la croissance demeure incomplète (absence de " tète »). Chez les individus âgés ou les races à développement lent, la destruction n'est jamais totale. - Ce sont les graines qui propagent la maladie.

Mécanisme de l'infection. Lésions. - Agent : $B a c^{-}$ terium campestre. L'infection a lieu au niveau des pores aquifères, les stomates étant protégés par les dépôts cireux. Chez les jeunes plantes, seulement, les microbes peuvent pénétrer au niveau des racines. Il est aisé de 
reproduire la maladie (pulvérisation ou trempage cultures pures). L'incubation dure plusieurs semaines, mais, déjà après $4 \cdot 6$ jours, les dents des feuilles noircissent. Les germes se développent dans la chambre sousstomatique, puis envahissent le système vasculaire du limbe et du pétiole (les vaisseaux de pétioles sains en apparence offrent déjà, à la coupe, le ton noir caractéristique). La tige se prend ensuite; les vaisseaux du cylindre ligneux apparaissent tolalement ou partiellement obstrués par les bactéries; le progrès reste d'autant plus lent que la lignification est plus avancée. De la tige, la maladie gagne les feuilles encore saines, avec une rapidité et une intensité variables suivant les cas.

Partout, les vaisseaux, bientôt désintégrés, laissent sortir les microbes, qui gagnent les tissus voisins. Ils se multiplient entre les éléments anatomiques, qu'ils dissocient d'abord et détruisent ensuite (cavités, remplies de bactéries et de débris cellulaires). Dans les feuilles, l'envahissement du mésophylle demeure lent et atteint rarement la surface. Dans les racines charnues (turneps), le parenchyme est rapidement et profondément attaqué et tout se termine par une pourriture aiguë, dueà la collaboration d'agents des soft-rots.

Un peut reproduire la maladie par piqùre des tiges ; les feuilles offrent les altérations caractéristiques, après un temps variable. - On peut aussi contaminer les crucifères avec des larves de Plusia (lépidoptère) ou des Agriolimax infectées].

En résumé : multiplication locale des germes; envahissement des vaisseaux; obstacle croissant au cours de la sève; altération des vaisseaux; envahissement des tissus voisins. La rapidité avec laquelle se produit l'oblitération vasculaire (lésion dominante) décide du sort de la plante.

\section{Maladie des cucurbitacées (wilt-flétrissement).}

Symptômes. - Les feuilles prennent tout à coup une coloration vert sombre, mate, se flétrissent, se recro. 
quevillent et brunissent. Généralement, ce sont les feuilles inférieures qui s'altèrent les premières. Chez les individus résistants, on voit le feuillage, flétri pennant les jours chauds et secs, redevenir normal pendant les jours frais et humides. Cet état de mal intermittent peut se prolonger et permet d'observer des modifications curieuses dans le développement de la plante : nanisme, tassement des ramifications et des fleurs. Chez les individus sensibles, la mort arrive vite.

Mécanisme de l'infegtion. Lésions. - Agent : Bacillus tracheiphilus (parasite de blessure). L'infection naturelle doit être transmise presque toujours par la Diabrotica vittata (coléoptère). L'infection expérimentale se réalise facilement en piquant les feuilles avec une aiguille chargée de germes (cultures pures). L'incubation dure un temps très variable. Au voisinage des premières feuilles malades, les vaisseaux sont déjà gorgés de microbes (exsudat blanc et gluant, à la coupe). Le système vasculaire se prend ensuite progressivement; des tiges, normales en apparence, peuvent être infectées sur une très longue étendue.

En résumé: oblitération vasculaire progressive, débutant à la base de la tige (maladie naturelle) ou au niveau des feuilles (maladie expérimentale) et comportant les suites que l'on aurait pu prévoir d'avance.

\section{Maladie jaune des jacinthes.}

Symptomes. - On voit apparaitre, à l'extrémité des feuilles, des bandes humides et blanchâtres, puis jaunes, puis brunes. Elles s'étendent lentement de haut en bas, plus lentement encore sur les côtés. Les lésions gagnent les tuniques du bulbe et le plateau, d'où elles envahissent les écailles encore saines. Finalement, le bulbe est détruit par un ramollissement auquel comtribuent, d'ordinaire, les microbes de pourriture venus du dehors.

Mécanisme de L'infection. Lésions. - Agent : Bacll- 
lus hyacinthi. Les bulbes infectés propagent la maladie naturelle, dont le mécanisme est encore discuté. L'affection expérimentale se réalise facilement par piqùre des feuilles (émulsions de cultures pures). Incubation variable; bulbe pris au bout de $2-4$ mois. Les vaisseaux sont rapidement envahis (glaire jaunâtre) et cet envahissement s'étend ensuite à tout le végétal. Après désintégration des parois vasculaires, les bactéries pénètrent dans les parenchymes, mais s'y développent lentement; elles se multiplient d'abord entre les éléments anatomiques, puis les détruisent (cavités, contenant des microbes et des débris cellulaires). Le bulbe peut se ramollir sans ingérence de germes étrangers, mais c'est l'exception.

En résumé : histoire d'une oblitération vasculaire, se terminant ordinairement par pourriture (infection secondaire).

\section{Maladie du maïs de Slewart.}

Symptomes. - Nanisme, parfois très marqué. Développement prématuré et mort précoce des inflorescences mâles (aspect blanchâtre, caractérislique, de l'extrémité des plantes). Les feuilles sèchent, de bas en haut, sans s'étioler. Finalement, la tige se ride et sèche à son tour. Quelquefois, du mucus bactérien sort au niveau des glumes. Guérison exceptionnelle.

Mécanisme de L'infection. Lésions. - Agent : Bacillus Stewarti. Infection, lors de la germination, par les slomates et les pores aquifères du haut des feuilles. Maladie expérimentale aisément reproduite avec des cultures pures (piqùre). Incubation de 1-3 mois, pendant laquelle la plante croît en apparence normalement. Les bactéries se multiplient dans la chambre sous-stomatique et envahissent lentement le système vasculaire. Successivement, se prennent les vaisseaux de la tige, des racines, des feuilles, des inflorescences. Avant que la tige ne présente d'altérations visibles, le 
tissu conducleur apparait, à la coupe, rempli de mucus bactérien jaune, brun ou mélangé (le mucus est d'abord jaune).

En résumé : maladie vasculaire pure.

\section{Maladie des solanées (brown-rot).}

Symptomes. - (Pommes de terre, tomates). - Chez les plantes déjà assez développées, on voit le feuillage jaunir et mourir peu à peu; chez les sujets jeunes, il se flétrit subitement. Les grandes feuilles et les tiges molles des tomates s'incurvent et se froncent.

Au travers des parlies translucides (tige, pétioles), les vaisseaux malades apparaissent comme des bandes brunes.

Les plantes jeunes périssent rapidement; les adultes résistent plus ou moins selon les cas. Les tomates montrent parfois un début de racines adventives.

Dans les infections précoces de la pomme de terre, les tubercules ne se forment pas; dans les infections ultérieures, ils demeurent chétifs et s'altèrent bientôt; dans les infections vraiment tardives, ils sont à peine touchés (lésions minimes, près du point d'insertion).

Mécanisme de l'infection. Lésions. - Agent : Bactérium solanacearum (parasite de blessure). La maladie naturelle débute généralement au niveau de la base de la tige; les limaçons et les nématodes jouent un rôle important dans sa propagation. La maladie expérimentale se réalise facilement par inoculation de cultures pures. Incubation variable (avec des germes très actifs et chez des plantes jeunes, flétrissement après 2 jours et mort en 6 jours). Les vaisseaux se remplissent de mucus bactérien, blanc ou brûnâtre, sur une étendue croissante; quand ils sont détruits, les germes envahis. sent les tissus voisins. Ils dissocient les cellules, puis les détruisent, formant des cavités à parois foncées qui confluent. Dans les tiges relativement àgées, le tissu ligneux brunit, mais n'est pas dissocié; le développe- 
ment intravasculaire demeure du reste assez lent. Chez la tomate, la moelle peut ètre au contraire totalement ramollie et le magma produit s'évacue parfois au dehors. Dans les tubercules de pomme de terre, des taches brunes apparaissent autour des faisceaux malades, s'étendent, se réunissent, "fondent "; les tissus sont profondément altérés et les téguments cèdent. Les bactéries du sol précipitent alors la pourriture de l'organe atteint.

En résumé : oblitération vasculaire, évoluant plus ou moins vite et compliquée de destruction plus ou moins intense des parenchymes.

\section{Maladie de la canne à sucre de Cobb.}

Symptones. - Nanisme, étiolement, diminution de la richesse saccharine. Sur les feuilles, bandes blanches ou jaunes, puis dessiccation et mort du limbe. Quelquefois, un mucilage bactérien s'épanche à la face interne des feuilles supérieures el les accole au-dessus du bourgeon terminal, qui s'incurve et sort de côté. D'ordinaire, ce bourgeon s'arrête dans sa croissance et l'on voit apparaître des pousses latérales (il peut mème naitre des racines adventives). Selon les cas, la plante meurt (parfois très vile) ou guérit. Chez les jeunes sujets, l'affection progresse rapidement.

Mécanisme de L'infretion. Lésions. - Agent: Bacterium vascularum. Facilement inoculable (cultures pures). Incubation variable. Les vaisseaux de la tige se remplissent d'un mucilage bactérien jaune, rouge ou mélangé (le mucus est d'abord jaune). Après destruction de ces vaisseaux, les germes envahissent le voisinage et détruisent les tissus par le mécanisme déjà indiqué plusieurs fois. Les parties situées au-dessous du bourgeon terminal sont en général profondément altérées, d'où la perte de celui-ci. Des cavités du mésophylle, les germes peuvent s'épancher à travers les stomates (supra). 
En résumé : oblitération vasculaire el destruction des parenchymes, avec siège électif dans les régions supérieures de la plante.

\section{MALADIES CHRONIQUES}

MALADIES LOCALES

\section{NÉCROSES}

Nécrose du poirier (pear blight).

Symptomes. - (Poirier, pommier, cognassier). Les fleurs se fanent et brunissent; les lésions gagnent les pédoncules et les jeunes rameaux, dont les feuilles deviennent brunes et plissées. L'écorce meurt peu à peu; elle laisse exsuder un liquide gommeux, foncé, rempli de microbes. Les grosses branches (voire le tronc) peuvent se prendre et périr lorsque la nécrose s'y développe circulairement. L'infection, rapide et sévère dans les printemps chauds et humides, s'arrête d'ordinaire après quelques semaines, mais il faut toujours craindre de la voir réapparaitre l'an suivant; c'est pourquoi nous l'avons classée parmi les maladies chroniques. - La greffe et l'émondage constituent des modes de propagation redoutables.

Mécanisue de l'infegtion. Lésions. - Agent : $B a-$ cillus amylovorus. L'affection naturelle est due au transport des germes par les insectes. On la reproduit en pulvérisant des émulsions de cultures pures sur les fleurs. Les germes se multiplient dans les nectaires, envahissent l'ovaire, puis les rameaux, d'où ils gagnent les pétioles et les feuilles (on réalise très bien l'infection, quand on pique les rameaux avec une aiguille chargée de microbes). Les plus souvent, l'agent pathogène meurt au sein de l'écorce nécrosée, mais il peut 
hiverner, loco loeso, protégé par les exsudats et les insectes l'y r'eprennent l'an suivant.

Lor'squ'on inocule les poires, elles brunissent, deviennent molles, se rident. Tout le fruit se transforme en une gelée grisâtre, poisseuse, fourmillant de germes qui sortenl à travers les crevasses el les stomates].

\section{Nécrose du mürier.}

Moins complètement étudiée. Les feuilles montrent des taches d'abord humides, puis brunes, puis noịres. Mèmes lésions sur les jeunes pousses, qui périssent rapidement. Au niveau des rameaux malades, apparaissent des sortes de verrues de couleur sombre. - Agent : Bacillus mori. Il est aisé de reproduire la maladie; celle-ci se traduit exclusivement par des altérations nécroliques.

YALADIES GEVERRALES

TUMEURS

Tumeurs de l'olivier.

Symptones. - La maladie alteint surtout les jeunes rameaux. Les nodules, de forme et de dimension variables, sont souvent confluents; aux tumeurs primitives viennent se joindre les tumeurs secondaires. Les unes et les autres finissent par se crevasser, dégénérer et sécher; le rameau qui les porte périt fréquemment. L'olivier sauvage jouit d'une immunité absolue.

Mécanisae de L'infection. Lésions. - Agent : Bacillus olex (son activité se conserve longtemps in vitro). Affection naturelle toujours consécutive à des blessures. Il est aisé de reproduire la maladie, en piquant des jeunes pousses ou des feuilles jeunes avec 
des émulsions de cultures pures; il est difficile ou impossible d'infecter les parties plus anciennes du végétal. Voici comment évoluent les phénomènes. La tumeur primitive débute au bout de 1-2 semaines et acquiert son volume maximum en 3-4 mois; les tumeurs secondaires apparaissent ensuite, sur les pousses et les feuilles. Les microbes, introduits dans le parenchyme cortical, détruisent les cellules après avoir provoqué leur hyperplasie; d'où la formation de cavités, qui creusent peu à peu les tumeurs et de fissures, par où pénètrent les germes étrangers (lesquels activent la désintégration des néoplasmes).

Les nodules secondaires sont dûs à la migration intravasculaire de l'agent pathogène. Par suite du développement de la tumeur primitive, les microbes arrivent près du bois interne et de la moelle, pénètrent dans les vaisseaux, s'y multiplient (généralement de bas en haut), en altèrent les parois, envahissent les tissus voisins et y provoquent la naissance de nodules caractéristiques. On peut reconnaître, à l'œil nu, le trajet suivi par les germes, de la tumeur primitive à la tumeur secondaire; il se dessine sous la forme d'une mince ligne brun foncé (vaisseaux altérés).

En résumé: hyperplasie des tissus jeunes (développement de parenchyme indifférencié), aboutissant à leur destruction; généralisation du parasite par la voie vasculaire.

\section{Crown-gall.}

[E. Smith rappelle que le mot crown, dans l'argot des jardiniers américains, signifie collet et estime défectueuse l'expression de crown-gall, car la néoformation peut intéresser n'importe quelle région des plantes].

Symptomes. - Les végétaux sensibles sont excessivement nombreux : marguerite de Paris (Paris daisy ou Chrysanthemum frutescens, qui a servi, avant tout, aux expériences de E. Smith), pècher, poirier, rosier, peuplier, vigne, navet, laitue, luzerne.... Tumeurs de 
forme, volume, consistance très divers, selon les plantes et les organes affectés. Elles s'accroissent, restent stationnaires, puis se crevassent et dégénèrent; les galles molles sont fréquemment envahies par des bactéries étrangères et leur destruction s'en trouve accélérée. Le Bacillus amylovorus peut s'introduire dans les néoplasies et infecter l'arbre qui les porte.

Aux nodules primitifs, succèdent couramment des nodules secondaires; les tumeurs initiales récidivent souvent sur place, après ablation incomplète. La maladie est bien ou mal tolérée, selon les espèces frappées; les jeunes boutures et les jeunes rameaux meurent d'ordinaire assez vite, les vignes succombent fréquemment en 3-4 ans, les pêchers, rosiers, amandiers, framboisiers s altèrent à la longue, les pommier's résistent indéfiniment. L'affection du poirier, dite hairyroot, est caractérisée par des tumeurs radiculaires aplaties, d'où naît un chevelu abondant / véritable balai de sorcière).

Mécanisue de L'infection. Lésions. - Agent : Bacillus tumefaciens (parasite de blessure). Sous ce nom, il convient d'entendre un groupe de bactéries appartenant soit à la mème espèce, soit à des espèces très voisines (la question n'est pas encore tranchée). Tous ces germes se comportent pareillement chez les végétaux sensibles et l'on infecte d'ordinaire sans peine une plante donnée avec des cultures provenant d'une plante très différente. La virulence disparaît rapidement in vitro.

Le Bacillus tumefaciens ne détermine guère de tumeurs que dans les tissus en voie de développement. Les néoplasies, qui débutent parfois après quelques jours, offrent généralement un volume notable au bout de 1-2 mois. Elles peuvent être provoquées sur des points variés du végétal; elles contiennent les divers tissus de la partie inoculée, mais avec dominance constante de l'élément parenchymateux. Les vaisseaux demeurent peı abondants, d'où la nécrose centrale, inévitable (précoce pour les organes charnus) et les cre- 
vasses, à travers lesquelles s'introduisent les germes étrangers. Les tissus néoformés amènent la mort des tissus normaux par compression.

Chose singulière, les parasites sont très peu nombreux au sein des lésions; on les obtient par culture, mais il n'est pas sùr qu'on les ait vus in silu. E. Smith pense que les germes se multiplient dans les cellules infectées, déterminant ainsi leur division; lor's de cette division, la majorité des parasites périrait, le resle se multiplierait dans les cellules-filles et ainsi de suite.

Comment se forment les mélastases? De la tumeur primitive partent des cordons, généralement ascendants, qui s'insinuent entre les éléments sains et deviennent de place en place l'origine d'une tumeur secondaire. Celle-ci, comme le nodule initial, gagne la surface en écrasant les tissus interposés. Les tumeurs secondaires offrent la mème structure que les néoplasies qu'elles prolongent; ainsi, un nodule secondaire de la feuille, issu d'un nodule de la tige, présente les caractères histologiques de ce dernier et non ceux des tumeurs primitives des feuilles.

E. Smith compare la crown-gall aux néoplasmes malins des animaux supérieurs, particulièrement aux sarcomes. Il a obtenu de véritables embryomes, par inoculation du Bacillus tumefaciens dans certains points déterminés des végétaux. La surface de ces curieuses productions montre des racines el des bourgeons (végétatifs ou floraux) rudimentaires; dans l'intérieur, on rencontre des ébauches d'organes, disposées sans ordre au sein d'un parenchyme indifférencié, qui tend à les supplanter. Les métastases sont constituées, tantôt par les embryomes, tantôt par leur's éléments parenchymateux seuls.

E. Smith admettait d'abord que le Bacillus tumefaciens provoque l'hyperplasie des cellules en sécrétant un poison spécifique. Il voit aujourd'hui, dans les néoplasies, la conséquence de simples troubles osmotiques. On obtient, en effel, des développements très nets (bien que limités), quand on fait agir diverses 
substances chimiques sur les tissus de plantes variées. Comme certaines de ces substances résultent de la croissance in vitro de l'agent pathogène, E. Smith pense que c'est leur production in vivo qui détermine la multiplication des cellules, par élévation de la pression osmotique; il ne nie pas d'ailleurs l'influence possible de facteurs chimiques concomitants.

En résumé : hyperplasie des tissus jeunes (développement dominant d'un parenchyme indifférencié), aboutissant à leur dégénérescence; généralisation du néoplasme par continuité. Dans la crown-gall, ainsi que dans la maladie de l'olivier, la mort des organes ou plantes atteints reconnait pour cause principale l'obstacle mécanique apporté au cours de la sève. 


\section{MÉGANISME DE L'INFEGTION}

Le mème, sous beaucoup de rapports, que chez les maladies cryptogamiques. Aussi nous bornerons-nous à rappeler brièvement les analogies, pour n’insister que sur les différences.

PARASITES FACULTATIFS

ET PARASITES STRICTS

Ceux des germes étudiés ici qui peuvent vivre dans le sol constituent en réalité des parasites facultatifs. Mais, contrairement aux champignons facultativement pathogènes, ils ne tuent les cellules des plantes infectées qu'après s'être multipliés autour d'elles. [E. Smith fait remarquer qu'i] n'existe aucun exemple probant de la transformation de microbes vraiment saprophytes en agents pathogènes].

Ciomme type de parasite strict, on peut citer le Bac. amylovorus. 


\section{VIRULENCE DES PARASITES}

Aspect qualitatif. - Certains n'attaquent qu'une espèce ou une famille (Bac. hyacinthi, Bac. Stewarti, Bac. vascularum, Bac. olcc...; Bact. campestre, Bac. tracheiphilus, Bact.solanacearum, Bac. amylovoris...), d'autres se montrent susceptibles d'infecter des plantes fort éloignées (agents des soft-rots, Bac. tumefaciens).

Aspect quantilatif. - Divers échantillons d'un même organisme possèdent souvent une activité très variable; celle-ci se conserve plus ou moins longtemps en culture, suivant les cas.

SENSIBILITÉ DES PLANTES

Liée, ici encore, à l'espèce, la race, l'individu. Presque toujours mavima chez les sujels ou organes jeunes. Obscure dans ses causes intimes.

INFLUENCE DES CONDITIONS

AMBIANTES

Comme pour les infections cryptogamiques. 
MOYENS D'ATTAQUE

DES PARASITES

Nous avons déjà fait remarquer que la spoliation, constante, ne joue qu'un rôle effacé chez les maladies bactériennes.

INTOXICATION

INTONICATION PROPREMENT DITE

Lésions locales. - Nécrose. Toujours secondaire à la multiplication des germes; sèche ou humide, selon la teneur en eau des tissus et de . l'atmosphère; souvent suivie de destruction.

Troubles généraux. - Les anomalies de croissance et l'affaiblissement des végétaux malades tiennent sans doute, pour une part (variable, selon les circonstances), à des phénomènes d'empoisonnement.

\section{IRRITATION}

Hypertrophie et surtout hyperplasie des tissus; formation soit exclusive (tumeurs de l'olivier), soit dominante (crown-gall), de parenchymes indifférenciés. Généralisation du parasite par les 
vaisseaux (tum. de l'ol.); généralisation du néoplasma par continuité (cr.-g.). Parasite extracellulaire (tum. de l'ol.); vraisemblablement intracellulaire (cr-g). Nécrose des néoplasies (tum. de l'ol.); mort liée à une insuffisance d'irrigation (cr-g).

Rappelons que nous admettons parfaitement, dans la formation de toutes les hyperplasies, l'influence, subordonnée, des modifications osmotiques.

Il faut attribuer certainement à un effet d'excitation : le développement prématuré des fleurs, la naissance de racines adventives, la formation du chevelu exubérant qui caractérise le hairy-root.

DESTRUCTION

Les bactéries désintègrent les tissus, après les avoir nécrosés, par le moyen d'enzymes cytolytiques. La pourriture, ainsi produite, revêt d'ordinaire le type humide (soft-rot), parfois le type sec (tumeurs de l'olivier).

Nous avons vu que beaucoup de parasites envahissent électivement le système vasculaire, l'oblitèrent peu à peu et apportent ainsi une gêne croissante au cours des liquides. Cette gêne constitue parfois la cause unique, presque toujours la 
cause essentielle des troubles observés dans les affections correspondantes.

MOYENS DE RÉSISTANCE DES PLANTES

Rappelons que les causes de l'immunité naturelle demeurent encore fort obscures. 


\section{PATHOGÉNIE}

Nous savons que toutes les maladies bactériennes, mentionnées ici, ont été reproduites expérimentalement (piquare des organes; pulvérisations à la surface des feuilles et des fruits; immersion des parties dans les émulsions virulentes).

\section{MODE DE PÉNÉTRATION DES PARASITES}

Les germes peuvent pénétrer par les stomates (affections maculeuses, maladie de Stewart), par les pores aquifères, situés au niveau des dents des feuilles (nervation noire des crucifères, maladie de Stewart), par les nectaires (nécrose du poirier), par des blessures, de cause variée (soft-rots, maladie des cucurbitacées, maladie des solanées, tumeurs de l'olivier, crowngall). Les parasites de blessure ne se développent que s'ils sont portés direclement dans les tissus; les autres croissent à leurs portes d'entrée électives, pourvu qu'ils y rencontrent un degré suffisant d'humidité. 
Aux maladies acquises, dont les agents viennent du dehors, s'opposent les maladies héréditaires, caractérisées par l'infection des graines. Nous n'en connaissons, dans les affections bactériennes, qu'un seul exemple (malheureusement peu étudié), celui qui concerne l'Ardisia crispa (myrsinacée).

Les dents des feuilles, blanches ou jaunes et légèrement tuméfiées, renferment des amas de microbes bien tolérés (pas de nécrose); aussi avait-on jadis pris ces apparences pour des glandes. Les germes, moins abondants chez le reste de la plante, ne font jamais défaut chez les graines, lesquelles demeurent cependant fertiles (Miehe).

E VOLUTION DES ACCIDENTS

Les bactéries qui pénètrent par les stomates ou les pores aquifères, se développent d'abord dans la chambre sous-stomatique. Puis, tantôt elles envahissent les vaisseaux (nervation noire des crucifères, maladie de Stewart), formant ensuite, éventuellement, des foyers ramollis au sein des tissus; tantôt, elles se multiplient entre les cellules des parenchymes, se bornant à les nécroser ou bien les détruisant ultérieurement (affections maculeuses).

Comme exemple de germes pénétrant par les nectaires, rappelons l'histoire du Bac. amylosorus. 
Les parasites de blessure se comportent de façon fort diverse. Les uns désintègrent les parties (soft-rots), faisant d'ordinaire la tache d'huile, mais manifestant parfois une électivité relative pour les vaisseaux. D'autres envahissent d'emblée le système conducteur et déterminent ensuite des lésions destructives des parenchymes, soit localisées (maladie de Cobb), soit étendues (maladie des cucurbitacées, maladie des solanées). Le Bac. oleæ prolifère entre les cellules, dont il amène l'hyperplasie, puis la désingrégation; il se généralise par les vaisseaux. Le Bac. tumefaciens se développe sans doute dans les cellules, dont il provoque seulement l'hyperplasie; le néoplasme s'étend par continuité.

La durée de l'incubation, nous le savons, varie beaucoup selon les maladies. Quant aux causes qui régissent le cours des accidents, leur degré d'extension, leur issue, elles ne diffèrent nullement de celles que nous avons invoquées en parlant des affections cryptogamiques. 


\section{PROPHYLAXIE ET TRAITEMENT}

Prophylaxie. - Identique à celle des maladies cryptogamiques. Rappelons simplement les dangers éventuels de la greffe et de l'émondage (pear-blight, tumeurs de l'olivier).

Traitement. - Pour protéger les organes encore sains, enlever les parties atteintes : feuilles de jacinthe, au début de la maladie jaune; feuilles de chou, au début de la nervation noire... Pendant l'hiver, chez les poiriers qui ont souffert de pear-blight, reséquer les lambeaux d'écorce altérés, où peuvent persister les bactéries spécifiques (Waite a obtenu ainsi de parfaits r'ésultats). - L'emploi des germicides reste toujours délical ; celui des insecticides rendra de grands services. - En somme, le traitement se résume dans l'intervention chirurgicale el la désinfection externe; les effets de cette dernière demeurent, on le sait, fort limités. 


\section{BACTÉRIES SYMBIOTIQUES}

Les bactéries peuvent vivre en "association " avec les levures (képhir, ginger-beer), mais l'exemple classique de "symbiose " est fourni par l'histoire des nodosités radicales des légumineuses. Hellriegel et Willfarth ont établi une relation, aujourd'hui incontestée, entre la fixation de l'azote atmosphérique, la présence des nodosités et la physiologie des bactéries radicicoles. On doit la culture de celles-ci à Prasmowsky, Beyerinck, Béal... et l'étude de leurs effets à Hellriegel et Willfarth, Schloesing et Laurent, Nobbe et Hiltner, Mazé...

Rejetant, ici encore, tout point de vue téléologique, nous considérerons successivement : la maladie bactérienne des racines et ses effets sur la nutrition des plantes infectées.

\section{MALAdIE BACTÉRIENNE DES RACINES}

Elle se traduit, dans les cas typiques, par l'apparition de nodules, d'aspect et de dimensions variables, qui s'accroissent, demeurent stationnaires et dégénèrent finalement. Il s'agit d'une hypertrophie 
énorme des éléments de l'écorce primaire, toujours suivie d'hyperplasie. Les parasites, intracellulaires et très nombreux, offrent au début l'apparence de bacilles, puis affectent des formes diverses et irrégulières, en même temps qu'ils s'entourent d'une gangue muqueuse (bactéroïdes).

L'agent pathogène_(Rhizobium radicicola) vit dans le sol et pénètre par les poils radicaux. Il provoque d'abord l'hypertrophie et la multiplication des cellules, les tue ensuile et les désintegre; bien des parasites nous ont déjà montré pareil mode d'action. Malpighi, qui a décrit le premier les nodosités des légumineuses, les classe, fort justement, parmi les galles. Molliard réalise l'épaississement des radicelles, avec les cultures filtrées du $R h i$ zobinm.

Tel est le cas classique. Mais, selon la virulence des germes, variable qualitativement et quantitativement, on peut obtenir des effets très différents, que nous allons résumer en suivant l'ordre croissant.

Qualilativement partant, certaines races de Rhizobium n'infectent que certaines espèces de légumineuses. Quanlitalivement, voici ce que l'on observe. Virulence nulle : aucun résultal. Virulenee limite: les germes pénètrent, mais sont détrùits rapidement. Virulence faible : formation de nodules, qui se résorbent (au moins partiellement). Virulence optima (par définition) : cas classique. Virulence très grande : si la plante est normale, nodosités et état général médiocre du végétal; si elle est déjà affaiblie, pas de nodosités et dépéris- 
sement progressif (les bactéries, extracellutaires, envahissent alor: les tissus - infection diffuse).

Chez les sujets préalablement inoculés avec une culture de virulence optima, la réinoculation de germes plus actifs augmente le nombre et le volume des nodules; la réinoculation de germes aussi actifs échoue absolument (immunité).

EFFETS SUR LA NITRITION DES PLANTES INFECTÉES

Les bactéries radicicoles fixent "au passage " l'azote de l'air, qui s'est dissous dans les liquides du sol et pénètre avec eux par la sève ascendante. Ciette fixation s'opère sur la gangue muqueuse que forment les parasites (le moment venu) et que le végétal résorbe au fur et à mesure de sa production. Pour que le phénomène classique ait lieu, il faut donc que les germes ne soient ni trop, ni trop peu virulents : dans le premier cas, ils demeurent bacillaires et la sécrétion du mucus fait défaut; dans le second, ils sont détruits prématurément par l'organisme.

Telle est, brièvement résumée, l'histoire des nodosités des légumineuses. Elle paraîtrait moins singulière, tout en gardant son grand intérêt, le jour où l'on montrerail que d'autres parasites exercent également une influence marquée sur la nutrition de leurs hòtes. Or, tout porte à admettre que la chose ne doit pas être rare. 



\section{V}

\section{VUE GENEERALE SUR}

LES MALADIES PARASITAIRES

DES PLANTES 



\section{$V^{\top}$}

Nous nous proposons de faire, pour l'ensemble des affections parasitaires des végétaux, ce que nous avons déjà fait pour chaque groupe en particulier : rechercher, derrière l'extrème variété des apparences, le petit nombre des éléments irréductibles. On se limitera aux maladies des phanérogames, causées: par les métazoaires, phanérogames, champignons et bactéries; le reste ne permet pas, actuellement, une synthèse sérieuse.

\section{CARACTĖRES GENNERTUX DES PARASITES \\ PARASITES FACULTATIFS ET PARASITES STRICTS}

Parasites facultatifs. - Certains organismes peuvent mener " indifféremment " la vie libre ou la vie parasitaire. Reste à savoir si, pour une lignée déterminée, l'existence libre prolongée ne diminue pas l'aptitude pathogène. Il est impossible de le dire a priori. 
Exemples de parasites facultatifs. - Quelques coléoptères, habituellement saprophages, attaquent parfois les végétaux vivants. Le Santalum album évolue, le cas échéant, sans hôte. Les Sclerotinia et les champignons " parasites de blessure » croissent très bien dans le sol. La majorité des bactéries pathogènes également, pense E. Smith.

Parasites stricts. - Certains ne sont dangereux que pendant une partie de leur existence (parasites périodiques), les autres durant toute leur vie ou presque (parasites permanents). Rappelons brièvement les divers groupes de parasites stricts.

Insectes. Un certain nombre de coléoptères; les hémiptères. - Acariens. -Nématodes. Libres seulement au début de la plıase larvaire. - Phanérogames. Certains ne germent que sur l'hôte; les autres périssent rapidements'ils ne rencontrent pas une plante nourricière. - Champignons. Chez les parasites stricts, les tubes de germination meurent bientôt en l'absence d'hôte convenable. - Bactéries. Les agents des nécroses semblent incapables de vivre dans le milieu extérieur,

PARTICULARITÉS UORPHOLOGIQUES ET PHYSIOLOGIQUES DE CERTAINS PARASITES STRICTS

Ces particularités ne sont pas spéciales au parasitisme, mais elles s'y rencontrent avec une fréquence indéniable.

Forme. - Parfois anormale (voire très anormale), surtout en ce qui concerne les organes végétatifs. 
Insectes. Dimorphisme sexuel (coccides). Différence d'aspect entre deux générations alternatives, que l'une comprenne des sexués et l'autre des agames ou que les deux soient constituées par des sexués (cynipides gallicoles). "Dégradation " de nombreuses larves parasites. - Nématodes. Dimorphisme sexuel (genre Heterodera). - Phanérogames. Dégradation habituelle, atteignant son maximum chez les cytinacées.

Appareil reproducteur, fonction reproductrice. Grande fécondité habituelle, s'alliant volontiers à des modifications anatomiques et surtout physiologiques.

Insectes. Parthénogénèse (reproduction sexuée exceptionnelle chez les Rhodites; parthénogénèse cyclique de certains cynipides; parthénogénèse des pucerons cécidogènes). Viviparité(pucerons). - Nématodes. Viviparité éventuelle. - Phanérogames. Réduction habituellement marquée des organes femelles; état peu différencié des embryons. - Champignons. Multiplicité des formes de reproduction chez certaines urédinées.

Résistance aux influences extérieures. - Souvent très prononcée.

Insectes. Grande résistance des œufs fécondés (œufs d'hiver), comparée à la faible résistance des œufs parthénogénétiques. - Nématodes. Résistance deslarves à la dessiccation (genre Tylenchus). - Phanérogames. Longue durée de la faculté germinative des graines. Champignons. Résistance marquée des œufs des péronosporées, des spores des ustilaginées, des téleutospores des urédinées. 
CYCLES DE CERTAINS

PARASITES PERMANENTS

L'évolution complète des parasites permanents se réalise habituellement sur le même hôte, par un développement continu aux points d'élection; quelquefois, cependant, elle a lieu en deux temps, soit sur les mèmes organes, soit sur deux organes différents (cas le plus fréquent). Ailleurs, le cycle nécessite la présence de deux hôtes, d'espèce distincte et éventuellement fort éloignée. Nous renvoyons aux exemples cités antérieurement avec détails (insectes, urédinées).

MODE DE PROPAGATION

L'instinct intervient dans la dissémination des parasites animaux et dans le dépôt de leurs œufs. Partout ailleurs, le hasard reste seul en jeu. (Nous prenons les mots instinct et hasard avec leur sens banal).

Les plantes ou parties de plantes attaquées constituent des agents de propagation redoutables; de même, les fruits et graines des phanérogames parasites. Le rôle des oiseaux, de la pluie, du vent, saute aux yeux.

Pour les parasites "microscopiques", les eaux et fumiers d'une part, les insectes (y compris leurs 
larves), mollusques terrestres et nématodes d'autre part, devront être souvent incriminés.

Bornons-nous à rappeler, en terminant, l'existence du virus " invisible " de la nielle du tabac.

\section{CARACTÈRES GÉNÉRAUX \\ DES MALADIES PARASITAIRES}

Nous distinguons les maladies parasitaires en : locales, localisées, générales. Après avoir justifié cette division par de nombreux exemples, il convient, pensons-nous, de la formuler verbalement. Inutile de définir les affections locales. Les affections localisées traduisent la croissance, pratiquement exclusive, des parasites loin de leur porte d'entrée. Quant aux maladies générales, elles résultent d'un envahissement de la majeure partie (voire de la presque totalité) de l'organisme ou du système vasculaire; elles reconnaissent, uniquement, pour cause les champignons et les bactéries.

Nous ne pensons pas qu'il faille appeler également maladie générale, le retentissement, sur l'ensemble de l'économie, des désordres, soit locaux, soit généraux. Une semblable terminologie manquerait d'autant plus de clarté qu'elle conduirait à admettre des affections " doublement générales", conception ridicule. 
On étudiera, successivement, les signes généraux, les signes locaux et l'évolution des maladies.

\section{SIGNES GÉNÉRAUX}

Tantòt, ils représentent la conséquence directe d'une infection envahissante, tantôt, ils marquent l'effet, sur la totalité de l'individu, d'une attaque plus ou moins circonscrite. Voici comment ils peuvent se manifester.

Aspects anormaux. - Lésions étendues des rameaux, ayant amené leur mort et leur remplacement suivant des types insolites (insectes prédateurs). Destruction du bourgeon terminal (pourriture du cœur de la betterave, maladie de la canne à sucre). Habitus étrange, résultant de l'action directe du parasite et compliqué de stérilité (menthe poivrée basiliquée, euphorbe infectée par l'Uromyces). Inutile de multiplier les exemples.

Arrêts de développement du trpe pseudo-hypertrophique (soi-disant galles organoüdes). - Raccourcissement des entre-nœuds, tassement des feuilles (et des lleurs, quand il ne survient point de stérilité). Tantòt, apparence trapue et ramassée de toute la plante, tantôt, dominance de la déformation soit à la base, soit à l'extrémité de la tige. Causes : insectes spoliateurs, acariens, nématodes, rarement champignons et bactéries.

Etat débile. - Avec nanisme plus ou moins marqué. Bourgeons moins numbreux et pousses 
chétives; feuilles clairsemées, petites, pâles, tombant prématurément chez les feuillus, caduques chez les résineux; fleurs peu abondantes, fruits n'arrivant pas d'ordinaire à maturilé. Conséquence: de l'épuisement général; des lésions sévères des rameaux, tiges, racines; des oblitérations vasculaires accentuées. Les dénudations étendues du feuillage engendrent les mêmes effets, sauf, bien entendu, l'altération des feuilles (disparues). Causes: insectes, nématodes, phanérogames parasites, champignons, bactéries.

Flétrissement, dessiccation. - Généralisés. Plus ou moins rapides et annonçant la mort. Conséquences: de l'épuisement total; de la dénudation complète du feuillage chez les végétaux herbacés; des lésions très étendues des tiges vertes ou des rameaux (jeunes arbres); des altérations très graves du tronc et des grosses branches (arbres adultes); des vastes destructions des racines; des oblitérations vasculaires massives. Causes : insectes, nématodes, cuscute, orobranche, champignons, bactéries.

Noircissement. - Total; stigmate de mort rapide. Chez les jeunes sujets (infoctions généralisées, nécroses progressives).

\section{SIGNES LOCAUX}

Ils font souvent défaut dans le cas des insectes spoliateurs et se traduisent par une ablation pure 
et simple dans celui des insectes prédateurs. Ailleurs, on observe des modifications variées, dues, les unes à l'action directe, les autres à l'action indirecte de l'agent pathogène.

\section{Symptômes traduisant l'action direcle des parasites.}

Lésions nécrotiques. - Affections maculeuses, nécroses proprement dites (champignons, bactéries); rouilles, chancres (champignons).

Pourritures. - Sèches (champignons), généralement humides (bactéries). - Les insectes (surtout leurs larves), les acariens et les nématodes déterminent volontiers une désintégration des tissus profonds, qui ne diffère en rien de la pourriture.

Cécidies. - Tous les types de parasites peuvent en produire. Les entomocécidies, qui contiennent les formes les plus différenciées, demeurent souvent intactes pendant longtemps. Les nématocécidies sont rapidement détruites par leurs agents. De mème, pour la plupart des mycocécidies (exception : les hypertrophies pures, cloque du pécher, pochettes du prunier). Les bactériocécidies dégénèrent à un moment donné; désintégrées par le parasite (tumeur de l'olivier) ou " victimes " de leur irrigation insuffisante (crown-gall).

Développements anormaux: - Apparition de racines adventives; croissance prématurée de bourgeons dormants (balais de sorcière, hairy root); 
formation d'organes reproducteurs inatlendus, aux dépens de rudiments minimes.

Symptòmes dûs à l'action indirecte des parasites.

Parties situées au-dessus des lésions. - (Organes aériens). Déformations variées, débilité, flétrissement; dessiccation.

Parties situées au-dessous des lésions. - Atrophie des organes souterrains, lors d'altérations étendues du fcuillage.

Chez les végétaux malades, le parasite se voit ou non du dehors. Dans le premier cas, il peut frapper immédiatement les yeux (plantes couvertes de coccides, plantes infestées par le gui et la cuscute); ailleurs, on doit le rechercher avec soin. Dans le second cas, il échappe forcément, soit en raison de son siège profond (intérieur des tissus), soit en raison de sa localisation au niveau des parties souterraines. Il n'est pas rare que l'agent pathogène masque les lésions qu'il a produites d'emblée ou après quelque temps.

\section{ÉVOLUTION DES ACCIDENTS}

Ce qui suit s'applique surtout aux maladies cryptogamiques et baclériennes. Après une incubation de durée très variable, les accidents apparaissent, tantòt brusquement, tantòt rapidement, 
tantôt lentement. Début brusque ne veut pas dire, ipso facto, infection brutale, comme le montre l'histoire des oblitérations vasculaires et celle de certains pourridiés.

Puis, l'infection suit un cours différent selon les circonstances. Nous avons montré ce que sont les maladies aiguës, subaiguës et chroniques; il nous faut, maintenant, tenter de les définir. Dans les maladies aiguës, l'évolution se compte par semaines (voire, par jours); dans les maladies subaiguës, par mois; dans les maladies chroniques, par années (une maladie chronique ne saurait durer moins d'un an). Il est impossible d'apporter plus de précision en l'espèce; à idée vague, formule quelque peu flottante. Les maladies chroniques des plantes comportent habituellement de longs entr'actes (sommeil hivernal de l'hôte), auxquels elles doivent leur physionomie spéciale.

Les affections parasitaires se terminent, le moment venu, par la guérison ou la mort. La guérison entraîne toujours des pertes de substance, que des régénérations peuvent compenser dans une mesure fort diverse. Elles laissent souvent le sujet définitivement affaibli.

Bornons-nous à rappeler les métastases, caractéristiques des tumeurs bactériennes et mentionnons les infestations ou infections secondaires.

Comme conséquence des lésions quils provoquent, les parasites ouvrent souvent la porte à d'autres agents, de même nature ou de nature diffé- 
rente; il s'ensuit des désordres complexes, d'une interprétation quelquefois fort difficile. [Certains gros parasites, mème sans déterminer d'altérations notables, inoculent aux plantes des champignons ou bactéries palhogènes].

$L \dot{E} S 10 N S$

Nous laisserons de côté les pertes de substance que produisent les insectes prédateurs, ainsi que leurs divers modes de cicatrisation et les régénérations qui peuvent s'ensuivre.

On se limitera donc aux lésions "véritablement parasitaires ". Les voici, brièvement résumées.

Lésions nécrotiques. - Aboutissant de dégénérescences variées et assez mal connues. Sèches ou humides, selon la teneur en eau des tissus et de l'atmosphère. L'escharification sèche se traduit par l'apparence indistincte du contenu des éléments anatomiques, lequel brunit et se rétracte; la paroi brunit ensuite. Les parties atteintes, privées d'eau, reviennent sur elles-mêmes et se fissurent volontiers. L'escharification humide, également caractérisée par l'aspect homogène des cellules, ne saurait s'accompagner de rétraction; elle peut aboutir au ramollissement et à la désintégration passive des tissus, sans aucune ingérence microbienne. Les foyers nécrosés sont quelquefois limités par la formation d'assises subéreuses.-Dansleschancres,

Nicollz et Magrov. - M. P. des plantes. 
on observe des alternatives pathognomoniques de mortification et de cicatrisation (bourrelets).

Pourritures. - Les parasites digèrent souven les tissus (qu'ils ont éventuellement hyperplasiés et toujours tués, avant de les détruire). Ici encore, le processus affecte soit la forme sèche, soit la forme humide, suivant les circonstances. La pourriture sèche (champignons) débute d'ordinaire par la dissolution des lamelles moyennes, moins fréquemment par celle des membranes cellulaires internes. Les éléments anatomiques s'émiettent, le volume global des parties diminue et l'on voit apparaître des lacunes pleines d'air. Dans la pourriture humide (bactéries), même mécanisme essentiel, mais en milieu gorgé d'eau; les tissus " fondent " et leurs débris flottent au sein de cavités remplies de liquide; l'ouverture extérieure de la " collection " n'est pas rare. - La disparition des cellules de l'hôte, que déterminent les phanérogames parasites, diffère de la pourriture en ce que les éléments sont résorbés au fur et à mesure de leur désintégration; il s'agil donc d'une suppression totale. Les cellules du parasite se substituent " automatiquement" aux cellules de l'hòte.

Cécidies. - Caractérisées par l'hypertrophie et surtout l'hyperplasie des tissus. Plins ou moins compliquées dans leur structure. -- Les erineums constituent de simples hypertrophies des poils La majorité des galles apparaissent formées d'un parenchyme indifférencié : cellules riches en eau, 
offrant des membranes minces et des noyaux volumineux, contenant parfois beaucoup d'amidon, rarement beaucoup de chlorophylle (le contraire est de règle); vaisseaux peu nombreux, larges, à parois minces. Ces productions sont souvent détruites par leurs agents mêmes; elles peuvent aussi périr avec l'organe qui les porte ou par suite d'irrigation insuffisante. - Certaines cécidies offrent, périphériquement, des éléments scléreux, qui s'épaississent encore davantage quand l'évolution du parasite s'est terminée. Les galles de l'Heterodera radicicola contiennent, avons-nous $\mathrm{vu}$, des cellules géantes multinucléées, d'origine vasculaire, etc. - Mais le type le plus parfait de cécidies réside dans les galles des cynipides. Inutile de décrire à nouveau leur couche nourricière, leur anneau de sclérenchyme, leurs canaux d'irrigation...; rappelons seulement que des assises subéreuses les isolent, le moment venu.

Il convient de noter que, suivant $\mathrm{E}$. Smith, on doit considérer la crown-gall comme une "cécidie maligne ". De même, pour les "embryomes ", découverts par cet auteur.

Quelques mots sur le róle des saisseanx et leurs altérations. On sait que le système conducteur des phanérogames parasites s'anastomose avec celui de l'hôte. On vient de parler de la vascularisation des galles. Dans certaines maladies cryptogamiques et surtout bactériennes, l'agent pathogène 
offre une affinité spéciale pour les vaisseaux; il les oblitère et détruit fréquemment leur paroi, donnant alors naissance à des foyers métastatiques (nécrose et surtout désintégration). Dans la maladie de l'olivier, " cécidie bénigne ", le bacille de Savastano envahit également les vaisseaux, les altère et forme, au voisinage, des tumeurs secondaires. (Rappelons, encore une fois, que les métastases de la crown-gall se font par continuité).

En dehors des lésions directes, les parasites peuvent déterminer, on l'a vu, des altérations indirectes de nature très simple. L'inanition et la compression limitées engendrent l'atrophie des éléments anatomiques (avec diminution des réserves, décoloration des parties vertes...). L'inanition excessive conduit au collapsus, à la dessiccation, à la mort (locale ou générale).

MÉCANISME DES MALADIES PARASITAIRES

VIRULENCE DES PARASITES

Nous avons défini la virulence, la "végétabilité in vipo " et nous lui avons reconnu un double aspect, qualitatif et quantitatif. Le premier répond à la notion très claire d'électivité et apparaît nettement chez tous les parasites. Le second 
répond à la notion de dose active minima, laquelle manque de précision quand il s'agit de gros parasites.

Rappelons, en ce qui concerne le côté qualitatif, que des espèces d'un même genre offrent souvent des aptitudes pathogènes fort diverses et que, dans une même espèce, se rencontrent parfois des races exclusivement caractérisées par leur électivité (cécidomyie destructrice, divers Chermes, gui, puccinie du blé, certains Erysiphes, Uromyces pisi). A l'électivité, pour tout ou partie d'une plante donnée, se rattache la question des cycles (" électivité alternante ", pour deux organes du même végétal ou pour deux végétaux distincts).

$\mathrm{La}$ nature de la virulence demeure obscure. Qualitativement, elle apparaît en rapport avec les besoins nutritifs du parasite (formule un peu vague malheureusement) et avec son insensibilité à certaines substances hostiles (indication bien insuffisante). Et quantitativement?...

On sait que la virulence des champignons et bactéries pathogènes se conserve plus ou moins longtemps in vitro, selon les cas.

SENSIBILITÉ DES PLANTES

Locale ou générale; liée à l'espèce, la race, l'âge....

Les expériences de Pierce, Massee, Miyoshi, 
confirment l'idée, d'ailleurs naturelle, que la composition chimique des sucs joue un ròle important. Mais les cellules vivantes diffèrent grandement de nos milieux de culture; les substances « nuisibles " y voisinent avec les substances "utiles " et les proportions respectives des deux varient sous l'influence des réactions, presque inconnues, des éléments anatomiques. On sait que les organes ou plantes jeunes offrent d'ordinaire une extrême sensibilité au regard de " leurs " parasites; il semble légitime de voir, dans la teneur en eau et dans l'abondance et la varićté des substances présentes, la cause de cette extrême vulnérabilité.

[Les conditions ambiantes se montrent tantôt favorables, tantòt défavorables à l'infection par les parasites microscopiques. Elles agissent sur ceux-ci, sur l'hôte ou sur les deux, suivant les circonstances. Il est incontestable que l'humidité, la chaleur, l'ombre excessive, l'encombrement jouent un rôle considérable dans l'éclosion et la dissémination des maladies cryptogamiques et bactériennes].

MOYENS D'ATTAQUE DES PARASITES

Laissant de côté les insectes prédateurs, nous rappellerons que les parasites spolient, intoxiquent, détruisent. 


\section{SPOLIATION}

Dans certains cas, elle est purement mécanique : les hémiptères et acariens sucent directement les liquides cellulaires; les phanérogames parasites pompent la sève brute de l'hôte, grâce aux anastomoses qui relient leurs vaisseaux et les siens.

Partout ailleurs, il s'agit d'un processus en deux temps, de nature surtout chimique. Le parasite secrète des enzymes appropriés, qui vont solubiliser les réserves des éléments anatomiques voisins, puis résorbe les substances devenues ainsi mobilisables. Avec ces substances, dénuées de spécificité biologique de par leur caractère simple, il constitue sa matière vivante propre. (Notons que les spoliateurs animaux accomplissent le même travail, dans leur tube digestif, aux dépens des sucs déglutis).

Les phanérogames parasites offrent les deux types d'action spoliatrice : ils assimilent la sève brute, que puisent les vaisseaux et le contenu cellulaire, que puisent les suçoirs.

De nombreuses larves d'insectes, habitant les parenchymes et surtout les cécidies, divers nématodes, beaucoup de champignons et quelques bactéries - développés dans les tissus normaux ou hypertrophiés (sous leur influence), se nourrissent, au moins pro tempore, en pratiquant la spoliation par les enzymes; ils détruisent ensuite le plus souvent les cellules. 
La spoliation, comme telle, offre peu d'importance pour l'hôte, quand il s'agit des bactéries et même des champignons. On lui attribue exclusivement les arrêts de développement à forme pseudohypertrophique, la stérilité, l'état débile, le collapsus mortel - quand il s'agit des insectes, acariens, nématodes, phanérogames; nous espérons montrer bientôt que cette opinion paraît trop absolue.

\section{INTOXICATION}

Nous distinguons, on le sait, l'intoxication proprement dite et l'irritation formative.

\section{Intoxication proprement dile.}

Lésions locales. - De nature nécrotique. Elles frappent, suivant les cas, des cellules normales, des cellules hyperplasiées, des cellules plus ou moins épuisées.

Empoisonnement général. - La spoliation nous semble insuffisante pour rendre compte, seule, des troubles dont nous avons parlé tout à l'heure, car leur gravité se montre souvent hors de proportion avec les pertes subies. Il paraît indiqué, croyonsnous, de faire intervenir alors le facteur " empoisoinement général ", commc explication toute naturelle. Deux raisons légitiment celte manière de voir : d'abord, l'existence habituelle de la propriété toxigène chez les parasites; ensuite (et surtout), les 
manifestations asșez communes de cette propriété, chez les plantes atteintes, sous forme de taches nécrotiques.

\section{Irritation formative.}

Elle se traduit, tantòt par de simples développements anormaux (que nous nous contentons de mentionner), tantôt par des cécidies et même des "cécidies malignes ". Il est impossible, depuis Malpighi, de ne pas attribuer la production des galles (largo sensu) à des "venins " (toxines). Cette manière de voir admet d'ailleurs le rôle, subordonné, des modifications osmotiques.

Tout indique que les toxines " malpighiennes" se confondent avec les toxines "ordinaires " et que c'est bien le même poison qui, émis d'une façon brusque et abondante, engendre la nécrose des tissus et qui, sécrété d'une façon continue et discrète, détermine leur hypertrophie. L'évolution, variable, des cécidies ne saurait se comprendre autrement. Interprétons-la, dans cette hypothèse.

La majorité des champignons eécidogènes provoque exclusivement la multiplication des cellules, tant que le développement mycélien suit un cours régulier. La croissance du parasite s'accélère ensuite, au moment de la formation des organes reproducteurs; la vitalité s'exalte; toxines et enzymes sont élaborés avec énergie et occasionnent la mort et la digestion des tissus néoformés. - 
La désintégration des tumeurs de l'olivier survient quand les bactéries sont devenues très nombreuses. Dans la crown-gall, où les parasites demeurent toujours rares, la néoplasie ne succombe qu'à l'in suffisance de son irrigation. - Les nématodes se comportent en réalité comme les champignons. - Les insectes et acariens, au contraire, cessent peu à peu de sécréter leur "venin " et les galles s'éteignent. Pour certains cynipides, le schéma peut même être absolument inverse de celui que fournissent les cryptogames. Les hyménoptères en question forment leur cavité larvaire par nécrose et digestion des tissus, puis, tout se calme, l'intoxication devient purement formative et s'arrête, le moment venu.

Il nous semble que l'histoire des cécidies, ainsi comprise, satisfait pleinement l'esprit.

\section{DESTRUCTION}

Toujours consécutive à la mort des cellules. Elle revêt deux types distincts. Dans le premier, les tissus sont totalement résorbés (cas des phanérogames parasites). Dans le second, l'utilisation ne va pas de pair avec la destruction; de ce "gaspillage ", résulte, la persistance de lésions plus ou moins étendues (pourritures).

[En résumé, les parasites spolient et détruisent par leurs enzymes, intoxiquent et irritent par leurs poisons]. 
MOYENS DE RÉSISTANCE DES PLANTES

- L'immunité naturelle, mal connue dans sa nature, apparaît liée, avons-nous dit : à la résistance des tissus, à l'absence de matériaux nutritifs convenables, à la présence de corps nuisibles. Mais on ne saurait parler de résistance absolue, puisque certains parasites peuvent, soit forcer les obstacles mécaniques, soit se contenter d'aliments médiocres, soit encore demeurer indifférents à des substances habituellement toxiques (ou les neutraliser).

Le plus bel exemple d'immunité naturelle est celui des vignes américaines, dont les racines résistent au phylloxera. La résistance se transmet à la graine, mais le greffon ne l'acquiert pas.

L'immunité contre certaines maladies cryptogamiques peut être obtenue par sélection.

Les parasites demeurent extérieurs ou pénètrent dans le végétal, dont on les voit souvent ressortir, à un moment donné, sous des formes très diverses : animaux, adultes ou non, qui s'échappent activement; fructifications cryptogamiques, qui s'effleurissent sur les parties mortes; glaire bactérienne, habituellement mêlée de débris cellulaires, qui traverse les stomates ou les perles de substances. Les 
phanérogames sont d'ordinaire implantés dans leurs hôtes, comme ceux-ci dans le sol; les cytinacées, dissimulées sous l'écorce, laissent sortir périodiquement au dehors des fleurs parfois énormes. Derrière cette extrême variété d'allures, se cachent les quelques facteurs simples dont nous venons de parler.

Pour le démontrer, prenons comme exemple les infections cryptogamiques et bactériennes, réduites à leurs traits essentiels. Les parasites pénètrent de façon fort diverse : envahissant les blessures, passant par les stomates, dissolvant les cuticules. Ils se comportent ensuite de manièreencore plus variée. Tantôt, le développement des germes reste localisé; tantôt ces germes s'étendent au loin, demeurant inoffensifs tant qu'ils n'ont pas trouvé leur organe d'élection; ailleurs, ils infectent toute la plante, qui périt rapidement; ailleurs enfin, ils se cantonnent dans le système vasculaire, dont ils peuvent sortir sur certains points, déterminant des métastases de nature variable. - Ici, on observe des dégénérescences, là, des hyperplasies, éventuellement malignes. Suivant les circonstances, les maladies sont aiguës ou lentes. -- Certaines affections tuent, d'autres permettent la guérison. - Tout dépend, en dernière analyse, du parasite et de l'hôte. Le premier agit par son électivité, son énergie de croissance, ses sécrétions. "Au départ ", la plante résiste plus ou moins, par ses propriétés normales; elle 
demeure ensuite passive, la plupart du temps, mais peut se défendre : par le sommeil hivernal, par lá formation d'assises subéreuses et, certainement aussi, par des réactions humorales (de nature inconnue).

Rappelons, en terminant, que certaines maladies sont héréditaires.

Nous ne reviendrons pas sur la prophylaxie des maladies parasitaires des plantes, ni sur le traitement, toujours externe.

\section{QUESTION DE LA SYMBIOSE}

Envisagée sans aucune arrière-pensée extrascientifique, ta symbiose (cryplogames, bactéries) ne saurait être séparée de l'infection. Fort souvent, d'ailleurs, les agents, dits symbiotiques, déterminent des affections, soit abortives, soit au contraire très graves. Dans l'unique cas où s'établit un équilibre, plus ou moins durable, entre le parasite et son hôte, il peut en résulter, pour ce dernier, des conséquences anatomiques et physiologiques bien connues aujourd'hui (depuis les travaux de N. Bernard et de Hellriegel et Willfarth, particulièrement) : germination des graines, formation du protocormus, formation du bulbe (orchidées); formation du tubercule (pomme de 
terre); état vivace (toutes les plantes à mycorrhizes); fixation de l'azote atmosphérique (légumineuses). Ces conséquences offrent le plus grand intérêt, mais ne comportent aucun caractère mystérieux.

Nous devons, aux recherches sur la symbiose, certaines observations précieuses, concernant l'immunité des plantes, ainsi que la destruction intracellulaire des parasites (due, selon N. Bernard et nous, à de véritables anticorps). L'étude approfondie de ces questions offrirait une importance capitale. [Picado a publié, récemment, des recherches sur les anticorps végétaux, qui méritent d'être vérifiées et poursuivies]. 


\section{TABLE DES MATIĖRES}

Avatt-Propos ................ . . . . . .

\section{I. - MALADIES DES PLANTES DUES AU.Y ANIMAU.Y}

Maladies dutes atx INSECTES. . . . . . . . . 15

Insectes parasites en général. . . . . . . . . 15

Forme . . . . . . . . . . . . 16

Reproduction .............. 17

Parthénogénèse . . . . . . . . . 18

Cynipides cécidogènes. . . . . . . . . . 18

Pucerons cécidogènes . . . . . . . . . . . 19

Cycle du Cynips calicis. . . . . . . . . . 21

Cycle des Chermes (Adelges). . . . . . . . 21

Insectes phytophages . . . . . . . . . . . 22

Enumération (principaux types). . . . . . . . 22

Diptères . . . . . . . . . . . . 22

Hémiptères(homoptères) . . . . . . . . . . 22

Lépidoptères . . . . . . . . . . . . 23

Hyménopteres. . . . . . . . . . . . 23

Coléoptères.............. . . . . .

Orthoptères. . . . . . . . . . . 24

Effets. . . . . . . . . . . . 24

Prédateurs ............. . . 2. 2

Lésions des feuilles. . . . . . . . . . . 23

Lésions des fleurs, fruits, graines. . . . . . . . 26

Lésions des rameaux . . . . . . . . . . 26 
Lésions des tiges herbacées et des troncs ligneux. 27

Lésions des racines . . . . . . . . . . . 28

Spoliateurs . . . . . . . . . . . 29

Mécanisme de l'infestation .......... 30

Electivité des parasites. . . . . . . . 30

Sensibilité des plantes .......... . . 31

Moyens d'attaque des parasites. . . . . . . . 31

Moyens de résistance des plantes . . . . . . 32

Insectes cécidogènes. . . . . . . . . . . . 33

Enumération (principaux types). . . . . . . . 33

Diptères . . . . . . . . . . . . 33

Hémiptères. . . . . . . . . . . . 33

Lépidoptères . . . . . . . . . . . . . . 34

Hyménoptères. . . . . . . . . . . 34

Coléoptères.............. 34

Effets. . . . . . . . . . . . . . 35

Etude des galles............ 35

Siège. . . . . . . . . . . . . 35

Forme . . . . . . . . . . . . . 36

Galles développées en surface . . . . . . . . . 36

Enroulements et plissements. . . . . . . . 36

Galles en bourse. . . . . . . . . . . . 37

Galles développées en profondenr . . . . . . 37

Tumeurs.............. . 37

Productions plus différenciées. . . . . . 38

Structure ............... . 4 41

Euroulements et plissements......... 41

Galles en bourse. . . . . . . . . . . . . 41

Tumeurs superficielles. . . . . . . . . . . 41

Tumeurs profondes et galles bien différenciées . 42

Autres effets des insectes cécidogènes . . . . . 43

Mécanisme de la cécidogénèse. . . . . . . . . 44

Electivité des parasites. . . . . . . . . 44

Sensibilité des plantes . . . . . . . . . . 44

Moyens d'attaque des parasiles . . . . . . . 45

Moyens de résistance des plantes. . . . . . . 46

Cécidogénèse . . . . . . . . . . . 4 46 
Prophylaxie et traitement . . . . . . . . . . . . 49

Maladies dees aux Acariens . . . . . . . . 31

Action spoliatrice ................... 51

Action cécidogène. . . . . . . . . . . . 52

Erineums. . . . . . . . . . . 52

Galles profondes ............. 52

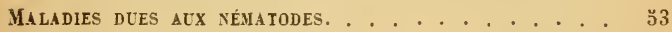

Spoliateurs . . . . . . . . . . . . . 53

Destructeurs. . . . . . . . . . . . . วั

Cécidogènes. . . . . . . . . . . . . . \$5

Parasites des feuilles . . . . . . . . . . s̆

Parasites des fruits. . . . . . . . . . . 55

Parasites des racines. . . . . . . . . . . . . . 56

\section{II. - MALADIES DES PLANTES} DUES AUX PHANEROGAMES

Principales plantes parasites. . . . . . . . . 61

Descriptiox somatre des parasites et de letrs efFets. 62

Parasites des ramifications principales. . . . . . . . 62

(iui. . . . . . . . . . . . . . . 62

Parasites des tiges. . . . . . . . . . . . . . . . . . 63

Cuscutes ................ . . 63

Parasites des racines . . . . . . . . . . . . 66

Rhinanthées. . . . . . . . . . . . 66

Orobanches . . . . . . . . . . . . 66

Cytinacées . . . . . . . . . . . Bi

Méchisisue de t'infestation. . . . . . . . . 68

Électivité des parasites. . . . . . . . . . . . 68

Sensibilité des plantes . . . . . . . . . . . . . 68

Moyens d'attaque des parasites . . . . . . . . . . . 69

Moyens de résistance des plantes . . . . . . . . . . 70 


\section{III - MALADIES DES PLANTES DUES AUX THALLOPHYTES}

Principaux champignons pathogènes . . . . . . . 77

Enumération ............... . . 77

Basidiomycètes ............. . . . 77

Hétérobasidiès . . . . . . . . . . . 78

Homobasidiés. . . . . . . . . . . . . . 78

Ascomycètes. . . . . . . . . . . . . 78

Oomycètes . . . . . . . . . . 80

Yyxomycètes ............. . . 81

Habitat. . . . . . . . . . . . . . 81

Agents de propagation. . . . . . . . . . . . 83

Pritcipales affections Cryptogamletes. . . . . . . 84

Maladies aiguës et subaiguës. . . . . . . . . . . . 84

Maladies locales................ 84

Affections des parties aériennes. . . . . . . 84

Fumagines . . . . . . . . . . 84

Blancs . . . . . . . . . . . 85

Rouills. . . . . . . . . . . . 85

Mildious ................. . 86

Autres affections maculeuses (pourriture grise et black-rot de la vigne) . . . . . . . . . 88

Affections des racines . . . . . . . . . . 89

Hernie du chou. . . . . . . . . . . . . 89

Maladies localisées. . . . . . . . . . . . 90

Charbons . . . . . . . . . . . . 90

Charbons des céréales. .......... . . 9 90

Charbon des caryophyllées . . . . . . . 9 91

Carie du blé. . . . . . . . . . . . . 91

Rouilles blanches............ . . . 92

Maladies générales. . . . . . . . . . . . . 93

Infections massives. . . . . . . . . . . 9 93

Maladies vasculaires. . . . . . . . . . . . 93

Pourriture du cceur de la betterave . . . . . . 93 
Flétrissement du melon d'eau, du cowpea et du colonnier. . . . . . . . . . . . 94

Nécroses progressives (dues aux Sclerotinia). . 95

Affections dues à la S. libertiania. . . . . . . . 9 9̆

Affections dues à la S. trifoliorun . . . . . . . 96

Affections dues à la S. bulborum. . . . . . . . 96

Muladies chroniques. . . . . . . . . . . . . . . 97

Affections des parties aériennes. . . . . . . . 97

Nécroses: Rouille courbeuse du pin sylvestre. . 97

Chancres: Chancre du mélèze. Chancredes arbres fruitiers . . . . . . . . . . . . . . 98

Pourritures: Pourritures du bois dues aux gros champignons .............

Hypertrophies: Cloque du pêcher. Pocheltes du prunier. . . . . . . . . . . .

Balais de sorcière: Balais du cerisier. Chuudrons et balais du sapin pectiné . . . . . . . . . 101

Affections des racines . . . . . . . . . 103

Pourritures (pourridies) : Pourriture due atc Polyporus annulosus. Pourriture due à l'Armillaria mellea. Pourriture due à ln Rosellinia necatrix.

Maladie de l'Euphorbia cyparissias due à l'Uromyces pisi.

MÉCANISME DE L'IYYFECTION.

Parasites facultatifs et parasites stricts.

Virulence des parasites (stricts).

Aspect qualitatif.

Aspect quantitatil .

Sensibilité des plantes .

Influence des conditions ambiantes.

iloyens d'attaque des parasites.

Intoxication . 
Irritation . . . . . . . . . . 112

Destruction ............... 113

Moyens de résistance des plantes . . . . . . . . 113

Pathogénie . . . . . . . . . . . . 114

Infections expérimentales. ......... 114

Mode de pénélration des parasites. . . . . . 115

Evolution des accidents. ......... 116

Affections aiguës, subaiguës et chroniques. . . . 116

Affections locales, localisées et générales. . . . . 117

Cas curahles, cas mortels. . . . . . . . . 118

Prophylaxie et tratenent .......... 120

Champignons symbiotiques. ........... 121

Champignons et orchidées ......... 121

Germination des graines. . . . . . . . . 122

Formation du tubercule embryonnaire (protocormus). . . . . . . . . . . 123

Formation du bulbe. . . . . . . . . . 124

Mécanisme de l'infection. . . . . . . . . . 124

Champignons et pomme de terre . . . . . 126

Champignons des mycorrhizes. . . . . . . . . 127

Conclusions. - Cas des lichens . . . . . . . . 129

\section{IV. - MALADIES DES PLANTES DUES AUX BACTÉRIES}

Principales bactéries pathogènes. . . . . . . . 134

Caractères. Énumération. . . . . . . . . 134

Habitat. . . . . . . . . . . . . . 133

Agents de propagation. . . . . . . . . . . 135

Principales affections Bactériennes. . . . . . . 137

Maladies aiguës ou subaiguës . . . . . . . . . . . . 137

Maladies locales. . . . . . . . . . . . 137

Affections maculeuses . . . . . . . . . 137

Des feuilles. . . . . . . . . . . . . 137

Des fruits. . . . . . . . . . . . . . . 138 
Pourritures humides. . . . . . . . . . 139

Des racines, tubercules, fruits . . . . . . . . 139

Maladies générales. . . . . . . . . . 140

Nervation noire des crucifères. . . . . . . 140

Maladies des cucurbitacées (wilt-flétrissement) . 141

Maladie jaune des jacinthes. . . . . . . . . 142

Maladie du maïs de Stewart. . . . . . . . . 142

Maladie des solanées (brown-rot) . . . . . 144

Maladie de la canne à sucre de Cobb. . . . . . 145

Maladies chroniques ............ 146

Maladies locales . . . . . . . . . . 146

Nécroses ............. 146

Nécrose du poirier. . . . . . . . . . 146

Nécrose du mûrier. . . . . . . . . . . . 146

Maladies générales. . . . . . . . . . 147

Tumeurs . . . . . . . . . . 147

Tumeurs de l'olivier. . . . . . . . . 147

Crown-gall. . . . . . . . . . . 148

MÉCANiSue de L'infection . . . . . . . . . 152

Parasites facultatifs et parasites stricts. . . . . . . . 152

Virulence des parasites. . . . . . . . . . . 153

Sensibilité des plantes. . . . . . . . . . . . 153

Influence des conditions ambiantes. . . . . . . . 153

Moyens d'attaque des parasites. . . . . . . . . . . 154

Intoxication. ................ 154

Intoxication proprement dite . . . . . . 154

Irritation . . . . . . . . . . . 154

Destruction . . . . . . . . . . . 155

Moyeris de résistance des plantes. . . . . . . . . 130

Pathogénie . . . . . . . . . . . . 157

Mode de pénétration des parasites. . . . . . . . . . 157

Evolution des accidents. . . . . . . . . . 158 
Phophylaxie ET TRAITEMENT . . . . . . . . . 160

BACTF́RIES SYMBIOTIQUES . . . . . . . 161

Maladie bactérienne des racines . . . . . . . . . 161

Effets sur la nutrition des plantes infectées. . . . . . . 163

\section{Y. - VUE GÉNÉRALE SUR LES MALADIES PARASITAIRES DES PLANTES}

Caractères gévéraux des parasites. . . . . . . . 167

Parasites facultatifs et parasites stricts. . . . . . . . 167

Particularités morphologiques et physiologiques de certains parasites stricts. . . . . . . . . . . 168

Cycles de certains parasites permanents. . . . . . 170

Mode de propagation . . . . . . . . . . 170

CARACTÈRES GÉNÉRAUX dEs MaLAdIES PARASITAIRES. . . . 171

Séméiologie. . . . . . . . . . . . . . 171

Signes généraux. . . . . . . . . . . . . . . 172

Signes locaux. . . . . . . . . . . . . . 173

Symptômes traduisant l'action direcle des parasites. 17t

Symptômes traduisant l'action indirecte des parasites ............. 175

Evolution des accidents. . . . . . . . . . 175

Lésions. . . . . . . . . . . . . . . $17 T$

Méchisue des MaladieS PARASITAIREs. . . . . . . 180

Virulence des parasites. . . . . . . . . . . 180

Sensibilité des plantes . . . . . . . . . . 181

Moyens d'attaque des parasites . . . . . . . . . . 182

Spoliation. . . . . . . . . . . . 183

Intorication. . . . . . . . . . . 184

Intoxication proprement dite. . . . . . 184

Irritation formative . . . . . . . . 185 
Destruction . . . . . . . . . . . . . 186

Moyens de résistance des plantes. . . . . . . . . . . 187

Pathogénie . . . . . . . . . . . . . 187

QUeSTION DE LA SYMBiose. . . . . . . . . . . . . . 189

Coulommiers. - Imprimerie E. Dessaint. - 3.22.

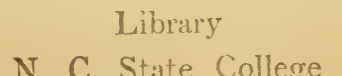





\section{-MASSON ET CIR, ÉDITEURS}

\section{LIBRAIRES DE L'ACADÉMIE DE MÉDECINE}

120, BOULEVARD SAINT-GERMAIN, PARIS

\section{Mars 1922.}

\section{NOUVEAU TRAITÉ DE MÉDECINE}

PUBLIÉ SOUS LA DIRECTION DE MM. LES PROFESSEURS
G.-H. ROGER
F. ШТDAZ
P.-J. TEISSIER

Secrétaire de la Rédaction: Marcel GARNIER

Le Nouveau Traité de Médecine formera : 22 FASCICULES grand in- $8^{\circ}$, avec nombreuses figures 22 dans le texte, en noir et en couleurs, et planches hors texte en couleurs, sous une élégante $1 / 2$ reliure toile dos plat.

\section{Fascicules parus:}

FASCICULE I. Maladies infectieuses. I vol. de 482 pages avec $55 \mathrm{fig}$. dans le texte et 3 planches en coul., reliê. $35 \mathrm{fr}$. not

FASCICULE II. Maladies infectieuses (suite). I vol. de 765 pages avec 89 figures et 8 planches en couleurs. $50 \mathrm{fr}$. net

FASCICULE III. Maladies infectieuses (suite). I vol. de 564 pages, $62 \mathrm{fig}$. et 4 pl. en couleurs, relié. . . $40 \mathrm{fr}$. net

Toute commande de liures doit être accompagnée de snn montant en uno valeur sur paris augmenté de $111 \%$ nour frais de onrt et d'emhallaae. 
FASCICULE IV. Maladies infectieuses et parasitaires. I rol. de 709 pages avec 134 figures dans le texte et 5 planches en couleurs, relié.. . . . . . . . . . 40 fr. net

FASCICULE V. Maladies infectieuses et parasitaires ( fin). - Cancer. I vol. de 740 pages alec 335 figures el 4 planches en couleurs........... 50 fr. net

FASCICULE VI. Intoxications. 1 vol. de 506 pages avec $23 \mathrm{fig}$. dans le texte et + planches en couleurs, relie. $35 \mathrm{fr}$. net

FASCICULE VII. Avitaminoses. Maladies par agents physiques. Troubles de la nutrition. I vol. de 552 pages avec figures, relié.

35 fr. net

Pour paraitre incessamment :

FASCICULE VIII. A/fections des glandes endocrines. Troubles du développement.

(Sous presse.)

FASCICULE XV. Alpections des gtandes salivaires, du pancréas et du pẻritoine. . . . . . (Sous presse.)

Tout le labeur de cette magnifique période médicale que fut la fin du XIX siècle avait été condensé dans le monumental Traité de Médecine de Charcot-Bouchard-Brissaud, dont l'apparition marqua de son empreinte toutes les générations médicales

de cette époque et rayonna bien au delà de nos frontières.

Si la médecine française de la fin du XIX siècle fut grande, non moins brillante est la période actuelle, et une génération qui, dans la série des grands progrès médicaux actuels, occupe une place de premier rang, ne pouvait que donner au monde une œuvre forte et s'acquitter brillamment d'un lourd héritage.

On a voulu, dans ce Traité, apprendre au Médecin dans quel cas il doit recourir aux nouvelles méthodes d'exploration, et comment il doit interpréter les résultats qui lui sont communiqués. On a voulu surtout, en expliquant le mécanisme des troubles, en fournissant des explications indispensables au diagnostic, donner les indications du traitement: Le Nouveau Traité de Médecine fait une très large part à la Thérapeutique, àl'Ilrgiène, àla prophiflaxic. 


\section{PLAN DU FASCICULE I}

G.-H. ROGER. Notions générales sur les Infections. A. SACQuéPéE. Les Septicémies. - G.-H. Roger. Les Streptococcies. - P. Menetrier et H. Stévenin. Pneumococcie. P. Menetrier et H. Stévenin. Pneumonie. - M. Macaigne. Staphylococcie. Entérococcie. Psittacose. Infections à Tétragènes. à Cocco-bacilles, à Diplobacilles, à Protéus. - A. Veillon. Infections putrides et gangreneuses. - Ch. Dopter. Méningococcie. - M. Hudelo. Gonococcie.

\section{PLAN DU FASCICULE II}

P.-J. Teissier et II. Duroir. Scarlatine. - P.-3. Teissier. Rubeole. Quatricme malatie, Cinguieme malatie. Rougeole. Varicelle. Irariole. - P.-J. Terssier et L. Tavon. Vaccine. Paul Ravater. Le Zona, les Herpès el les Fières herpétiques. - P.-J. llevard. Fière aphtellse. - Jules Rexielt. Suelle miliaire. - G.-HI. Roger. Charbon. - Charles Nicolde et E. Coxsen. Typhus exanthématique. - P. Loxde. Coqueluche. - P.-J. Teissier et Eisuen. Oreillons. - E.-C. Avir.anket, B. Weill Halué, P.-L. Mirie. Diphtéric. - J. Camus et J.-J. Gourray. Tétanos. - M.-H. B.ARBIER. Le Rhumatisme arliculaire aigu. - H. DE Brus. Dengue, Fière de Papataci.

\section{FASCICULE III}

F. Widal, A. Lenierre et P. Abrami. Fièvres typhoĩde $t$ t paratyphoïdes. - F. Widal 'et A. Lemierre. Colibacillose. Ch. Dopter. Dysenteries. - M.-A. Ruffer et Milton CrendiRopoulo. Choléra. - SACquépéE. Botulisme. Fièvre de Malte. - R.-P. Strong. Fièvres des tranchées. - P. Menetrier et H. Stévenin. Grippe. - E. Sacquépée et Garcin. Peste. - Azevedò Sodré. Fièrre jaune.

\section{FASCICULE IV}

Ch. Dopter. Maladie de Heine-Medin. - May. Encephalile léthargique. - FERrÉ. Rage. - H. Roger. Tuberculose en général. - P. COURmont. Septicémiles tuberculeuses. - H. ROGER. Pseudo-Tuberculoses bacillaires. - P. Coursont et A. Defourt. Morve. - Perrin. Lèpre. - Guiart. Verruga. - Laederich. 
Actinomycose. Aspergillose. - Langeron. Oosporoses. Mycétomes. Sporotrichoses. Blastomycoses. - Brumpt. Spirochétoses en général. - Nicolas. Syphilis.

\section{PLAN DU FASCICULE V}

R. Denavent. Chancre simple. Ciranulome des organes genitaux. - Cir. Jorecx. Goundou, Pian et Bouba. - Charles Nicolle et L. Blaizot. Fièves récurrentes. - D. Thibaut. Sodoku. - H. Tricext et J. Riexx. Le paludisme. La Fière bilieuse hémoglobinurique. - Cimarles Nicolle. Kala Azar, Bouton dOrient. - Cin. Jortux. Trichinose - J. Guiart. Filariose, Strongylose, Distomatose, Coccitiose, Sarcosporidiose. F. Dévé. Echinococcose, Crsticercose. - E. BRuMPt. Les Trypanosomoses humaines, les Bilharioses.

Gilstave Roussy et Malrice IVolf. Le Cancer.

\section{FASCICULE VI}

H. Roger. Intoxications en général. - Pinard. Saturnisme. Intoxications par le cuivre, l'étain, le zinc. - BALTHAzARD. Phosphorisme. Arsenicisme. Hydrargyrisme. Intoxications par l'oxyde de carbone, le gaz d'éclairage, l'hydrogène sulfuré, le sulfate de carbone, les hydrocarbures. - CLERC et L. RAMOND. Intoxications par les gaz de guerre. - Triboulet et Mignot. Alcoolisme. - Rénon. Caféisme et théisme. - Dupré et J.-B. Loure. Intoxications par l'opium et ses dérivés, la cocainc, le chanvre indien, l'èther. - ReNon. Tabagisme. -. Thibaut. Inloxications diverses. - SACQUĖPÉE. Intoxications alimenlaires. - Langeron. Intoxications par les champignons. - RÉnon. Intoxications par le Kawa. - GARNiER. Intox. par l'acide picrique.

\section{FASCICULE VII}

G.-H. Roger. Vitamines et Avitaminoses. - E.-P. Benolt. Scorbul. - G. ARAOz Alfaro. Scorbut infantile. - Aldo Perroncito. La Pellagre. - E. Sacquépée. Béribéri. A. Calmette. L'Intoxication par les venins; la sérothérupie.PH. Pagniez. Maladies determinces par l'Anaphylaxie. - PauL Courmont. Maladie Serique. - J.-P. LANGlors et LÉon Binet. Maladies par agents physiyues. - PaUl LE Gendre. Troubles et maladies de la nutrition. 


\section{Précis de Pathologie médicale}

par F. BEZANCON, MARCEL LABBÉ, LiON BERNARD, J.-1. SICARD A. ClERC, P. Emile WEILL, PHILIBERT, S.-I de JONG, A. SEZARY, ('h. FOIX, PASTEUR V.ALLERY-RADOT, G. VITRY, Marcel BLOCH.

\section{DE L.I COLLECTION IOES I'RÉCIS IEEDICALI}

Sera complet en ", volumes yui se ventront brochés $120 \mathrm{fr}$. et cartonnés $150 \mathrm{fr}$. Chaque volume se ventra séparément, broché $20 \mathrm{fr}$. el cartonné $25 \mathrm{fr}$.

\section{TOME IV}

Maladies du sang et des organes liématopoiétiques, par P. EnHLe Went, medecin de Thôpital Tenon et MArcer. Buocir, chef de Lahoratoire il la Faculté de Paris.

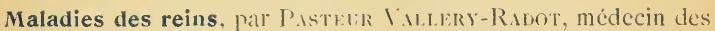
Hoppitaux de Paris.

I volume te 628 pages, 1 .no fierures, + planihes en conlenrs. Broche. $20 \mathrm{fr}$. ('xrlomne. $25 \mathrm{li}$.

\section{TOME V}

Maladies de l'appareil digestif et de la nutrition, par IARCEI. LABвÉ, professeur à la Faculté de Médecine de Paris, médecin de l'hopital de la Charité et G. Vitrs, ancien chef de clinique a la Faculté de Médecine de Paris.

I rolume te 7 go pages, 31 h figlures. a planches en couleurs. Broché. $20 \mathrm{fr}$. Carlonné. $25 \mathrm{fr}$.

\section{AUTRES TOMES A PARAITRE}

Tome I. Maladies Infectieuses et Intoxications par F. Bezançon, Philibert. Léon Bernard.

Tome II. Maladies de l'appareil respiratoire par F. Bezançon et S. I. de Jong.

Tome III. Maladies du cœur et des vaisseaux par M. A. Clerc.

Tome VI. Maladies du Systeme nerveux par MI. Sicard et Ch. Foix Glandes endocrines par A. Sezary. 


\section{IAC АРЕेRE}

Med.cin de Saint-Lazare.
Ch. ZAURENT

dedecin des hôpitaux de Saint-Étienne.

\section{Le traitement de la Syphilis} par les composés arsenicaux

3. ÉDITION REVUE ET AUGMENTÉE

1 volume te 238 pages. ............ 8 fr. net

Dans ce petit volume, la partie théorique est résolument D sacrifiée à la pratique, et cette troisième édition est très modifiée : les divers traitements au mercure, bismuth, etc., sont comparés, la médication est exposée en détails, un chapitre spécial est réservé à l'emploi des divers arsenobenzines : toutes ces données permettent d'envisager le fonctionnement d'un laboratoire sérologique à peu de frais. Des nouveaux chapitres sont consacrés à la vie sociale du syphilitique : critérium de guérison. mariage, traitement des femmes enceintes, etc.

$\mathcal{P}_{\text {aul }} \boldsymbol{R} \mathcal{A} \mathcal{V} \mathcal{A U T}$

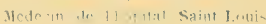

Syphilis,Paludisme,Amibiase

Le traitement d'attaque et les traitements secondaires (Préventif, abortif et d'entretien)

1 volume de $22+$ proes.

(pour paraitre en mai 1922)

CE livre est le manuel de la a cure de blanchiment s pour trois $\cup$ maladies dont l'érolution clinique suit des règles communes. Le blanchiment a ses règles propres. 11 ne peut cependant pas être envisagé sans rues bien nettes sur le traitement ultérieur. ("est pour cela que ce rolume expose également avec tous les détails nécessaires les cures secontuires. Les traitements préventifs et abortifs font l'objet de chapitres spéciaux. 


\section{A. CHAUTF ARD \\ Professeur à la Faculté de Mlédecine de Paris. \\ Medecin de I'horital Saint-Antoine \\ Hembre de 1 Academie de médecine. \\ La Lithiase biliaire}

\section{DEUXIÈME ÉDITION}

1 rolume de 21 : pages arec 24 planches hors terte . . 20 fr. net

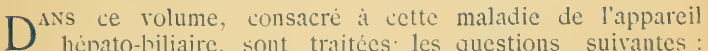
pathogenie clinique de la lithiase hiliaire. Role de l. infection. Róle de l'hypercholestérinémie. Les calculs biliaires. Les réactions vésiculaires. La colique hèpatique. Les lésions vésiculaires l'origine lithiasique. Le radiodiagnostic de la lithiase biliaire. Diagnostic des états douloureux d'origine vésiculaire. Diagnostic topographique des calculs biliaires. L'èlimination intestinale des calculs biliaires. Les traitements.

\section{Georges GUTLLATN}

Professeur acrècé a la Faculté de médecine de Paris.

Iledecin de l'hópital de la Charité.

Membre de filcatinic is medecine.

Guy LAROCHE

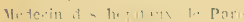

P. LÉCHELLE

\section{La réaction \\ du benjoin colloïdal \\ et les réactions colloïdales du liquide céphalo-rachidien}

1 bolume de 1 fo prges, 30 figures et 4 planches hors terte. $12 \mathrm{fr}$, net

I a reaction du benjoin colloïdal permet aussi bien que la L réaction de Wassermann de faire rapidement le diagnostic de la syphilis érolutive du système nerveux. Les auteurs ont exposé dans ce volume la technique de leur réaction colloïdale du liquide céphalo-rachidien, son intèrêt et les résultats acquis. 


\section{LÉON BERNARD}

Professeur à la Faculté de Médecine de Paris.

Mlédecin de l'hòpital Laënnec.

Membre de l'Academie de Hédecine.

\section{La Tuberculose pulmonaire}

Etudes de Phtísiologie clinique et sociale

I volume de 258 pages .......... 10 fr. net

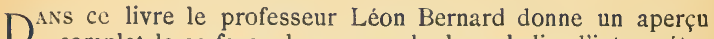
D complet de sa façon de comprendre la maladie, d'interpréter sa physionomie clinique si diverse, de formuler ses méthodes de traitement et ses modes de prévention.

\section{TIANOEL DE ABREU \\ Radiodiagnostic}

\section{dans la Tuberculose Pleuro-Pulmonaire}

I vol. de 168 pages avec 31 figures dans le texte et 16 planches radiographiques hors texte originales. . . . $15 \mathrm{fr}$. net

E livre, écrit sous les auspices du Docteur Rist et dans les C Services de l'Hôpital Laënnec, est le fruit d'une collaboration particulièrement intéressante du point de vue clinique pur et de la technique radioscopique la plus perfectionnée.

\section{L'Armement antituberculeux}

\section{en France}

Publié par le Comité national de défense contre la tuberculose I volume de 303 prges . . . . . . . . 10 fr. net 


\section{Louis TIMBAL}

Préparateur à la Façulté de mèdecine de l'Université de Toulouse.

\section{Les diarrhées chroniques}

Étude clinique, coprologique et thérapeutique

Préface du docteur J.-C'In IRLEs ROI'X.

1 rolume de 2 -o pages arec figures. . . . . . . . 12 fr. net

I'Auteur consacre plus de la moitié de l'ouvragè à la desL cription des types cliniques de la diarrhée : d'origine mécanique (trouble cardiaque), toxiques (renales), parasitaires (amihiase), spécifiques (syphilis, tuberculose), d'origine intra-intestinales (dyspeptiques, infectieuses).

C'ette importante partie est précédee et suivie d'un crposé complet des méthodes de dixgnoslic et de traitement.

Thierry DE MARTEL et $\dot{E}$ doward ANTOINE

Les fausses appendicites

Étude clinique, radiologique et thérapeutiques des Syndromes douloureux du crecum et du colon proximal

Préface du docteur R. BENSAUDE.

1 volume de lin pages avec 29 figures et io planclies. . $10 \mathrm{fr}$. net

E diagnostic des syndromes douloureux du cxcum est diffiL cile car, en dehors des appendicites chroniques, on observe fréquemment des lésions cæcales; or il est important de pouvoir décider entre le traitement médical et le traitement chirurgical; on trouvera dans ce volume toutes les méthodes d'examen clinique, radiologique et hématologique nécessaires. 


\section{DIDE et P. GUTRATUD}

Médecins de l'Assistance d'aliénés de Braqueville.

\section{Psychiatrie}

du

\section{Médecin pratícien}

\section{DE LA a COLLECTION DU MÉDECIN PRATICIEN ,}

1 volume de 416 pages in-80, avec 8 planches hors lexte. . 20 fr. net

CETTE psychiatrie s'adresse spécialement au médecin non spécialiste; une grande part acite faite à la description clinique, l'exposé des doctrines a été très objectivé, des catégories ont été délimitées nettement, et, dans chaque cas, les auteurs indiquent ce que praliquement, le médecin devra faire.

\section{CHEINTSSE}

Chargé du "Mouvement Thérapeutiquen dans la Presse Medicale, Ancien Rédacteur de la Semaine Mcdicale.

\section{L’Année Thérapeutique}

A NNÉE 1920

I volume de I 44 pages.

6 fr. net

ANNÉE 1921

I volume de 160 pages. . . . . . ...... 6 fr. net

$\mathrm{E}^{*}$ créant ce recueil rraiment international, le docteur CheiE nisse a cherché à faciliter au praticien la tâche qui lui incombe de se tenir au courant des progrès réalisés dans l'art de guérir. L'auteur a groupé toutes les acquisitions de l'annie sur le traitement de l'arythmie, l'asthme, la coqueluche, le diabète, la lievre typhoïde, l'insuffisance cardiaque, la syphilis et de nombreuses autres affections.

Ine place importante a été faite à la technique thérapeutique, à ses nouveautés et perfectionnements. 


\section{Questions Neurologiques}

\section{d'actualité}

Vingt conférences faites à la Faculté de Médecine de Paris en 1921 sous la direction de

\section{M. le Professeur Pierre Marie}

1 rolume de 5.52 pages arec $14^{2}$ figures. . . . . 28 fr. net

Liste des conferrences:

S. A. Kinvier Wilson. Sur quelques questions de pathogénie, de diagnostic et de physiologie pathologique it propos de la dégrénération lenticulaire progressive.

Cil. Chatelin. Les tumeurs cérébrales.

II. CLAUDE. L'hypertension intra-cranienne et les méningites sèreuses.

G. Roussy. Les troubles sensitifs d'origine cérébrale.

Gieorges Gicillin. Les lésions traumatiques de la moclle.

J. Liermitte. L'encéphalite léthargique.

A. Soveues. La paralysic agitante, ses rapports arec le sindrome parkinsonien post-encéphalo-lèthargique.

L. BABONNEIx. Les encéphalopathies infantiles.

A.NRÉ LÉRI. Les atrophies musculaires syphilitiques.

PaUL S.IIXToN. Le goitre exophtalmique.

J.-A. SiCARD. Les algies et leur traitement.

O. Crouzox. Les maladies familiales atypiques.

Poulard. Les modifications de la pupille.

Cir. Forx. L'automatisme médullaire.

L.IIGNEL-LaristiNe. Les psychoses thyroïdiennes.

Cir. Verpss. Petits syndromes mentaux. Les obsédés.

Georges Bourguignon. La chronaxie.

Ilexri Bouttier. L'état de mal épileptique.

P. BĖHate. L'épilepsie traumatique.

Pierre Mlarie. Existe-t-il, chez l'homme, des centres préformès ou innès du langage. 


\section{André ТНОЖАS}

Mlédecin de l'Hópital Saint-Joseph.

Vice-Président de la Socièté de Biologie.

\section{Le Réflexe Pilo-Moteur}

\section{Etude Anatomo-Clinique sur le Système Sympathique}

1 volume de 242 pages avec 74 figures et 12 planches en noir et en couleurs. . . . . . . . . . . 25 fr. net

Cer ouvrage est le résultat de travaux nombreux d'ordre $C$ clinique et anatomique et constitue une documentation précieuse consacrée à la plus récente acquisition de la Neurologie française; il intéresse la Sémiologie et la Physiologie de l'ensemble du système sympathique.

Les Cliniciens comme les Neurologistes et les Physiologistes seront intéressés par cet ouvrage.

\section{R. LUTEMB $\mathcal{A} C H E R$ \\ Les nouvelles Méthodes \\ d'Examen du Cour \\ en Clinique}

I vol. de 186 pages, avec 138 figures originales. 20 fr. net

Es méthodes graphiques et la radioscopie sont le complément L indispensable de l'examen clinique dans l'étude des cardiopathies. Ce sont des méthodes d'exploration fonctionnelle.

Dans la première partie du livre sont réunis 75 tracés originaux, chacun d'eux est progressivement déchiffré avec le lecteur, qui apprend ainsi à identifier chaque type d'arythmie. Ensuite sont

décrites les épreuves nécessaires pour préciser leur nature.

La deuxième partie est réservée à l'interprétation des schémas radioscopiques. En regard de chacun d'eux se trouve la photographie des pièces anatomiques correspondantes. 


\section{ARMAND-DELTLLE et NĖGRE}

\section{Techniques du Diagnostic} par la Méthode de

\section{Déviation du Complément}

Avec utilisation spéciale de la méthode de Calmette et Massol $2^{*}$ Étilion refondue.

1 rolume in-8 de 200 pages. . . . . . . . . . . 9 fr. net

$C^{E}$ manuel est destiné non seulement à indiquer les dispositions générales de l'expérience et les doses à employer pour obtenir les réactions que nécessite la méthode de déviation du complément, mais à donner en même temps le détail des procédés de récolte et de conservation des différents éléments de la réaction; aussi bien qu'une série de recettes de manipulations qui permettent d'éviter nombre de causes d'erreur.

M. BRULÉ

Ancien Interne des Hópitaux.

('hel de Laborature a la Faculté de Medecine.

\section{Recherches}

\section{sur les Ictères}

1 volume in 8 de 280 pages. $3^{\circ}$ édition ...... $9 \mathrm{fr}$, net

I E Dr Brulé a cherché à justifier l'intérét qu'on a porté à cet L ouvrage en tenant successivement les nouvelles éditions au courant des principales recherches qui ont éte effectuées récemment sur les icteres, tant en France quà l'ètranger. Aussi bien ces faits nouveaux sont-ils signalés dans cette troisième édition, quı contient 100 pages de plus que la première. 


\section{P. NOBÉCOURT}

professeur agrégé à la Faculté de Mèdecine de paris.

Mlédecin des Hôpitaux.

\section{Conférences pratiques \\ sur l'alimentation \\ des Nourrissons}

1 volume de 318 pages. - 3e étition remaniée. . 18 fr. net

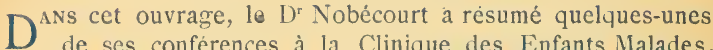
On y trouvera exposé d'une façon simple et précise toutes les notions qu'un médecin doit posséder s'il veut diriger judicieusement l'èlevage de ses nourrissons.

Les précédentes éditions de ce livre n'ont pas seulement eu la faveur des étudiants français, mais aussi celle des étrangers qui en ont fait plusieurs traductions.

\section{V. Ж АLLІСН}

Professeur agrégé

a la Faculté de Hédecine de Paris.

\section{Éléments \\ d'obstétrique}

QUATRIEME EDITION REFONDUE

1 vol. de 7og pages arec 180 figures dans le texte. . 26 fr. net

$\mathrm{C}^{\mathrm{E}}$ manuel contient, sous un volume réduit, tout l'enseigne- ment de l'Obstétrique. On y trouvera trois parties: Obstétr $i$ que normale, Pathologie obstétricale, Opérations, toutes les matières que l'on est en droit de demander à un manuel, expo-

sées avec un souci tout particulier de la pratique.

En ce qui concerne les réactions humorales provoquées par la grossesse normale ou pathologique; les nouveaux traitements de la syphilis au cours de la puerpéralité, la chirurgie obstétricale, l'allaitement artificiel, cette édition a étẹ très remaniée. 


\section{P. NOBÉCOURT}

Prufegseur de clinique medicale des enfants

à la faculte de médecine de Paris

Medecin de l'hopital des Enfants Malade:

\section{Précis de}

\section{Médecine des Enfants}

\section{QUATRIEME EDITION}

1 lol. de 1022 puges arec 220 figures. . . Broché. $30 \mathrm{fr}$. net
Cartonne. $\mathbf{3 4} \mathrm{fr}$. net

$C^{E}$ livre sadresse aux ètudiants et aux médecins qui désirent trouver, dans un petit nombre de pages, les principaux élèments de la médecine des enfants.

L'auteur s'arcẹte assez longuement sur les maladies quion observe dans le jeune âge, les plus communes et les plus intéressantes à connaître pour la pratique journalière. Il insiste sur l'étude clinique et, toutes les fois qu'il est nécessaire, sur l'étiologie et la palhogénie, sur la prophylaxie et le traitement. Par contre, pour ne pas trop ètendre les dimensions de ee Précis il a été aussi bref que possible sur la bactériologie et l'anatomic palhologique, sauf dans les cas où elles présentent une importance spéciale.

\section{E.virait de la table:}

Maladies de la bouche. des glandes salivaires, du nez. du pharyux.

Maladies de l'oesophage, de l'estomae et de l'intestin.

Maladies du foie, de la rate, du pancrias. du péritoine et des ganglions mésentériques.

Maladies du larynx, de la trachee, des bronches, des poumons, des plerres, des ganglions tracheo-bronchiques.

Maladies de l'appareil circulatoire.

Maladies de l'appareil urinaire.

Maladies du sang, de la moelle osseuse, des ganglions lymphatiques, des glandes vasculaires sanguines, de la nutrition.

Maladies du systeme nerveux.

MIaladies infectieuses générales,

Mémento diètétique. - Némento thèrapeutique. 


\section{Eugène TERRIEN}

incien chef de clinique infantile

de la Faculté à l'hòpital des Enfants Malades.

\section{Précis d'alimentation}

\section{des nourrissons}

QUATRIÈME ÉDITION REVUE ET AUGMENTÉE

1 rolume in-8 de 309 pages. . . . . . . . . . . 12 fr. net

\section{Précis d'alimentation des jeunes enfants du sevrage à 10 ans}

1 vo'ume in- 8 de fo.j pages.

$14 \mathrm{fr}$. net

EST une proplylaxic şénérale infantile en mème temps $\checkmark$ qu'un guide de l'alimentation normale et pathologique que forment les deux rolumes publiés simultanement par le Docteur Terrien.

Ces livres ont été écrits pour permettre au Métecin de guider les mères dans leur délicate tàche quotidienne et, au besoin, pourront, avec les indications nécessaires, être mis entre leurs mains. Les volumes comprennent deux parties: la première consacrée à l'alimentation de l'enfant bien portant, et contenant, en quelques formules faciles à retenir, les règles d'un bon régime; la deuxième concernant l'alimentation de l'enfant malade, et dans laquelle on trouvera surtout l'exposé dés régimes qu'il convient d'instituer dans chaque cas particulier. 


\section{A. MARTINET

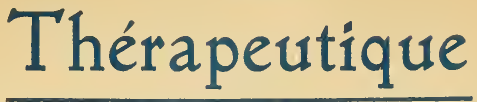

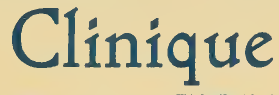

Avec la collaboration de

MM G. LAURENS, DESFOSSES, Léon MEUNIER, LOMON, LUTIER, MARTINGAY, MOUGEOT et SAINT-CENE.

2 vol. in $-8^{\circ}$ formant ensemble 1340 pages avec 312 figures dans le texte et de nombreux tableaux. . . . . . . 70 fr. net

CE volume est le complément logique et nécessaire du « Dia-

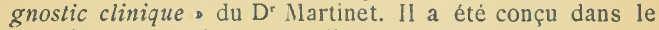
même esprit « pragmatique ,, réalisé typographiquement, dans des conditions identiques. Les deux volumes ne constituent, à proprement parler, qu une même cuvre : un manuel de pratique médicale d'un plan essentiellement nouveau, adéquat aux exigences cliniques. - La méthode générale d'exposition est la même dans les deux ouvrages, et constitue une synthèse entıe les nécessités de l'exposé scientifique et l'aspect concret que

présentent les cas particuliers de la pratique.

4 PART1Es : Agents thérapeutiques, techniques therapeutiques, lhérapeutique des symptómes, thérapeutique des malaties.

\section{Diagnostic Clinique}

avec la collaboration des Docteurs : DEsFossis, G. LAUREN, LÉON MEUNIER, LUTIER, SAINT-CÈNE, TERSON QUATRIB̈MB ÉDITION EN PRÉPARATION

I vol. grand in-8 de 10.40 pages avec une riche illustration de 851 figures dont 3i en couleurs.. . . . . . 55 fr. net

I A première partie du Manuel apprend à examiner le malade. L La deuxième, dans le but d'éclairer la clinique, étudic tous les symptômes sous la forme où ils s'observent. 


\section{Gaston IYON}

Anclen Chef de Clinique médicale à la Fazulté de Paris.

\section{Traité élémentaire}

de

DIXIEME EDITION

1 fort volume grand in-80 de 1840 pages, broché. . . . 65 fr. net Relie toile.................. 70 fr. net

UTRE les modifications nécessitées par l'étude des maladies relatives notamment aux maladies de l'oesophage, aux spasmes de l'estomac, aux ptoses, aux tachycardies, à la poliomyélite aiguë,

à l'encéphalite léthargique, au traitement de la syphilis.

\section{G. IYON}

Ancien Chef de clinique

à la Faculté de Médecine.
P. LOISEAน

Ancien préparateur a l'École Supérieure de Pharmacie.

\section{Formulaire Thérapeutique}

\section{2. Édition}

I volume de 863 pages . . . . . . . . 25 fr. net

CETte nouvelle édition du Formulaire a été revisée avec soin. velles et les modifications apportées au codex de 1908 par le supplément de 1920. 


\section{G. MARION}

Prolesseur agrégé à la Faculté de Médecine de Paris.

Chirurgien du service Civiale (llòpital Lariboisière).

\section{Traité d'Urologie}

2 vol. grand in-8 formant ensemble 1050 pages, avec 418 figures en nour et en couleurs dans le texte et 15 planches hors texte en couleurs formant 81 figures. Reliés toile. $120 \mathrm{fr}$. not

Tout ouvrage traitant d'une spécialité est nécessairement 1 médico-chirurgical. Mais l'Urologie est de tous les domaines de la mèdecine celui où les activités parallèles ou convergentes du Médecin et du Chirurgien sont le plus directement intéresscies. Le livre du $\mathrm{D}^{\mathrm{r}}$ Marion se présente comme un Traité complet d'Urologie et embrasse à la fois la description clinique des maladies, les procédés d'examen, d'exploration et de diagnostic, l'anatomie pathologique, enfin et surtout le traitement médical et la technique de l'intervention chirurgicale ; c'est dire qu'il s'adresse non pas seulement au spécialiste des maladies des voies urinaires, mais encore à tout médecin qui veut éclairer ou enrichir sa pratique de toutes les connaissances qui dans le domaine restreint d'une spécialité évoluent si vite et gagnent chaque jour en précision, en sécurité et en efficacité.

Robert HENRY

André DEMONCHY

\section{Manuel \\ d'Urétroscopie \\ Préface du D* Marion}

Professeur agrégé à la Faculté. Chirurgien de l'hòpital Lariboisiere.

I vol. de I16 pages avec 56 figures dans le texte et 30 figures hors texte en couleurs.......... 25 fr. net 


\section{F. LEJ TRS \\ Traité de \\ Chirurgie d'Urgence}

\section{HUITIÈME ÉDITION}

I vol. de 1 I 20 pages, grant in- $8^{\circ}$, arec I 100 figures dans le texte, en noir et en couleurs, et 20 planches hors texte en deux tons Broche, sous couverture forte. . . . . . . 75 fr. net Edition de luxe sur beau papier couche, relie toile pleine, fers spéciaux, en deu.r volumes. . . . . . $90 \mathrm{fr}$. net I a paru de ce traité huit éditions françaises et six étrangères 1 souvent rééditées. Tous les chapitres ont été revus d'après l'expérience acquise et les données nouvelles, entre autres sur les plaies viscérales, les grands écrasements, les hémorragies, les fractures, etc.

А-C. GUTLLАนМЕ

\section{Les Occlusions}

\section{aiguës et sub-aiguës de $1^{\dagger}$ Intestin}

Clinique, expérimentation, théra peutique

I rolume de 304 pages arec 21 figures. . . . . 12 fr. net

Es divers chapitres de ce volume, illustrés de nombreuses L figures schematiques et de tableaux sont consacrés : $1^{\circ}$ à l'anatomie pathologique générale; $2^{\circ}$ au tableau clinique et aux formes particulières de locclusion; $3^{\circ}$ au pronostic; $4^{\circ}$ au diagnostic; $5^{\circ}$ à la pathologie expérimentale; $6^{\circ}$ au mécanisme des aecidents et de la mort au cours de l'ileus; $\tau^{\circ}$ aux méthodes de traitement médical et chirurgical. 


\section{BRACHET}

Professeur à l'Université de Bruxelles

Correspondant de l'Institut.

\section{Traité d'Embryologie}

\section{des Vertébrés}

I volume de 602 pages avec 567 figures.. . . . . 60 fr. net

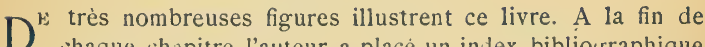
chaque chapitre l'auteur a place un index bibliographique des ouvrages les plus spécialement utilisés et les plus récents. Le lecteur y trouvera un exposé historique des questions traitées.

La partie génerale est consacrée aux premières phases de l'ẻvolution ontogenétique des vertébrés et à l'établissement des grandes lois fondamentales dont elles sont la conséquence.

Dans la partie spéciale, les chapitres qui ont un intérêt proprement embryologique sont exposés avec ampleur.

\section{H. F. OSBORN}

\section{L'origine et l'évolution \\ de la vie}

Edition française avec préface et notes

par Félix SARTIAUX

I volume de 304 pages avec 126 figures. . . . . 25 fr. net L'Auteur, H.-F. Osborn, a tourné d'une façon convergente les L sciences les plus diverses sur le problème des origines et l'a éclairé ainsi d'une lumière nouvelle.

11 possède à la fois les connaissances particulières et ce goût des idées génèrales nécessaire à un tel travail : géologue, paléontologiste et biologiste, c'est l'un des maitres les plus éminents et les plus populaires des Etats-Unis d'Amérique. 


\section{COLLECTION DE PRÉCIS MÉDICAUX}

\section{G.-H. ROGER}

Professeur à la Faculté de Médecine de Paris

\section{Introduction à l'Etude de la Médecine =}

$7^{\circ}$ édition. 1 vol. de 812 pages, broché. 22 fr. net; cartonné. 25 fr. net

\section{H. ROUVIERE}

Professeur agrégé, Chef des travaux anatomiques à la Faculté de Médecine.

\section{Anatomie et Dissection =}

Tome 1. $-3^{\circ}$ édition: Téte, cou, membre supérieur.

Tome 11. $-3^{3}$ édition : Thorax, abdomen, bassin, membre inférieur. Chaque volume...... Broche 22 fr. net; cartonne 25 fr. net

\section{POIRIER}

Professeur d'Anatomie à la Faculté.

\section{BAUMGARTNER}

Ancien Prosecteur

\section{Dissection =}

$4^{\circ}$ édition. I vol. de xxir-36o pages, avec $24 \mathrm{I}$ figures dans le texte. Broche .... $10 \mathrm{fr}$. net; carlonne.... $12 \mathrm{fr}$. net

\section{G. WEISS}

Professeur à la Faculté de Paris.

\section{Physique biologique $=$}

$4^{\circ}$ édition, $56_{4}$ pages, 584 figures.

Broché. . . . $11 \mathrm{fr}$. net

Cartonné..... $13 \mathrm{fr}$. $\overline{\text { net }}$

\section{Aug. BROCA}

Profésseur d'operations et appareils à la Faculté de Médecine de Paris.

\section{Précis de Médecine Opératoire}

$2^{\circ}$ didition. 510 figures dans le texte, broché. . . . . . $14 \mathrm{fr}$. net. cartonni.... $16 \mathrm{fr}$. $\overline{\text { net. }}$ 


\section{COLLECTION DE PRECIS MEDICALY (SUite)}

\section{Précis de Pathologie Chirurgicale}

PAR MM. P. BÉgOUIN, H. BOURGEOIS, P. DUVAL, GOSSET, E. JEANBRAU, LECÈNE, LENORMANT, R. PROUST, TIXIER

Professeurs aux Facultés de Paris, Bordeaux, Lyon et Montpellier.

TROISIÈME ÉDITION, REVUE ET AUGMENTÉE

Tomf I. - Pathologie chirurgicale générale, Tissus, Crine et Rachis. 1152 pages et 387 figures.

Tome II. - Téte, Cou, Thorax. 890 pages et 385 figures.

Tome III. - Glandes mammaires, Abdomen, Appareil génital de l'homme, 1068 pages el 320 figures.

Tоме IV. - Appareil urinaire, Gynćcologie, Fractures et luxations, Affections des membres, 1162 fages et 384 figures.

Prix de chacun desvolumes: Broché. 25 fr. net Cartonné toile. 28 fr. net

\section{ARTHUS}

Professeur de Physiologie à l'Université de Lausanne.

\section{Physiologie $=$}

6. édition. I vol. de 978 pages et 326 figures. Broché. . 25 fr. net Cartonné. . $28 \mathrm{fr} . \overline{\mathrm{net}}$

\section{ARTHUS}

\section{Chimie physiologique $=$}

$9^{\circ}$ edition. I vol. de $4 \Sigma_{2}$ pages, 115 fig., et 5 planches. Broché. . $20 \mathrm{fr}$. net; Carlonné. $22 \mathrm{fr}$. net

\section{ARTHUS}

\section{Physiologie Microbienne $=$}
$1 \mathrm{rol}$. de 408 pages. Broché. . . . . . . . . . . . 17 fr. Cartonné. . . . . . 19 fr.

Nouveluté: Les ouvrages de Physiologie du professeur Arthus ont toujours obtenu un succès complet daris le monde des Etudiants. Ce précis a été écrit spécialement pour eux afin qu'ils aient sous la main un manuel plus expérimental que la plupart des ouvrages de biologie et de microbiologie analogues 


\section{COLLECTION DE PRECIS MËDICAUX (Suile)}

\section{LA АМBIING}

Professeur à la Faculté de Médecine de Lille.

\section{Biochimie $=$}

3e Édition, 1 vol. de 408 pages. Brochẻ. . 25 fr. Carlunné. 27 fr.

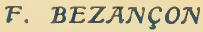

Professeur à la Faculté de médecine de Paris.

\section{Microbiologie Clinique =}

3. édition. 600 pages, 200 figure:, 7 planches en couleurs. Broché. . . 30 fr. net - Cartonné. . . 35 fr. net

\section{IH. LANGERON}

Cher de Laboratoire à la Faculté de Médecine de Paris.

\section{Microscopie =}

3. édition. 1 vol. de 916 pages avec 292 figures. Broché. . . $30 \mathrm{fr}$. net Carlonné. . $\mathbf{3 4}$ fr. $\overline{\text { net }}$

\section{L. $B A R D$}

Professeur de clinique médicale à l'Universite.

\section{Examens de Laboratoire employes \\ en Clinique}

$4^{*}$ edstion. 1 vol. in-8 de 830 pages avec 162 figures. Bro.he. 32 fr. net

Carlonné. 35 fr. $\overline{\text { net }}$

\section{A. RІСНАนD}

Professeur agrégé a la Faculté de Médecine de Paris. Docteur es sciences.

\section{Thérapeutique et Pharmacologie}

5• édilion. I vol. de 1016 fages, broché. $27 \mathrm{fr}$. net; carlonné. $30 \mathrm{fr}$. net

\section{J. COURMONT}

Professeur d'hygiène à la Faculté de Médecine de Lyon.

\section{Précis d'Hygiène}

$2^{\circ}$ édition, revue par Paul Courmont, prof. d'hygiène à la Fac. de Lyon, el A. Rochaix, chargé de cours, chef des travaux a la Fac. de Lyon. I vol. de 880 pages avec 227 figures. Broché 32 fr. net. Cartonné 35 fr. net 


\section{COLLECTION DE PRECIS MEDICAUY (Suite)}

\section{NOBÉCOURT}

Professeur à la Paculté de Médecine de Paris

\section{Médecine des Enfants =}

\section{$4^{\circ}$ édition}

1 vol. de 1024 pagis avec figures. Broché. $30 \mathrm{fr}$. net Cart. $34 \mathrm{fr}$. net

r. MORתX

\section{Ophtalm logie $=$}

3. édition. 1 vol. avec 450 figures et 4 planches en couleurs.

Broché. ... $34 \mathrm{fr}$. net; cartonné ... $37 \mathrm{fr}$ net

\section{J. DARIER}

Medecin de l'hôpital Broca.

\section{Dermatologie $=$}

3. édition. I vol. avec figures... . . . . . . En réimpression.

\section{E. BRU}

Prolesseur de Parasitologie à la Faculté de Médecine de Paris.

\section{Parasitologie $=$}

3. édition. I vol. avec figures..... I’our parailre ei juin 1922.

Et. MARTIN

Professeur d la Faculte de Lyon.

\section{Déontologie = et Médecine professionnelle}

1 vol. de 316 pages, broché.... Nouvelle édition en préparation

\section{LAСASSAGNE}

professeur de médecine légale

a l'Université de Lyon.

\section{Érienne M IRTIN}

Professeur agrégé

a la Faculté de Médecine de Lyon.

\section{Médecine

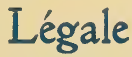

$3 \cdot$ édition. 1 vol. de 752 pages, avec $115 \mathrm{fig}$.

Broché. . 27 fr. not

Cartonné. . 30 fr. $\overline{\text { not }}$ 
L. LANDOUZY

\section{Éléments d’Anatomie}

\section{et de Physiologie Médicales}

DEUXIĖE ÉDITION PUBLIÉE SOUS LA DIRECTION DE

LÉON BERNARD

Professeur à la Facultè de Médecine de l'Université de Paris.

PAR MM.

LÉON BERNARD, GOUGEROT,

HALBRON, S. I. DE JONG, LAEDERICH, LORTAT-JACOB, SALOMON, SEZZARY, VITRY

I vol. de 867 pages avec 337 fig. el + pl. en couleurs. 50 fr. net CEs éléments d'Anatomie et de Physiologie médicales rassemblent pour l'étudiant des données éparses dans les ouvrages traitant de diverses branches des sciences médicales. Ils réunissent suivant une méthode clinique dans un enseignement particulier toutes les notions fondamentales d'Anatomie et de Physiologie susceptibles, par leur application immédiate à la pathologie, d'éclairer le médecin sur le mécanisme des troubles fonctionnels comme sur les symptômes qui les révèlent.

\section{Georges DIEULAFOY}

Professeur à la Faculté de Paris, Membre de l'Académie de Médecine.

\section{Manuel de}

\section{Pathologie interne}

NOUVEAU TIRAGE CONFORME A LA SEIZIÉME ÉDITION

4 vol. in-16, ensemble 4300 pages, avec figures en noir et en couleurs. Les 4 volumes. $70 \mathrm{fr}$. not 


\section{FRECIS DE TECHNIQUE}

G. Roussr

Professeur agrégé,

Chef des Travaux d'Anatomie pathologique da Faculté de Paris.
7. BERTRAND

Externe des Hôpitaux de Paris, Moniteur des Travaux pratiques d'anatomie pathologique.

\section{Travaux pratiques \\ d'Anatomie Pathologique \\ EN QUATORZE SÉANCES}

$2^{\circ}$ edition, 240 pages, 114 figures . . . . . . 12 fr. net

\section{Gustave RoussY}

Professeur agrégé.

Chef des Travaux d'anatomie pathologique

à la Facultè de, Paris.

\section{Roger LEROUX}

Moniteur des Travaux pratiques

d'Anatomie pathologique à la Faculté de Paris.

\section{Diagnostic des Tumeurs}

TRA VAUI PRATIQUES L'ANATOMIE PATHOLOGIQUE $2^{\circ}$ SERIE

1 vol. de 352 pages avec 129 figures. . . . . . 25 fr. net

\section{Christian CH $\boldsymbol{A M P Y}$}

Professeur agrégé la Faculté de Médecine de Paris.

\section{Manuel d'Embryologie}

I vol. de 216 pages avec 200 fig. originales et 6 pl.en coul. $12 \mathrm{fr}$. net

\section{H. BULLT $A R D$}

Preparateur d'Histologie d̀ la Faculté de Paris.
Ch. CH $\boldsymbol{A} \mathscr{A P Y}$

Professeur agrégé à la Faculté de Paris.

\section{Abrégé d'Histologie}

VINGT LEÇONS AVEC NOTIONS DE TECHNIQUE

TROISIENE ÉDITION REMANIÉE 


\section{COLLECTION DU MÉDECIN PRATICIEN}

\section{FLOR AND}

yéđecin de

Thopital Lariboisière. et

Attaché médical à la Clinique thérapeutique chirurgicale à la Faculté de mèdecine.

\section{Diagnostic et traitement des affections}

\section{du Tube digestif}

I volume de 412 pages, 62 figures

(parailra en mai 1922)

I plus grande préoccupation des auteurs a été de répondre L aux besoins de la pratique médicale; ils ont montré ce que l'on peut obtenir arec les moyens de recherches cliniques habituels, les cas où il faut demander le concours de spécialistes radiologistes, coprologistes et quels sont les résultats de ces suppléments d'enquête. Comme classification, il a paru clinique de partir du symptôme prédominant accusé par le malade, puis d'examiner les malades en allant des signes plus fréquents aux plus rares.

\section{Edition}

\section{Dr GUY-LAROCHE}

\section{Examens de Laboratoire du Médecin praticien}

Avec Préface du Professeur CHAUFFARD

I vol. in-8, de 415 p., Ir7 fig. et I pl. en couleurs rel. cart. souple. ........... $22 \mathrm{fr}$ net 


\section{Gaston LYON}

\section{Consultations pour les}

\section{Maladies des Voies digestives}

I vol. de 300 pages, relie carton souple. . . . . 16 fr. net

\section{Dr Pierre $R \dot{E} \boldsymbol{A L}$ \\ Stomatologie \\ du Médecin praticien \\ 2. Édition}

1 vol. in-8 de 290 pages avec 169 fig. et 4 pl., rel. carton souple. . . . . . . . 15 fr. net

G. LATRENS

Oto-Rhino-Laryngologie

du Médecin praticien

I vol. in-8 de 468 p: arec 593 fig., rel. carton souple. 22 fr. net

\section{Alb. TERSON \\ 2• Édition \\ Ophtalmologie \\ du Médecin praticien}

I vol. in-8 de 550 p. avec 356 fig. . . . . . . 26 fr. net

M. DIDE et P. GUTRAUD

Psychiatrie

du Médecin praticien

1 vol. de 416 pages in-8 avec planches hors texte. . 20 fr. net 
Ouvrages du Docteur MARTINET.

Éléments de Biométrie =

I vol. in-8 de 192 pages, avec 82 figures. $2^{\circ}$ édition.. . . 12 fr. net

Les Aliments usuels $=$

I vol. in-8 de 360 pages avec fig. Deuxième édition revie. 5 fr. net

Thérapeutique Usuelle des Maladies de la Nutrition I vol. in-8 de 429 pages, en collaboration avec le $D^{r}$ Legendre. 6 fr. net

Clinique hydrologique $=$

I vol. in-8 de 646 pages. . . . . . . . . . . 8 fr. net

Les Agents physiques usuels =

I vol. in-8 de 650 pages avec 170 fig. et 3 planches hors texte. 9 fr. net

\section{Dr LËMANSKI}

L'Art pratique de Formuler =

5. édition. I volume de 325 prges. . . . . . . . 15 fr. net

DEBOVE SALLARD POUCHET

Aide-Mémoire de Thérapeutique $=$

2. edition. 1 vol. in-8 de 912 pages. Cartonné. . . . 22 fr. net

\section{D $\mathrm{Ch} . S A B O U R I N$}

Traitement Rationnel de là Phtisie =

6. edition. Ln volume de 522 pages . . . . . . . 7 fr. net

F. BEZANÇON

Prolesseur agrégé à la Paculté de Paris.
S. 7. DE JONG Ancien chef de clin. à la Paculté de Paris.

Traité de l'examen des Crachats =

I vol in-8 de 4 II pages avec 8 planches en couleurs. . 12 fr. net

Antoine FLORAND Max FRANÇOIS Henri FLURIN

Les Bronchites chroniques =

I vol: in-8 d2 360 pages. . . . . . . . . . 5 fr. net. 


\section{Marcel L $\boldsymbol{A B B E}$}

Professeur de pathologie générale a la Faculté de Paris, Médecin de l'Hópital de la Charité.

\section{Le Diabète sucré}

Etudes cliniques, Physiologiques, Thérapeutiques I vol. de 376 pages avec 8 figures hors texte ... 20 fr. net

R. GOIFFON

Manuel

\section{de Coprologie Clinique}

Préface par le Dr J.-Ch. ROUX

I vol. de 232 pages avec 36 fig. et deux planches en

couleurs................. $12 \mathrm{fr}$. net

\section{H. C. $\boldsymbol{H} \boldsymbol{A} L L$}

Ancien chef de Clinique à "P'llôpital đe Bigpebjaerg" (Copenḩaguel.

$\mathrm{Cb}: \mathrm{f}$ de Laboratoire à l'Institut Serothérapique de l'Etat Danois.

\section{La Dégénérescence Hépato-Lenticulaire}

\section{Maladie de Wilson - Pseudo-Sclérose}

Préface du professeur Pierre MARIE

I volume de 362 pages avec 44 figures. . . . . 20 fr. net 
ВALTHAZARD, СESTAN, CLAUDE, IACAIGNE, NICOLAS, VERGER

PRECIS DE PATHOLOGIE INTERNE 3. Édition

Tome IV

\title{
Système Nerveux
}

Par MM. CESTAN et VERGER

I volume de 916 pages, avec 113 figures, cartonne. . . $28 \mathrm{fr}$. net

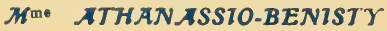

Aacien interne des Hòpitaux (Salpetrière).

Les Lésions des Nerfs

Traitement et Restauration

1 vol. de 158 pages in-8, avec 66 figures. . . . . . 7 fr. net

\author{
Я.- С. GUILLАนЖЕ
}

Le Sympathique

et les Systèmes associés

2. Édition I vol. in-8 de 396 pages avec 40 figures. 18 fr. net

Prof. VIGGO CHRISTIANSEN

Medecin de l'Hopital Royal de Danemark.

Correspondant de la Société de Neurologie.

\section{Les \\ Tumeurs du \\ Cerveau}

I vol. de 353 pages avec 100 figures. . . . . . 25 fr. net 
André $B \boldsymbol{A R B} \dot{E}$

Mèdecin Aliéniste des Hôpitaux de Paris

\section{Examen des Aliénés}

I vol. de 178 pages. . . . . . . . . . $8 \mathrm{fr}$ net

COURTOIS-SUFFIT

René GIROUX

\section{La Cocaine}

Étude d'Hygiène sociale et de Médecine légale I vol. in-8 de 228 pages ........... 4 fr. 50 net

\section{Dr Francis HECKEL \\ La Névrose d'Angoisse}

et les Etats d'émotivité anxieuse

I vol. gr. in-8 de 535 rages ........... $10 \mathrm{fr}$. net

\section{Drs DEVAUX et LOGRE}

Les Anxieux (Étude clinique)

I vol. in-8 de 256 pages. ............ 5 fr. net

Drs J. DOLÉRIS et J. BOUSCATEL

Néo-Malthusianisme - Maternité et Féminisme - Education sexuelle

I vol. in-8 de 262 pages... . . . . . . . . 5 fr. 50 net

P. DUBOIS (de Berne)

L'éducation de soi-même

I vol. in-8 de 265 pages. (Septième édition). . . . . 8 fr. net 


\title{
Jules COMBRY
}

Médecin de l'hôpital des Enfants Malades.

\section{Deux cents}

\section{Consultations médicales Pour les Maladies des Enfants}

\section{6. edition. I vol. in-16, cartonné . . . . . . . . 8 fr. net}

\section{A. LES $\mathcal{A G E}$}

Médecin des Hopitaux de Paris.

\section{La Méningite Tuberculeuse de l'Enfant}

I vol. in-8 de rgupages. . . . . . . . . . . 5 fr. net

A. B. MAREAN

Les Vomissements périodiques avec Acétonémie

I brochure de 63 pages. . . . . . . . . . . 4 fr. net

\author{
E. LESNÉ \\ I. BINET
}

Physiologie Normale et Pathologique du Nourrisson

Préface de Charles RICHET

1 vol. de 297 pages. . . . . . . . . 18 tr. net 


\section{A. B. MARF $\mathcal{A N}$}

Professeur à la Faculté de médecine de Paris, Medecin de l'Hopltal des Enfants Malades,

3॰ Édition Membre de l'Académie de Médecıne.

\section{Traité de l'Allaitement et de l'Alimentation des Enfants du premier âge} I vol. in-8 de 926 pages avec 2I figures. .... 45 fr. net

P. NOBÉCOURT

Professeur de Clinique medicale des Enfants a la Faculte de Mlédecine de Paris.

\section{G. SCHREIBER}

Ancien Interne des Hòpitaux de Paris, ancien chef de Clinique inlantile.

\section{Hygiène sociale de l’Enfance}

I vol. de 600 pages avec I 29 figures dans le texte. 30 fr. net

\section{Traité \\ des Maladies de l’Enfance}

PUBLIÉ SOUS LA DIRECTION DE

J. GR INCHER

7.

$2^{\circ}$ Édition

5 forts volumes $\mathrm{gr}$. in -8 avec figures dans le texte. . . $130 \mathrm{fr}$. net

H. BERTIN-SANS

Professeur

à la Faculté de Montpellier.
Dr M. F. CARRIEU

Chef de clinique

a la Faculté de Médecine de Montpellier.

\section{Prophylaxie des maladies transmissibles}

I volume de 254 pages. . . . . . . . . . 10 fr. net 


\section{Dr Georges ROBERT}

\section{Thérapeutique oculaire}

I lolume de r68 pages..............6 fr. net

D DUVERGER

Professeur de clinique ophtalmologique

à la Faculté de Médecine de Strasbourg.

\section{Anesthésie locale en ophtalmologie}

- val de 06 rages avec 19 figures. . . . . . . 6 fr. 500 net

\section{AXENFELD}

\section{Traité d'Ophtalmologie}

Traduction française du D' MENIER

1 vol. in-8 de 790 pages avec 12 planches en couleurs et 549 fig. 40 fr. net

Dr TERSON

Ophtalmologie

du Médecin praticien

2. édition. I vol. de 550 pages avec 356 figures (Collection du Médecin praticien).......... 26 ír. net

\section{F. TERRIEN}

Prolesseur agrege de la Faculté de Medecine de Paris, Ophtalmologiste de l'hòpital Beaujon.

\section{Chirurgie de l'Eil}

et de ses annexes

$2^{\circ}$ édition. 620 pages, 495 figures . . . . . . . 50 fr. nct

\section{Tb. HEIЖ $\lambda \mathcal{N}$}

L'Oreille et ses maladies

2 vol. in-8 de 1462 pages avec 167 figures ...... 44 fr. net 


\section{A. IAVER IN}

Professeur à l'Institut Pasteur, Membre de l'Institut.

\section{Leishmanioses}

Kala-Azar, Bouton d'Orient, Leishmaniosé Américaine

I vol. in-8 de 515 pages, 40 figures, 6 planches hors texte en noir et en couleurs............. 16 fr. 50 net

I. IUVERAN

Membre de l'Institut.

\section{F. MESNIL}

Professeur a l'Institut Pasteur.

\section{Trypanosomes et Trypanosomiases}

2. edition, 1 vol. gr. in-8 de 1008 pages avec 198 figures. 27 fr. 50 net

\section{R. SABOUR IUD}

Directeur du Laboratoire Municipal à l'Hôpital Saint-Louis.

\section{Maladies \\ $d u$ \\ Cuir \\ Chevelu}

Tome I. - Maladies séborrhéiques, I vol. gr. in-8 . . I 15 fr. net TOME II. - Malaties desquamatives. I vol. gr. in-8... (épuise). Tомe III. - Maladies cryptogamiques. I vol. gr. in-8. . (épuisé).

\section{La Pratique Dermatologique} PUBLIÉ SOUS

1a Direction de MM. Ernest BESNIER, L. BROCQ et L. JACQUET 4 vol., reliés toile. . 200 fr. - Chaque tome séparément. 50 fr. not 


\section{NTCOLLE}

de l'Institut Pasteur de Paris.

\section{Les Antigènes et les Anticorps}

Caractères généraux Applications diagnostiques et lhérapeutiques 1 vol. in-8 de in6 pages............. 4 fr. 50 net

\section{A. PRENANT}

Professeur

a la Faculté de Paris.

\section{L. ЖАILLARD}

Chef des trav. de Chim. biol. à la Facuité de Paris.
P. BOUIN

Professeur agrégé a la Faculté de Nancy.

\section{Traité d'Histologie}

TOME I. - CYTOLOGIE GÉNÉRALE ET SPÉCIALE. (Épuisé). Tome II. - HISTOLOGIE ET ANATOMIE. I vol. gr. in-8 de I 210 pages avec 572 fig. dont 3 i en couleurs. . . . 55 fr. not

\section{Maurice ARTHUS}

Prolesseur de Physiologie à l'Unitersité de Lausanne.

\section{De l'Anaphylaxie à l'Immunité}

Anaphylaxie - Protéotoxies - Envenimations Anaphylaxie-Immunité - Sérums antivenimeux I vol. de 36r pages.. . . . . . . . . 20 fr. net.

Emile ITEBREICH

Le sang in vitro

Eosinophilı - Fibrinogenèse Phagocytose des hématies 
Ch. BOUCH

Professeur honoraire de pathologie générale, Membre de l'Académie des Sciences.
G.-H. ROGER

Professeur de pathologie expérimentale, Membre de lícadémle de Médecine.

\section{Nouveau Traité de}

\section{Pathologie générale}

Tомг I. - I vol. gr. in-8 de 909 pages, relié toile. . . $28 \mathrm{fr}$. net

Cllaborateurs du Tome I : Ch. AChard, J. Bergonié, P.-J. C CADIOT et H. ROGER, P. COURMONT, M. DUVAL et P. MULON, A. IMBERT, J.-P. LANGLOIS, P. LE GENDRE, F. LEJARS, P. LENOIR, Th. NOGIER, H. ROGER, P. VULLLEMIN.

Tоме II. - I vol.gr. in-8, de 1174 fages, 204 fig. Relie toile. $35 \mathrm{fr}$. net

Collaboratevrs du Tome II : Fernand bezançon, e. Bodin, Jules COURMONT, Jules GUIART, A. ROCHAIX, G.-H. ROGER, Pierre TEISSIER.

\section{P.-T. BROR IT}

Professeur

à l'Université de Lyon.

\section{Maurice DoroN}

Professeur adjoint

a la Faculté de Médecine de Lyon.

\section{Traité de Physiologie}

Toms I. - Fonctions élémentaires ....... $18 \mathrm{fr}$. not

Tome II. - Fonctions d'innervation, avec 263 figures. Epuise.

Tome III.-Fonctions de nutrition.-Circul.-Calorif. 15 fr. net

Tomi. IV. - Fonctions de nutrition (suite et fin). - Respiration, excrétion. - Digestion, absorption, avec 167 figures. . $15 \mathrm{fr}$, net TOME V ET DERNIER. - Fonctions de relation et de reproduction 1 vol. gr in-8 avec 221 figures en noir et en couleurs. 28 fr. net 


\section{P. POTRIER - A. CMARPY}

\section{Traité d'Anatomie Humaine}

Nouvelle Édition entièrement refondue sous la direction de

\section{ג. NICOLAS}

Professeur d'Anatomie à la Faculte de Médecine de Paris.

Tome I. - Embryologie. Ostéologie. Arthrologie. Épuisé. Tome II. - 1*r Fasc. : Système musculaire . . 17 fr. net $2^{\bullet}$ Fasc.: Angéiologie (Cœur et Artères), $248 f i g \cdot\left(3^{\bullet} e d.\right) 15$ fr. net 3. Fasc.: Angéiologie (Capillaires, Veines), (3• $\left.{ }^{\bullet} d.\right) . \quad 22$ fr. net $4^{*}$ Fasc. : Les Lymphatiques, 126 figures $\left(2^{\circ}\right.$ édition $)$ Épuisé. TOME III. $-\mathrm{I}^{* 0}$ et $2^{\circ}$ Fasc. : Système nerveux central. 75 fr. net 3• Fasc.: Système nerveux périphérique. . (en préparation). Tome IV. - I*r Fasc. : Tube digestil, 213 fig. (3•édil.). 15 fr. net $2^{\bullet}$ Fasc. : Appareil respiratoire, 121 figures $\left(2^{\bullet} e ́ d i t.\right)$ Épuisé.

3. Fasc. : Annexes du tube digestif. Péritoine. $22 \mathrm{fr}$. net TOME V. - I" Fasc.: Organes génito-urinaires (en préparation). $2^{\circ}$ Fasc. : Organes des sens $\left(3^{\circ}\right.$ edition). . . 32 fr. net

\section{Georges GÉRARD}

Agrégé des Facultés de Médecine.

Professeur d'Anatomie à I'Université de Lille.

\section{Manuel}

d'Anatomie Humaine

DEUXIÈME ÉDITION

I vol. in-8 de 1275 pages, avec 1025 figures en noir et en couleurs et 4 planches en couleurs . . . . 75 fr. net 


\section{H. FAR}

Professeur à la Faculte de Médecine de Paris.

\section{Précis de}

\section{Manuel Opératoire}

I vol. in-8 de 1092 pages avec 862 figures. . . . . . . 26 fr. net

\section{Chirurgie réparatrice et orthopédique}

APPAREILLAGE ET INVALIDITÉS

OUVRAGE PUBLIÉ SOUS LA DIRECTION DE MM.

JEANBRAU, NOVÉ-JOSSERAND et OMBRÉDANNE

Secrétaire de la Rédaction : DESFOSSES

2 vol. in-8, formant ensemble 1340 fages avec $1040 \mathrm{fig}$. $80 \mathrm{fr}$. net

J. FIOLLE et J. DELAAS

Découverte des Vaisseaux profonds par des voies d'accès larges

1 vol. in-8 de 128 pages el figures de M. H. Beaufour. Prix. $6 \mathrm{fr}$.

\section{Professeur Th. JONNESCO}

Membre correspondant de l'Académie de Médecine de Paris.

\section{La Rachianesthésie Générale}

I vol. de $\mathbf{1 2 8}$ pages . . . . . . . . 4 tr. net 


\section{Précis de}

\section{Technique Opératoire}

PAR LES PROSECTEURS DE LA FACULTÉ DE MÉDECINE DE PARIS

Pratique courante et Chirurgie d'urgence, par V. Veau. $6^{\circ}$ édit., 33i fig. - Broché 6 fr. Cartonné 7 fr. 50

Tête et cou, par Ch. Lenormant. 5' edition, $247 \mathrm{fig} .-\mathrm{Br} .6 \mathrm{fr}$. Cartonne $\mathbf{7}$ fr. $\mathbf{5 0}$

Thorsx et membre supérieur, par A. Schwartz. $4^{\circ}$ édition, 199 fig. - Broché 6 fr. Cartonné $\mathbf{7}$ fr. 50

Abdomen, par M. GüBÉ. 5 édition, $24^{2} \mathrm{fig}$. $-\mathrm{Br} .10 \mathrm{fr}$. Cartonné $\mathbf{1 2}$ fr. 50

Appareil urinaire et appareil génit. de l'homme, par P. Duval. $5^{\circ}$ édit., 234 fig. - Brochè 6 fr. Cartonné 7 fr. 50

NOUVELLE SÉRIE

Appareil génital de la temme, par R. Proust. 5' édition; revisée par le Dr CharRIER, prosecteur à la Faculté de Médecine de Paris. - Broché $10 \mathrm{fr}$. Cartonné $12 \mathrm{fr}$.

Membre inférieur, par Georges Labey et Leveuf. 5• édition entièrement refondue. (pour paraître en juin 1922.)

Th. TUFFIER

Professeur agrégé

à la Faculté de Médecine de Paris.

\section{P. DESFOSSES}

Chirurgien

de l'hôpital Britannique à Paris.

\section{Petite Chirurgie pratique}

6. édition revue et augmentee. I vol. de 732 pages avec 425 figures dans le texte. . . . . . . . . . . 32 fr. net 


\section{OUVRAGES DE H. HARTЖINN}

Professeur de Clinique à la Faculté de Parls.

\section{Gynécologie opératoire}

I vol. gr. in -8 de 500 pages, 422 fig. dont 80 en couleurs, cart. 22 fr. net

\section{Organes génito-urinaires de l'homme}

I vol gr. in-8 de 432 pages avec 412 figures. . . . 16 fr. 50 net

\section{Travaux de Chirurgie anatomo-clinique}

Iree la collaboration de : MIM. C'unéo, Delamare, Esmonet, IIenry, Küss, Lavenant, Lebreton, Lecène, Okinczyc.

Voies urinaires. - Estomac. . . . . . . . épuisé Voies urinaires. - Testicule ........ $16 \mathrm{fr} . \overline{50}$ net Chirurgie de l'Intestin.......... $17 \mathrm{fr} .50 \overrightarrow{\mathrm{net}}$ Voies urinaires.............. 17 fr. 50 net

\section{F. LEJARS \\ Traité de}

\section{Chirurgie d'Urgence}

\section{HUITIËME ÉDITION}

I vol. de 1120 pages, grand in- $8^{\circ}$, avec $\mathrm{I} 100$ figures dans le texte, en noir et en couleurs, et 20 planches hors texte en deux tons Broché, sous couverture forte. . . . . . . . 75 fr. net Édition de luxe sur beau papier couché, relié toile pleine, fers spéciaux. en deux volumes. . . . . 90 fr. net 


\section{W $\boldsymbol{\text { ILIICH }}$}

Prolesseur agrégé à la Faculté de Paris.

\section{Eléments d'Obstétrique}

$4^{\circ}$ édition refondue, I volume de 709 pages avec 180 figures dans le texte............... 26 fr. net

\section{त. RIBENONT-DESSATGNES} Professeur a la Paculté de Paris.

\section{G. IEP $A G E$}

Professeur agr. à la Faculte de Paris.

\section{Traité \\ d'Obstétrique}

8. édition. I574 pages avec 587 figures. Relie toile. . $40 \mathrm{fr}$. net Relié en deux volures. . $44 \mathrm{fr}$.

\section{COUVELATRE}

Professeur de Clinique obstétricale à la Paculté de Paris.

\section{Chirurgie utérine obstétricale}

1 vol. in-4 de 224 pages avec 44 planches hors texte, cart. 36 fr. not

\section{VARNTER}

Professeur à la Faculte. Accoucheur des hòpitaux.

\section{La Pratique des Accouchements}

\section{Obstétrique journalière}

1 vol. in-8 de 440 pages avec 386 figures, relié. . . . 29 fr. net 


\section{Aug. BROCA}

Prolesseur d'opérations et d'appareils à la Faculté de Paris.

\section{Chirurgie Infantile}

1 vol. in-8 jésus de 1136 pages avec 1259 figures, cartonné 32 fr. net

I. OMBRÉDANNE

Professeur agrégé à la $\mathrm{F}$ aculté de Médecine de Paris.

\section{Technique Chirurgicale Infantile}

I vol. in-8 de 342 pages avec 210 figures........ 8 fr. not

Lion BÉRARD

Professeur de clinique chirurgicale.

\section{Paul VIGN ARD}

Chirurgien de la Charite (Lyon).

\section{L'Appendicite}

Étude clinique et critique

1 vol. gr. in-8 de 888 pages avec 158 figures dans le texte. 20 fr. net

\section{Traité Médico-Chirurgical des \\ Maladies de 1'Estomac et de l'CEsophage}

PAR MM

\section{․ ЖЛТНIЕU}

Médecin de l'Höpital St-Antoine.
2. SENCERT

Professeur ag. à la Faculté de Nancy.

\section{Th. TUFFIER}

Professeur ag., Chirurgien des Hopitaux.

AVEC la COLlaboration DE:

T. CH.-ROUX ROUX-BERGER F. MOUTIER I vol. gr. in-8 de 934 pages avec 300 figures dans le texte. 25 fr. net 


\section{Dr ARCELIN}

Chel de service de Radiologie à l'Hỏpital Saint-Joseph et à l'Hôpital Saint-Luc.

\section{L’Exploration radiologique des Voies Urinaires}

I vol.gr. in-8 de 175 pagesavec fig. et 6 planches hors texte.. 8 fr. net

\section{F. J}

Assistant de radiotherapie à l'Hôpital Saint-Antoine.

\section{Précis de Radiodiagnostic}

Deuxième édition revue et augmentée

I vol. de 550 pages, 220 figures et 63 planches hors texte. 24 fr. net

H. PILON

\section{Le Tube Coolidge}

Ses Applications scientifiques médicales et industrielles I volume in-8 de 86 pages avec 58 figures dans le texte. . 4 fr. 50 net

\section{LERMOYEZ}

Membre de l'Academie de Medecine, Módecin des Hópitaux de Paris.

\section{Notions pratíques d’Electricité}

I vol. de 876 pages, 426 figures. Cartonné. . . . . 24 fr. net

R. CHAPERON

Assistant de Radiologie des hôpitaux.

Etude Anatomo-Radiologíque Vaisseaux de la base du Cour

$1 \mathrm{rol}$. de 62 pages avec figures et 11 planches ratio . . $6 \mathrm{fr}$. net 


\section{P. RUD $\boldsymbol{T U} \boldsymbol{X}$}

Accoucheur de la malernité de l'hópital Boucicaut.

\section{Précis}

\section{d'Anatomie, de Physiologie et de Pathologie élémentaires}

$4^{*}$ edition. I vol. de 828 pages avec 580 figures. . . . . $24 \mathrm{fr}$. net

\section{Mile СНАРТ АL}

Directuice de la Maison-école des infirmières privées.

\section{Le Livre de l'Infirmière}

Idaptation de l'ouvrage anglais de Miss OXFORD

$2^{*}$ édition corrigée et très augmentée.

1 volume de $34^{8}$ pages. . . . . . . . . . $10 \mathrm{fr}$ net

\section{BROUSSES}

Ex-répétiteur de Pathologie chirurgicale à l'École du Service de Santé militaire

\section{Manuel technique de Massage}

$5^{\circ}$ édition. I vol. de 386 p. avec 85 figures dans le texte. 12 fr. not

\section{Manuel}

\section{de l'Infirmière hospitalière}

ridige sons la direclion de la Commission medicale dinseignement de l'Union des Femmes de France (Croix liouge Française' 


\section{COLLECTION " LES STIENCES D'ALIOURDHUI}

\section{La Médecine}

I volume in-8, de 430 pages.

La Physiologie 1 volume in-8, de 434 pages par H. ROGER

Doyen de la Faculte de Medecine de Paris Membre de l'Académie de Médecine.

$10 \mathrm{fr}$. net

par MALRICE ARTHCS

Correspondant National de l'Académie de Médecine. Professeurde Physiologie à la Faculté de Médecine de Lausanne.

\section{Rémy PERRIER}

Professeur adjoint à la Faculté des Sciences de l'Université de Paris.

\section{Cours Elémentaire de Zoologie}

I vol. de $87 \mathrm{I}$ pages, avec $765 \mathrm{fig}$. dans le texte el 16 planches. 30 fr. net

\section{William C. Mac LEWTS}

Protesseur de Chimie physique à l'Université de Liverpool.

\section{Traité de Chimie Physique $=$}

Traduit sur $1 \mathrm{a} 2^{\circ}$ édition anglaise par H. VIGNERON.

Tome I. - THíRIE CINÉTIQUe. - I volume in-8. . 40 fr. net Tome II. - ThermodinamiQue. -1 volume. . . . . 40 fr. $\overline{\text { net }}$ Tome III. - THĖories Modernes. - ThÉories nes QuaNta. 20 fr. $\underline{\text { net }}$

\section{Vittorio VILLAVECCHIA}

\section{Traité de Chimie analytique appliquée}

Traduit en français et annoté par Paul NICOLARDOT.

Les Tomes I et II (dernier) réunis . . . . . . $80 \mathrm{fr}$. net

Tome II seul (le Tome I ne se vend pas séparément) . 56 fr. net

\section{C.-R. FRESENJUS}

Traité d'Analyse chimique qualitative

12. Édition française rédigée et adaptée par M. FRENKEL.

I rol. de 83.4 pages avec lableaux, figures et i flanche. $60 \mathrm{fr}$. net

\section{Marie PHISALIX}

\section{Animaux Venimeux et Venins}

Prétace du professeur LAVERAN.

2 volumes, 1600 pages, 521 figures, 17 planches dont 3 en couleurs. 





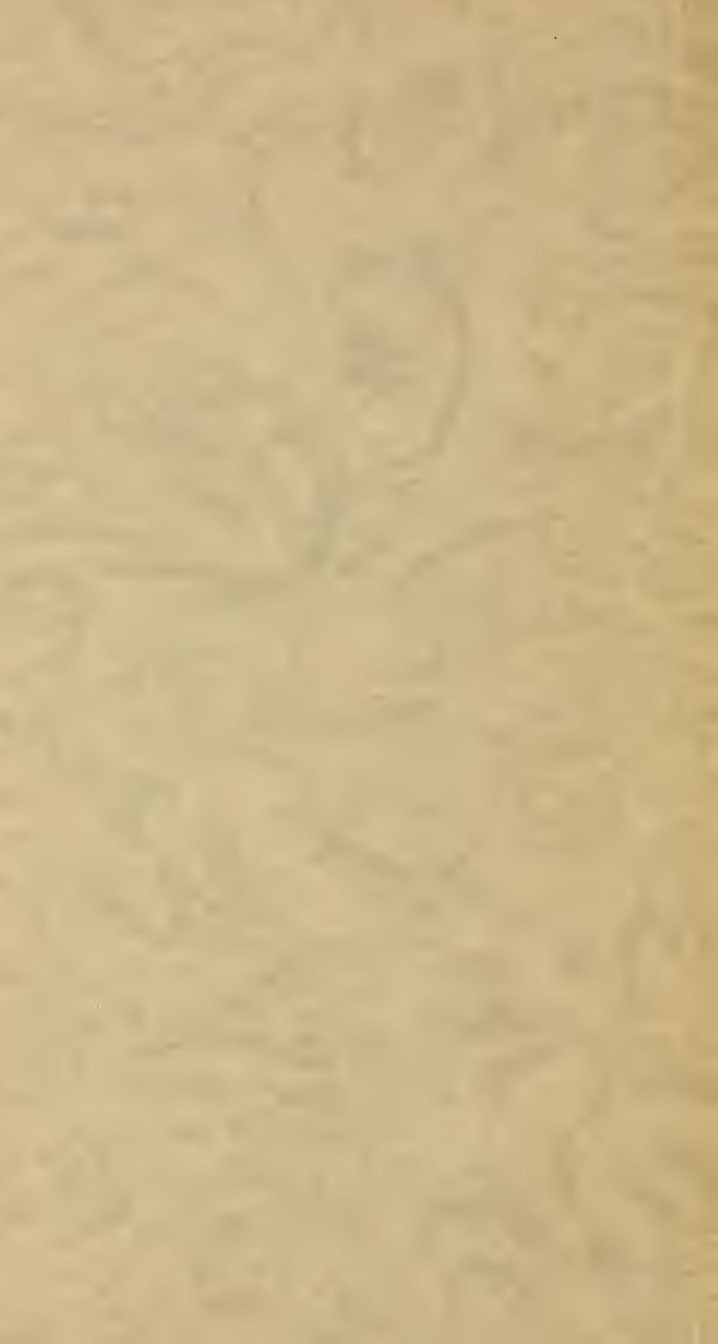





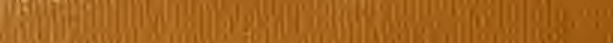

(II)

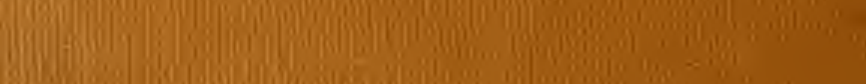
(I)

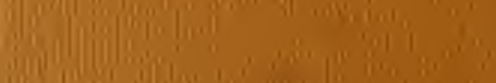

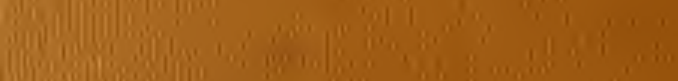
S mo 